\title{
Effect of diversified meals only, or either enriched with Amaranthus tricolor and Moringa oleifera leaf powder or commercial micronutrient powder on prevention/treatment of anemia in Adivasi children, West Bengal, India
}

Caroline Katharina Stiller ( $\nabla$ stiller.caroline@uni-hohenheim.de )

Universitat Hohenheim Fakultat fur Naturwissenschaften https://orcid.org/0000-0003-4410-2968

Silvia Konstanze Ellen Golembiewski

Universitat Hohenheim Fakultat Wirtschafts- und Sozialwissenschaften; Shining Eyes e.V.

Wolfgang Stuetz

Universitat Hohenheim Fakultat fur Naturwissenschaften

Monika Golembiewski

Shining Eyes e.V. (NGO)

Daniela Gomez Rincon

Universitat Hohenheim Fakultat fur Naturwissenschaften

Srikanta Mondal

Bolpur Manab Jamin (NGO)

Hans Konrad Biesalski

Universitat Hohenheim Fakultat fur Naturwissenschaften

Veronika Scherbaum

Universitat Hohenheim Fakultat fur Naturwissenschaften

\section{Research}

Keywords: diversified diets, Amaranthus tricolor, Moringa oleifera, leaf powder, nutrient content, young child feeding, anemia, malnutrition, intervention, Santals, Adivasi, West Bengal, India

Posted Date: May 7th, 2020

DOI: https://doi.org/10.21203/rs.3.rs-26436/v1

License: @ (i) This work is licensed under a Creative Commons Attribution 4.0 International License. Read Full License 


\section{Abstract}

Background and objectives: Malnutrition associated with anemia remains a leading cause of morbidity and mortality among Adivasi children in India. The present trial aimed to test three possible ways of designing improved supplementary meals and to define their role in decreasing rates of anemia, thus increasing hemoglobin $(\mathrm{Hb})$ concentrations as primary health objective: diversified meals only (intervention group 1 (IG 1)), with the addition of locally producible Amaranthus tricolor/Moringa oleifera leaf powders (ALP/MLP) in the ratio 2:1 (IG2) or with an adjusted amount of commercially produced micronutrient powder TopNutri (IG3).

Methods: Cluster-randomization of 21 villages resulted in the inclusion of $n=293$ children aged 6-39 months after baseline assessment. The trial duration was 18 months, beginning in February 2015 (baseline assessment), with application of study meals three times a week at community level. Anthropometric, $\mathrm{Hb}$ (HemoCue201+) and morbidity data were collected in a total of four assessment points. At baseline a socio-economic questionnaire was performed.

Results: Adjusted for age and $\mathrm{Hb}$ concentrations at baseline, time between assessment points, and gender; IG1 showed significant higher $\mathrm{Hb}$ concentrations as compared to the control group (CG) throughout the intervention period. The $\mathrm{Hb}$ of the remaining intervention groups IG2 or IG3, remained comparable to the CG at all assessment points. The effect on growth indices was less consistent, however most positive tendencies related to nutrition status (stunting, underweight, wasting) and morbidity reduction were attributable to IG3, indicating the beneficial role of a holistic nutrient composition in addressing undernutrition and infectious diseases.

Conclusion: This low-dose intervention trial proofed the feeding of diversified diets alone (IG1) to be sufficient to significantly increase $\mathrm{Hb}$ concentrations of study children. On the way of achieving diversified diets for Santal children the promotion of kitchen garden programs combined with interactive awareness trainings may be a key measure. Trial registration: the trial was retrospectively registered at the German Clinical Trials Register on the 1 st July 2019 (DRKS00017388). URL: https://www.drks.de/drks_web/navigate.do?

navigationld=trial.HTML\&TRIAL_ID=DRKS00017388

\section{Introduction}

Globally, almost half of all under-five deaths are attributable to malnutrition as underlying contributing factor to mortality and disease burden [1], [2]. The prevalence of stunting (HAZ), underweight (WAZ), and wasting (WHZ) varies across low- and middle-income countries in severity and affects on world level 22\% (2013-18) [3], 14\% (2010-15) [4], and $7 \%$ (2013-18) [3] of children below five years of age, respectively. Globally the WHO reports $43 \%$ of children below five years to suffer from anemia in 2011 [5] or according to data of the World Bank $42 \%$ in 2016 [6]. In India the National Family Health Survey (NFHS-4 of 2015-16) revealed prevalences of $38.4 \%, 35.8 \%$, and $21 \%$ for growth deficits (HAZ, WAZ, WHZ) respectively, with anemia affecting $58.6 \%$ of all under-five year old children [7]. In Birbhum district, West Bengal the anemia rate was similar (59.0\%), but the prevalence for stunting, underweight, wasting ranged higher with $40.5 \%, 43.1 \%, 29.5 \%$, respectively [8].

The Integrated Child Development Scheme (ICDS) program was launched in 1975 and is aimed at improving the nutritional and health status of children aged 0-6 years by supplementary nutrition, health checkups and education of mothers to improve their caring capacities [9]. Despite this holistic health program Kubde \& Kokowar found no significant difference in the prevalence of anemia in ICDS (47.9\%) versa non-ICDS (56.1\%) areas in urban slums of Nagpur city [10]. Studies including ICDS Centers in Hooghly and Nada District of West Bengal provide evidence that despite the implementation of the ICDS scheme children are still suffering from acute and chronic forms of malnutrition indicating a major public health problem ([11], [12]). On the avenue to address malnutrition supplementary 
feeding programs have to be optimized. Locally accessible, cost-effective and sustainable strategies have to be seeked to fight this burden. For anemia prevention and control three conventional approaches are in theory accessible: fortification or supplementation with iron or other micronutrients, and dietary modification/diversification including food-to-food fortification (increased availability and consumption of improved diversified diets composed of a variety of foods). Combined with disease control and education, the latter is a promising and sustainable approach on household $(\mathrm{HH})$ level through adequate selection of foods, proper preparation methods, and adequate feeding [13]; [14], [15], [16]. The greater usage of traditional plant biodiversity is of increasing importance in the scope of food scarcity and the upcoming nutrition transition toward simplification of diets and energy-surplus [17]. The leaves of Moringa oleifera, indigenous to northwest India [18], and Amaranthus tricolor are possible local sources of a variety of nutrients -including iron, beta-carotene, B-vitamins or vitamin C (improve iron absorption and utilization in the blood building system [19], [20], [21], [22]) (Supplementary Material 1). The nutritional value of green-leafy vegetables and its role in food security is discussed to be under-exploited [23], thus their utilization and cultivation may be promoted when seeking for sustainable food-based approaches on the avenue to diminish rates of anemia and undernutrition.

As primary health outcome the conducted trial assessed the effect of diversified diets alone (IG1), as well as diversified meals with the enrichments of Amaranthus tricolor leaf powder/Moringa oleifera leaf powder (ALP/MLP) (IG2), or an adjusted amount of a commercial micronutrient powder TopNutri (IG3) on hemoglobin (Hb) concentrations in Santal children aged 6-39 months (Table 1, Figure 2). Secondary objectives were to investigate the impact of the nutritionally improved meals on growth indicators (HAZ, WAZ, WHZ) and reduction of morbidity prevalence (diarrhea, fever, respiratory infection) of the targeted young children.

By applying the same framework conditions for the intervention and control groups, the study is able to define single effects of measures applied, thereby demonstrating the effect of the nutrient-dense meals and the added value of provided leaf powder or micronutrient sprinkle. This longitudinal study approach allows the investigation of long-term physiological effects implied by natural supplementation dosages in the children. Thereby Hb-development, growth trends, morbidity as well as the influence of season can be taken into consideration more precisely.

\section{Materials And Methods}

\section{Study design and intervention}

In the current trial three nutritionally improved meals have been valuated by mean increases of hemoglobin concentrations. Beneficiaries either received diversified meals only (IG1), the same diversified meals enriched with Moringa/Amaranthus leaf powder (ratio ALP 2:1 MLP) (IG2), or the same diversified meals enriched with an adjusted amount of an industrial micronutrient powder (MNP) TopNutri (IG3) (Figure 1). The supplementary feeding took place on community level in a supervised feeding setting, three times per week and beneficiaries were aware of the components of the meals. Children of the control group (CG) received no nutrition intervention however equally benefitted of medical checkups at each study point. To maintain social peace in the villages the CG received additional awareness sessions on community level in order to understand the usefulness of government schemes and offered nutrition programs, thereby the connection between the villagers to the respective ICDS Centre, surrounding health centres and accredited social health activists or health worker was strengthened.

The trial was conducted over a total period of 18 months from the end of winter season in February 2015 to rainy season in August 2016 including baseline assessment (t0), and three follow-ups, each consecutively 6 months later (t6, $\mathrm{t} 12$, t18), with $\mathrm{t} 18$ constituting the endline assessment. Prior to the baseline assessment a treatment protocol was 
designed by Shining Eyes e.V., which assures a defined treatment of all participants of the study in accordance with the overaching study objectives (i.e. iron/folic-acid supplementation was reserved for severely anemic $(\mathrm{Hb}<7 \mathrm{~g} / \mathrm{dl}) \mathrm{children}$, and in case of symptoms of other micronutrient deficiencies i.e. dry eyes - wavy strucutre of eyeball, Bitot's spot (vitamin A); skin lesions, pigmentation, rough skin, perlèche (vitamin B-complex); the supplementation was performed in a defined way). The incidence of symptomatic micronutrient deficiencies during baseline assessment is outlined in a previous publication [24], chi-square analysis showed comparability ( $>0.05$ ) across the study groups (not presented). Enrolled children allocated to the four study arms were assessed in the same manner (i.e. medical checkup/required treatment, $\mathrm{Hb}$ determination by HemoCue $\mathrm{Hb} 201+$, morbidity status and anthropometric assessment as well as the collection of demographic data by means of a semi-structured questionnaire addressed to the main caretaker).

As opposed to ICDS feeding programs enhancements included in the current research study design were dietary diversification (variety of locally available foods for adequate nutrient and energy density in the meal [25]), enhanced monitoring of program implementation, and community-based preparation and consumption of supplemented meals.

\section{Criteria for selecting children for intervention}

Inclusion criteria applied after baseline assessment were: children aged 6-39 months, having an $\mathrm{Hb} \geq 7.0 \mathrm{~g} / \mathrm{dl}$, residing in the 21 Santal villages around Bolpur defined as study site, and parents having given their informed consent. Children with severe anemia $(\mathrm{Hb}<7.0 \mathrm{~g} / \mathrm{dl})$ were referred to the St. Mary's Child and Mother Health Care Centre for further treatment. If the condition of severe anemia occurred during the baseline, $2^{\text {nd }}$, or $3^{\text {rd }}$ assessment children were excluded from statistical analysis. Still, excluded children continued to attend the nutrition program, and were eligible of all benefits - to ensure healthy development as well as social freedom in the village community. Severely wasted children were equally referred to the health care centre for clarification of health condition but remained in analysis as no targeted treatment for malnutrition was possible due to short admission periods as mothers perceived their children as active and healthy.

\section{Study area, village selection, target population and drop-out rates}

The cluster-randomized control trial was conducted in 21 villages (rural site) in the catchment area around Bolpur, Birbhum District in West Bengal, India with the majority of $n=243$ caretakers belonging to the Santals (94.4\%) (Table 2). All villages belong to the sphere of action of the NGO Manab Jamin and all are beneficiaries of the government schemes [9]. Cluster-randomization allocated the villages to the four trial arms (three intervention groups (IG 1-3), and one control group (CG)). An alphabetic list comprising 19 village names (of the 21 villages, four were forming two hamlets) was generated. 19 pieces of paper were serially numbered at random. Then all pieces were shuffled well and one by one the pieces were drawn and the number noted down next to the village starting at the top of the list. Then the village name list was ordered according to the randomly obtained numbers and from top to bottom categorized into the four homogenous study groups of participants (thereby a trial arm was composed of 3 up to 7 villages). A total of 295 children aged 6-36 months was estimated to be available in the 19 villages before performing baseline assessment, resulting in an average of 15.5 individuals sampled per cluster to be randomized.

Children aged 6-36 months at baseline assessment were the study's primary target group (due to reasons of sample size extended to 39 months). For further information on population data and response rate at baseline please see 
previous publication [24]. At baseline assessment a total of $n=307$ children were analyzed with the subsequent inclusion of $n=293$ children (6-39 months) in the feeding trial. Data analysis to validate the intervention effect on the primary indicator $\mathrm{Hb}$ concentration was based on $\mathrm{n}=254$ children that were present at all four consecutive assessment points with $n=64$ (IG1), n=58 (IG2), n=67 (IG3) and n=65 children in the CG. Drop-out rates from baseline measurement to analysis account for $n=53(17.3 \%)$, or when considering only children meeting the inclusion criteria at baseline $n=39$ (13.3\%) (Figure 1). In total $n=20$ children were excluded from intervention analysis due to being found severely anemic at the baseline or $2^{\text {nd }}$ assessment and subsequently having received medical treatment (investigator-caused discontinuation). Three children were lost due to child death due to drowning $(n=1)$, and infection $(n=2)$. Overall $n=30$ children were at least once absent out of all four measuring points (lost-to-follow-up or refused).

\section{Sample size calculation}

In June and September 2014 a small pre-study has been conducted to document mean hemoglobin values in two Santal villages to estimate the study sample size. The measurement of $n=40$ children aged between 6 to 35 months resulted in a mean hemoglobin value of $8.74 \mathrm{~g} / \mathrm{dl}$ with a variance of 2.163 and standard variation of 1.471 . The sample size calculation was performed according to Allen, 2011 [26], with the following values: $\mu=0.05, b=0.2, z \mu=1.6449$, $z b$ $=0.8416, d=0.7$. In the present long-term trial a difference of $8 \%(0.7 \mathrm{~g} / \mathrm{dl})$ in hemoglobin mean value between baseline and endline measurement was assumed according to observed effects by Hirve et al., 2013 [27]: after supplementing elemental ferrous fumarate (average dosage of $5 \mathrm{mg} / \mathrm{d} \approx 1.7 \mathrm{mg}$ elemental iron [28]) through the ICDS to reduce anemia in Indian pre-school children over a total period of four months, thereby achieving a significant increase in mean $\mathrm{Hb}$ concentrations of $0.71 \mathrm{~g} / \mathrm{dl}$ in boys and $0.48 \mathrm{~g} / \mathrm{dl}$ in girls. The sample size calculation for two independent groups resulted in a minimum sample size of $n=55$ children, multiplied with the design effect a sample size of $n=63$ children resulted. For calculation of the design effect the intra-class correlation-coefficient (ICC) was set according to Adams et al., 2004 [29] at ICC $=0.01$, and the cluster size accounted for $m=15.5$. With an assumed drop-out rate of $10 \%$, an estimated minimum sample size of $n=70$ children per study group is required.

Testing the overall fit of the performed regression models requires a minimum acceptable sample size of $\mathrm{N}=138$

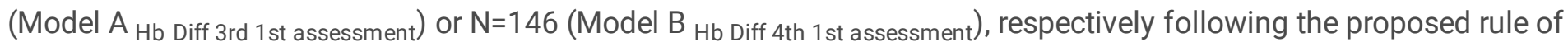
thumb $50+8 \mathrm{~m}$ (with $\mathrm{m}$ being the number of candidate predictor variables) [30], [31].

\section{Figure 1: Flow chart on enrolment, follow-up and drop-out in the trial}

\section{Socioeconomic household survey, anthropometric and hemoglobin measurement and devices}

Data on socio-demographic characteristics including maternal educational level, cash income, agricultural assets, or infant and young child feeding and caring practices were collected in form of a semi-structured questionnaire conducted by trained field workers. For further details please see previous publication to baseline assessment [24]. 
Moreover at baseline $\left(t_{0}\right)$ and the subsequent assessment points $\left(t_{6}, t_{12}, t_{18}\right)$ anthropometric outcome indicators and hemoglobin concentrations have been measured. $\mathrm{Hb}$ was determined by using a portable hemoglobinometer (HemoCue $\mathrm{Hb} 201+$ ) for all children donating a finger prick of capillary blood at each assessment point. At each checkup children were dewormed (albendazol/mebendazol) in order to reduce the risk of iron deficiency anemia due to worm infestation. For details on the assessment, computing and interpretation of $\mathrm{Hb}$ and anthropometric outcome variables (MUAC, weight, height, length) please see previous publication to baseline assessment [24].

\section{Morbidity incidence during the intervention period}

At baseline, $2^{\text {nd }}, 3^{\text {rd }}$ assessment the current health status, i.e. fever, cold and cough, or diarrhea during the week prior or on the respective medical checkup day were queried/diagnosed by the doctoral research team (endline assessment did not include a medical checkup). The morbidity prevalence is expressed as percentage of children suffering from any sickness. Morbidity data obtained during medical checkups give insight in possible trends over the study period, thereby seasonal variations in sickness can be taken into account.

Further a 5-weeks-morbidity questionnaire was conducted in Nov to Dec 2015 by social workers on $\mathrm{HH}$ level on a weekly basis. The findings of the five-weeks morbidity survey were analyzed as average per week (children with a response rate of $\geq 3$ social worker visits out of 5 were valid). Responses were given as number of days (sickness during last week). Results of the morbidity questionnaire were considered during regression analysis in order to assess possible effects of morbidity on $\mathrm{Hb}$ increases, and to compare days of sickness across the groups.

\section{Nutrient content of Amaranthus tricolor and Moringa oleifera leaves}

Supplementary Material 1 presents an overview on the nutrient content of Amaranthus tricolor and Moringa oleifera fresh as well as dried leaves. Average values of the leaf powder analysis are the basis for recipe calculation in this study. Supplementary Material 2 illustrates the amino acid content of dried Moringa leaves according to the analysis of the LA Chemie University of Hohenheim. Moringa oleifera leaf consumption can make a distinct contribution to the intake of vitamin $A, B, C$, and $E$ as well as the minerals calcium, iron, potassium, and magnesium. Moringa also contains valuable amounts of zinc, however whole-grains, legumes or seeds remain more outstanding plant-sources for enhancing zinc intake. Moreover Moringa leaves contain high amounts of protein composed of a good balance of all essential amino acids [32]. Amaranthus tricolor leaves were found during the current laboratory investigations to have an iron content five times higher than Moringa (Supplementary Material 1), thus the combination of both plants was decided in order to achieve an optimized nutrient composition in the intervention study. Moreover sensory attributes were decisive for the combined use of ALP and MLP, as ALP has a pleasant nutty taste, whereas MLP is characterized by a more leafy and slightly bitter taste.

\section{Recipes applied in the intervention groups}

Diets for children suffering from moderate malnutrition should aim at a fat energy percentage between 35 and 45 percent [33]. Recipes designed for this study (Table 1) are energy-rich with an adequate contribution of protein (Halwa 14E\%, Khechuri 22E\%) and fat (Halwa 42E\%, Khechuri 44E\%) to total energy for a sweet wheat-lentil-milk-fruit porridge 
served with half an egg "Halwa", and a rice-lentil dish with vegetables and chicken "Khechuri", respectively. Lentils were roasted during food processing to decrease antinutrients and enhance protein digestibility [25], [34].

Table 1: Ingredients of the study recipes Halwa (served twice a week plus half an egg per capita). Ingredients of Khechuri (served once a week).

Ingredients Halwa

Milk powder, whole

Wheat, flour, white (Ata, sada, packet)

Lentil, raw (Mosur dal)

Banana, ripe, raw

Dates, dried

Pumpkin, raw (Mistikumra)

Poppy seeds (posto dana)

Jaggery, solid (Gur, Akh)

Oil, sunflower, added Vit A, D, E

Water (absorbed after cooking process)

Water (entered in Nutrisurvey for subsequent use of the "boiled function")

Ingredients Khechuri

Rice

Green gram (Mung dal)

Soya chunks

Chicken (without bones)

Spinach, raw (Palong shak/ Kulmi)

Pumpkin, raw (Mistikumra)

Garlic, raw

Onion, raw

Ginger root, raw

Turmeric

Cumin seeds (Jira)

lodized salt

Oil, Sunflower, added A,D,E

Water (aborbed after cooking process)

Water (entered in Nutrisurvey for subsequent use of the "boiled function")
Amount (g)

10

10

5

60

16

55

5

8

10

94

120

Amount (g)

15

10

5

30

30

30

2.5

7.5

5

0.5

0.5

0.9

12

84

112 
The vitamin C density (Halwa: $24.5 \mathrm{mg} / 1000 \mathrm{kcal}$, Khechuri: $39.2 \mathrm{mg} / 1000 \mathrm{kcal}$ ) exceeds the minimum required density of ascorbic acid $(20 \mathrm{mg} / 1000 \mathrm{kcal})$ to maintain the desired iron absorption rate of $5-8 \%$ as stipulated by the Indian Council of Medical Research [33].

\section{Application of the enrichments leaf powder or industrial micronutrient sprinkle}

In IG2 the dosage of dried leaf powder was set at $3 \mathrm{~g}$ per $100 \mathrm{~g}$ cooked food, which equals an additional provision of $1.9 \mathrm{mg}$ iron per $100 \mathrm{~g}$ food consumed. The dosage of the industrial micronutrient powder (IG3) was adjusted to the iron content provided by the local plant sources (IG2) to make the groups comparable and allow the subsequent investigation of possible differences concerning bioavailability. Consequently per $100 \mathrm{~g}$ cooked food an additional $1.84 \mathrm{~g}$ TopNutri (=1.9mg iron) were provided. Children were entitled to eat as much they like, but the first portion distributed was set at $100 \mathrm{~g}$ for children aged $6-<12$ months, $150 \mathrm{~g}$ for children aged $12-<24$ months, $200 \mathrm{~g}$ for children $24-<36$ months and $250 \mathrm{~g}$ for children $>36$ months. Attendance was recorded throughout the study period, portion sizes consumed were documented by comparing food served versa left-overs. Two to three previously instructed village helpers performed the cooking at the community feeding centers during late afternoon. After completion of the cooking process a measured amount of the leaf powder or the micronutrient sprinkle was mixed into the ready cooked food before distributing it to the study children. The plants Moringa oleifera and Amaranthus tricolor were cultivated, and harvested followed by washing, shade-drying and further processing of leaves to powder on-sight by professional horticulturists, assuring high-quality of leaf powder due to self-optimized production sequence. The industrial micronutrient powder TopNutri was obtained by the company "Compact for Life". To summarize: a 200g portion (257.2kcal) of diversified meals alone (Halwa 2:1 Khechuri) provides on average $2.2 \mathrm{mg}$ iron. Thus, further enrichment with either $0.3 \mathrm{mg}$ iron ( $2 \mathrm{~g} \mathrm{MLP}$ ) and $3.5 \mathrm{mg}$ iron (4g ALP), or 3.8mg iron (3.68g TopNutri); results in a total iron provision of $6 \mathrm{mg}$ iron per supplementary meal ( $200 \mathrm{~g}$ portion) in IG2/IG3. The iron content per $100 \mathrm{kcal}$ accounts for $0.86 \mathrm{mg}$ (IG1), and 2.33mg (IG2/IG3).

Percent of fulfillment of Indian dietary reference intake values by study recipes

Figure 2 demonstrates the percentage of fulfillment of the dietary reference intake (DRI) values for Indian children [33] (CHO, vitamin E, D have been obtained from IOM [35]) by the three intervention groups. The graphs yields have been calculated in NutriSurvey by using the Food Composition Database for Bangladesh [36] (except B12 content for whole milk powder or egg have been obtained from USDA nutrient database [37]). Presented is the estimated daily intake of nutrients by a moderate breastmilk intake of $532.3 \mathrm{ml}$ ([38]; [39]), by complementary foods including the AWC meal ([40]), and further the nutrient intake provided by a $200 \mathrm{~g}$ exemplified supplementary meal enriched by ALP and MLP.

\section{Figure 2: Percent of fulfillment of Indian RDA by assumed moderate frequency of breastfeeding, by complementary feeding (CF) over the day, as well as Halwa:Khechuri (2:1) supplemented with either Amaranthus:Moringa (2:1) leaf powder mixture or an adjusted amount of TopNutri.}

Note: Potassium or vitamin B12 intakes are not presented in Figure 2, as no estimations were provided on CF by available food weighed protocol analysis [40]. Concerning the supplementary meal nutrient contents are as follows: $175 \mathrm{~g} \mathrm{Halwa}+25 \mathrm{~g}$ chicken egg provide 552mg potassium (18\% of DRI), $0.7 \mu \mathrm{g} \mathrm{B12}$ (78\% of DRI); $200 \mathrm{~g}$ Khechuri provide $568 \mathrm{mg}$ potassium (19\% of DRI), $0.1 \mu \mathrm{g} \mathrm{B12}$ (11\% of DRI) [35]. B12 and potassium intakes by breastmilk account for $0.085 \mu \mathrm{g}^{\mathrm{LL}}$, or $316.7 \mathrm{mg}$, respectively. For ALP no analysis for nutrient content were available concerning energy, $\mathrm{CHO}$, 
vitamin D, niacin, folate (compare Supplementary Material 1) thus reference intake values may be fulfilled at a higher percentage than presented in Figure 2.

\section{Statistical analysis}

The data were analyzed using SPSS statistics 22,25 and 26 . The general level of significance was set at $p<0.05$. The results are expressed in percentages or in means \pm SD/median. Tests applied were the Kolmogorov-Smirnov Test, Q-Qplots/histograms, the Pearson Chi-square/Fisher-test (Monte-Carlo-Simulation in case of 4x2 contigency tables if more than $20 \%$ have expected frequency $<5$ ) for proportions, for comparisons at multiple points of time within one group (intra-group comparison) univariate ANOVA with repeated measurements/Friedman, and for comparing multiple groups at one point of time (inter-group comparison) univariate ANOVA/Kruskal-Wallis test was applied. To determine which mean values varied over time Bonferroni-adjusted post-hoc test/Dunn-Bonferroni-test was performed, respectively, and in order to ascertain amongst which study groups a significant difference was found at one point of time the Duncan Post-Hoc test/Dunn-Bonferroni-test was performed. To identify significant predictors determining the highest percentile of $\mathrm{Hb}$ increases between $1^{\text {st }} / 3^{\text {rd }}$, and $1^{\text {st }} / 4^{\text {th }}$ assessment a multiple logistic binomial regression with Forward procedure was performed on a set of covariates ( $p<0.25$ in preceding bivariate analysis). The pre-post intervention effect (i.e. which study groups differ significantly over time) was validated by performing a general linear model: with $\mathrm{Hb}$ concentrations or Z-scores $(\mathrm{HAZ}, \mathrm{WAZ}, \mathrm{WHZ})$ at $2^{\text {nd }}, 3^{\text {rd }}$ and $4^{\text {th }}$ assessment respectively, being applied as dependent variable (post-test scores). Covariates considered for adjustment were: baseline $\mathrm{Hb}$ and age (significant confounders identified during linear Forward regression), time between assessment points, and gender (confounders additionally considered for reasons of integrity) (ANCOVA-post). Similarly the $\mathrm{Hb}$ changes or z-score changes occurred between baseline and $2^{\text {nd }}, 3^{\text {rd }}$ and $4^{\text {th }}$ assessment, respectively were investigated (adjusted for pre-treatment $\mathrm{Hb}$ values and age, time between assessment points, gender) (ANCOVA-change), in order to picture adjusted mean $\mathrm{Hb}$ gain scores over time per study group [41]. Both methods are reported to be equivalent resulting in same treatment effects [42], [43]. Although during data management HAZ, WAZ is already age/gender normalized -based on known population data rather than our sample; it was further adjusted for both the gender and age of the child during data analysis to find effects independent of age and sex. This way of adjustment was already chosen by other researchers [44].

Authors suggest LSD to be used as hypothesis generator rather than simultaneous hypothesis generation and testing [45], [46]. In the current trial LSD post-hoc test was chosen to test for study effects as it is inherently applied during GLM by the software SPSS itself when producing paramter estimates against the CG. Moreover LSD bears the advantage of keeping false negatives (type II errors, which may increase cost as failing to detect real differences) small, but thereby increases the possibility of false positive findings (type I error, claiming differences that are not real). Every comparison of repeated pairwise testing should be interpreted independently as the LSD post-hoc is not controlling for the family-wise error-rate, and the differences assessed need confirmation in subsequent studies. Still the only use of a more conservative test Bonferroni post-hoc may result in a waste of statistical power [47]. Thus, authors of the study suggest the LSD post-hoc test to examine trends amongst the study groups, and to validate main trends by additional consideration of the Bonferroni post-hoc test (equally presented).

\section{Results}


Socio-demographic characteristics of the households and the study children are presented in Table 2. Statistical significant differences between groups prior to the intervention were assessed for ethnicity, maternal age at the time of the interview, mean number of days mother and child sit together for eating (assessed for five consecutive weeks), and parity. The time investment in child caring activities was highest for mothers of IG1, and also sitting next to the child while eating was most practiced by IG1 -significantly more than in IG2 or CG.

\section{Table 2: Socio-demographic information by study group}


( $n=$ number of children ${ }^{c}$, or number of

mothers/households ${ }^{\mathrm{HH}}$.

Note: $10 \mathrm{HH}$ have two study children)

\begin{tabular}{|c|c|c|c|c|c|c|c|}
\hline \multirow{2}{*}{$\begin{array}{l}\text { Ethnicity } \\
(n=243) \mathrm{HH}\end{array}$} & Konra & $14(5.8)$ & $0(0)$ & $11(19.6)$ & $3(4.6)$ & $0(0)$ & \multirow[t]{2}{*}{$0.000 * * *$} \\
\hline & Santal & 229 (94.2) & $61(100.0)$ & $45(80.4)$ & $62(95.4)$ & $61(100.0)$ & \\
\hline \multirow{2}{*}{$\begin{array}{l}\text { Marital status } \\
(\mathrm{n}=234) \mathrm{HH}\end{array}$} & married & 229 (97.9) & $55(96.5)$ & $53(98.1)$ & $63(100.0)$ & 58 (96.7) & \multirow[t]{2}{*}{0.516} \\
\hline & $\begin{array}{l}\text { single, } \\
\text { formerly } \\
\text { married or } \\
\text { living } \\
\text { deserted } \\
\text { from } \\
\text { husband }\end{array}$ & $5(2.1)$ & $2(3.5)$ & $1(1.9)$ & $0(0)$ & $2(3.3)$ & \\
\hline \multirow[t]{2}{*}{$\begin{array}{l}\text { Child's age } \\
(n=254)^{c}\end{array}$} & $\begin{array}{l}6 \text { to } 23 \\
\text { months }\end{array}$ & $132(52.0)$ & $31(48.4)$ & $32(55.2)$ & $34(50.7)$ & 35 (53.8) & \multirow[t]{2}{*}{0.884} \\
\hline & $\geq 24$ months & $122(48.0)$ & $33(51.6)$ & $26(44.8)$ & 33 (49.3) & $30(46.2)$ & \\
\hline \multirow{2}{*}{$\begin{array}{l}\text { Child's sex } \\
(n=254)^{c}\end{array}$} & female & 110 (43.3) & $28(43.8)$ & $21(36.2)$ & $28(41.8)$ & $33(50.8)$ & \multirow[t]{2}{*}{0.437} \\
\hline & male & $144(56.7)$ & $36(56.3)$ & 37 (63.8) & 39 (58.2) & $32(49.2)$ & \\
\hline \multirow[t]{2}{*}{$\begin{array}{l}\text { Maternal } \\
\text { educational } \\
\text { level }(n=242) \\
\mathrm{HH}\end{array}$} & $\begin{array}{l}\text { no formal } \\
\text { education } \\
\text { (never } \\
\text { attended } \\
\text { school) }\end{array}$ & $\begin{array}{l}110 \\
(45.5 \%)\end{array}$ & $29(48.3)$ & $26(46.4)$ & $25(38.5)$ & $30(49.2)$ & \multirow[t]{2}{*}{0.605} \\
\hline & $\begin{array}{l}\text { any formal } \\
\text { education }\end{array}$ & $\begin{array}{l}132 \\
(54.5 \%)\end{array}$ & 31 (51.7) & $30(53.6)$ & $40(61.5)$ & $31(50.8)$ & \\
\hline \multirow[t]{2}{*}{$\begin{array}{l}\text { HH head } \\
(n=241) \mathrm{HH}\end{array}$} & $\begin{array}{l}\text { husband } \\
\text { only, parents } \\
\text { in law, elder }\end{array}$ & $223(92.5)$ & 55 (91.7) & $53(94.6)$ & $59(92.2)$ & 56 (91.8) & \multirow[t]{2}{*}{0.914} \\
\hline & $\begin{array}{l}\text { wife alone or } \\
\text { together with } \\
\text { husband }\end{array}$ & $18(7.5)$ & $5(8.3)$ & $3(5.4)$ & $5(7.8)$ & $5(8.2)$ & \\
\hline \multirow[t]{2}{*}{$\begin{array}{l}\text { HH type } \\
(n=243) \mathrm{HH}\end{array}$} & $\begin{array}{l}\text { nuclear } \\
\text { family }\end{array}$ & $121(49.8)$ & $27(44.3)$ & $26(46.4)$ & $40(61.5)$ & $28(45.9)$ & \multirow[t]{2}{*}{0.175} \\
\hline & $\begin{array}{l}\text { extended } \\
\text { family }\end{array}$ & $122(50.2)$ & 34 (55.7) & $30(53.6)$ & $25(38.5)$ & $33(54.1)$ & \\
\hline \multirow{2}{*}{$\begin{array}{l}\text { Type of } \\
\text { dwelling } \\
(n=243)^{H H}\end{array}$} & $\begin{array}{l}\text { kacha (mud } \\
\text { house) }\end{array}$ & 198 (81.5) & $52(85.2)$ & 47 (83.9) & $51(78.5)$ & 48 (78.7) & \multirow[t]{2}{*}{0.682} \\
\hline & $\begin{array}{l}\text { semi-pukka } \\
\text { (combination } \\
\text { mud with } \\
\text { metal or } \\
\text { stones) }\end{array}$ & 45 (18.5) & $9(14.8)$ & $9(16.1)$ & $14(21.5)$ & $13(21.3)$ & \\
\hline \multirow{2}{*}{$\begin{array}{l}\text { Household } \\
\text { cash income } \\
(n=226) \mathrm{HH}\end{array}$} & $\begin{array}{l}\text { O to } 4999 \\
\text { INR }\end{array}$ & 149 (65.9) & 35 (60.3) & $31(62.0)$ & 46 (76.7) & $37(63.8)$ & \multirow[t]{2}{*}{0.226} \\
\hline & more than & $77(34.1)$ & $23(39.7)$ & $19(38.0)$ & $14(23.3)$ & $21(36.2)$ & \\
\hline
\end{tabular}




\begin{tabular}{|c|c|c|c|c|c|c|c|}
\hline \multirow{2}{*}{$\begin{array}{l}\text { Does the } \mathrm{HH} \\
\text { cultivate any } \\
\text { land }(n=243) \\
\mathrm{HH}\end{array}$} & no & $132(54.3)$ & $30(49.2)$ & $34(60.7)$ & $39(60.0)$ & $29(47.5)$ & \multirow[t]{2}{*}{0.315} \\
\hline & $\begin{array}{l}\text { yes (own } \\
\text { land, leased } \\
\text { land) }\end{array}$ & $111(45.7)$ & $31(50.8)$ & $22(39.3)$ & $26(40.0)$ & $32(52.5)$ & \\
\hline \multirow{2}{*}{$\begin{array}{l}\text { Does the } \mathrm{HH} \\
\text { cultivate any } \\
\text { vegetables } \\
(n=238) \mathrm{HH}\end{array}$} & no & $213(89.5)$ & $55(91.7)$ & 45 (84.9) & $57(89.1)$ & $56(91.8)$ & \multirow[t]{2}{*}{0.605} \\
\hline & $\begin{array}{l}\text { yes, normally } \\
\text { or } \\
\text { sometimes }\end{array}$ & $25(10.5)$ & $5(8.3)$ & $8(15.1)$ & $7(10.9)$ & $5(8.2)$ & \\
\hline & & \multicolumn{5}{|c|}{ Mean $\pm S D$, Median, Min/Max, n } & \\
\hline $\begin{array}{l}\text { Age mother at } \\
\text { the birth of } \\
\text { her oldest } \\
\text { child (years) } \\
\text { NN*** HH }\end{array}$ & $\begin{array}{l}\text { Mean } \pm S D \\
\text { Median, } \\
\text { Min/Max }\end{array}$ & $\begin{array}{l}19.8 \pm 2.5 \\
19 \\
14 / 29 \\
n=236\end{array}$ & $\begin{array}{l}19.5 \pm 2.4 \\
19,14 / 27 \\
n=59\end{array}$ & $\begin{array}{l}19.3 \pm 2.1 \\
19,14 / 25 \\
n=56\end{array}$ & $\begin{array}{l}19.7 \pm 2.6 \\
19,15 / 29 \\
n=63\end{array}$ & $\begin{array}{l}20.5 \pm 2.7 \\
20,17 / 29 \\
n=58\end{array}$ & 0.147 \\
\hline 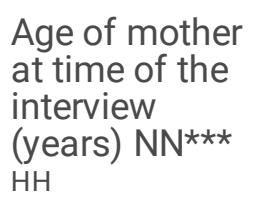 & & $\begin{array}{l}24.5 \pm 3.9 \\
24 \\
18 / 40 \\
n=237\end{array}$ & $\begin{array}{l}24.9 \pm 4.0 \\
23,19 / 37 \\
n=59\end{array}$ & $\begin{array}{l}23.2 \pm 3.1 \\
23,18 / 35 \\
n=56\end{array}$ & $\begin{array}{l}25.1 \pm 4.1 \\
25,19 / 40 \\
n=63\end{array}$ & $\begin{array}{l}24.8 \pm 4.2 \\
25,19 / 35 \\
n=59\end{array}$ & $\begin{array}{l}0.033^{*} \\
\text { (IG2 vs. } \\
\text { IG3) }\end{array}$ \\
\hline $\begin{array}{l}\text { BMI mother } \\
(\mathrm{kg} / \mathrm{m} 2) \mathrm{NN}^{\star \star} \\
\mathrm{HH}\end{array}$ & & 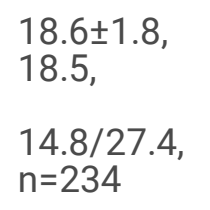 & $\begin{array}{l}18.6 \pm 1.7 \\
18.3 \\
16.0 / 24.6 \\
n=58\end{array}$ & $\begin{array}{l}18.7 \pm 2.3 \\
18.6 \\
14.8 / 27.4 \\
n=54\end{array}$ & $\begin{array}{l}18.4 \pm 1.7 \\
17.9 \\
14.8 / 26.5 \\
n=64\end{array}$ & $\begin{array}{l}18.9 \pm 1.6 \\
18.6 \\
15.2 / 22.5 \\
n=58\end{array}$ & 0.278 \\
\hline $\begin{array}{l}\text { Hb mother } \\
(g / d l) N^{\star *} H H\end{array}$ & & $\begin{array}{l}10.4 \pm 1.3 \\
10.6 \\
6.9 / 14.1 \\
n=234\end{array}$ & $\begin{array}{l}10.4 \pm 1.3 \\
10.3 \\
6.9 / 12.6 \\
n=58\end{array}$ & $\begin{array}{l}10.6 \pm 1.3 \\
10.6 \\
7.3 / 14.1 \\
n=54\end{array}$ & $\begin{array}{l}10.4 \pm 1.3 \\
10.7 \\
6.9 / 12.9 \\
n=64\end{array}$ & $\begin{array}{l}10.4 \pm 1.4 \\
10.5 \\
7.1 / 12.8 \\
n=58\end{array}$ & 0.907 \\
\hline $\begin{array}{l}\text { Average } \\
\text { number of FG } \\
\text { consumed by } \\
\text { study child at } \\
\text { baseline } \\
N N \star \star \star C\end{array}$ & & $\begin{array}{l}3.7 \pm 1.3,4 \\
0 / 6 \\
n=223\end{array}$ & $\begin{array}{l}4.1 \pm 0.9 \\
4 \\
2 / 6, n=58\end{array}$ & $\begin{array}{l}3.6 \pm 1.4 \\
4 \\
0 / 5, n=55\end{array}$ & $\begin{array}{l}3.5 \pm 1.3 \\
4, \quad 0 / 6 \\
n=57\end{array}$ & $\begin{array}{l}3.8 \pm 1.4 \\
4 \\
0 / 6, n=53\end{array}$ & 0.088 \\
\hline $\begin{array}{l}\text { Time use for } \\
\text { child caring } \\
\text { activities } \\
\text { (caring, } \\
\text { eating, } \\
\text { learning } \\
\text { together) } \\
\text { (h/day) NN*** } \\
\text { c }\end{array}$ & & $\begin{array}{l}2.9 \pm 1.9 \\
2.5 \\
0.5 / 9.5 \\
n=202\end{array}$ & $\begin{array}{l}3.1 \pm 2.1 \\
3 \\
0.5 / 8.0 \\
n=53\end{array}$ & $\begin{array}{l}2.8 \pm 1.7 \\
2.5 \\
0.5 / 7 \\
n=48\end{array}$ & $\begin{array}{l}2.9 \pm 1.9 \\
2.5 \\
0.5 / 9.5 \\
n=57\end{array}$ & $\begin{array}{l}2.6 \pm 2.0 \\
2, \\
0.5 / 8 \\
n=44\end{array}$ & 0.566 \\
\hline $\begin{array}{l}\text { Average } \\
\text { number of } \\
\text { days mother } \\
\text { and child sit } \\
\text { together/week } \\
\text { when eating } \\
\text { at home (5- } \\
\text { week }\end{array}$ & & $\begin{array}{l}2.19 \pm 1.03 \\
2 \\
1 / 7 \\
n=243\end{array}$ & $\begin{array}{l}2.44 \pm 0.73 \\
3,1 / 3 \\
n=61\end{array}$ & $\begin{array}{l}1.90 \pm 0.76 \\
2,1 / 3 \\
n=56\end{array}$ & $\begin{array}{l}2.20 \pm 1.10 \\
2,1 / 7 \\
n=64\end{array}$ & $\begin{array}{l}2.19 \pm 1.32 \\
2, \quad 1 / 7 \\
n=62\end{array}$ & $\begin{array}{l}0.002 * \star \\
\text { (IG1 vs. } \\
\text { IG2, IG1 vs. } \\
\text { CG) }\end{array}$ \\
\hline
\end{tabular}


questionnaire)

$N N \star \star \star C$

Parity $N^{* \star *}$

$\mathrm{HH}$

$\begin{array}{llllll}1.8 \pm 0.8,2, & 2.0 \pm 0.9, & 1.6 \pm 0.7, & 2.0 \pm 0.8, & 1.8 \pm 0.9, & 0.039 * \\ 1 / 5, & 2, & 1, & 2, \quad 1 / 5, & 2, & \text { (IG2 vs. } \\ n=237 & 1 / 5, n=59 & 1 / 3, n=54 & n=64 & 1 / 4, n=60 & \begin{array}{l}\text { IG3 } \\ \text { marginal } \\ \text { signif. } \\ (p=0.053)) .\end{array}\end{array}$

Note: Levels of significance ${ }^{*} p<0.05 ;{ }^{*} p<0.01 ; * \star * p<0.001$, and in case of multiple comparisons $p$-values are already adjusted for Bonferroni-correction. NN not normally distributed tested by Kolmogorov-Smirnov Test, the hypothesis regarding the distributional form is rejected with $*, * *, * \star *$. Definition of food groups (FG): starchy foods (grains, roots, tubers), legumes and nuts, dairy products, flesh foods (meat, fish, poultry, organ meats), eggs, vitamin A rich fruits and vegetables, other fruits and vegetables.

Mean changes in Hemoglobin concentrations occurred over time

Figure 3 depicts the mean $\mathrm{Hb}$ concentrations (as measured) at the different assessment points. IG1 had the highest $\mathrm{Hb}$ concentration at baseline assessment, followed by the CG, IG2, and IG3, respectively. These differences were nonsignificant $(p=0.055)$ according to ANOVA with subsequent Duncan Post-hoc test, thus ANOVA assessed comparability of the study groups at baseline (Table 3).

Figure 3: Mean $\mathrm{Hb}$ concentrations at baseline, $2^{\text {nd }}, 3^{\text {rd }}$, endline assessment $(n=254)$, per study group.

The mean $\mathrm{Hb}$ increase was highest for IG1 and IG3 until the $3^{\text {rd }}$ assessment. IG2 was characterized by a slower increase but almost caught up at the end of the first year of trial. The control group equally shows an increase over time, yet lower as compared to the intervention groups. Between the $3^{\text {rd }}$ and $4^{\text {th }}$ assessment all study groups experience a slight decrease in $\mathrm{Hb}$ concentrations. When comparing the baseline versa the endline assessment, then the highest increases in $\mathrm{Hb}$ were found for IG2/IG3, followed by IG1, and CG, respectively. Figure 4 depicts the mean changes in $\mathrm{Hb}$ concentrations over time.

Figure 4: Mean changes in Hb concentrations occurred over time ( $n=254)$, per study group.

\section{Inter- and intra-group comparisons}

The statistical analysis of possible effects induced by the different intervention measures on $\mathrm{Hb}$ concentration and nutritional status of the children is illustrated in Table 3 (Hb, HAZ, WAZ, WHZ), and Supplementary Material 3 (age, weight, height/length, MUAC z-scores). The statistical analysis presented along the lines show inter-group comparisons at one point of time, and those at the bottom of the columns depict intra-group comparisons over the different checkup points. 
For the primary indicator hemoglobin the mean values assessed at baseline were comparable across the groups (Table 3). At $2^{\text {nd }}$ and $3^{\text {rd }}$ assessment significant differences were found between IG1 to all other groups. When considering mean $\mathrm{Hb}$ changes occurred over time, no significant increase could be shown for the single intervention groups versa CG.

The age of children was comparable across all study groups at baseline and further assessment points (Supplementary Material 3).

Concerning weight, the initial baseline values were comparable across all study groups. The comparison of weight at respective assessments showed no significant differences across the groups (Supplementary Material 3). For height/length (Supplementary Material 3) and stunting z-score values (not comparable at baseline) (Table 3) no significant increases could be detected in relation to the control group, however IG2 was significantly inferior to IG3 concerning gain in HAZ-scores between baseline and endline assessment $(p=0.024)$. There was a tendency of highest achieved gains in HAZ scores for IG3 at $3^{\text {rd }}$ and endline assessment. Also mean underweight Z-scores could not be significantly improved when compared to the control group. Concerning WHZ-scores increases were significant higher for IG2 versa IG3 ( $p=0.056$, marginal significant), for CG versa IG3 ( $p=0.048)$, and for IG1 versa IG3 ( $p=0.004)$ between the $2^{\text {nd }}$ and $4^{\text {th }}$ assessment. Concerning MUAC z-score values similarly no significant differences occurred across study groups.

To sum up, effects observed in relation to the CG: At $2^{\text {nd }}$ and $3^{\text {rd }}$ assessment the hemoglobin concentration of IG1 was significantly higher as compared to CG (Table 3). Gain in weight, length or height, MUAC, HAZ, WAZ, WHZ scores showed no significant effects when compared to CG (Supplementary Material 3).

\section{Intra-group comparisons}

Mean $\mathrm{Hb}$ concentrations significantly increased between baseline and $3^{\text {rd }}$ assessment for all intervention groups and the control group, respectively. The strength of effect size between 1st and 3rd assessment was the weakest for CG $(r=0.392)$ and the strongest for IG1 ( $r=0.822)$, followed by IG3 ( $r=0.736)$, and IG2 ( $r=0.557)$. Between baseline and endline assessment all intervention groups experienced a significant increase, whereas the increase in CG was not significant. The strength of effect size between $1^{\text {st }}$ and $4^{\text {th }}$ assessment was strongest in IG3 ( $\left.r=0.548\right)$, followed by IG2 $(r=0.538)$, and IG1 $(r=0.535)$. The increase of $\mathrm{Hb}$ concentrations between $2^{\text {nd }}$ and $4^{\text {th }}$ assessment was significant for IG2 (Table 3).

Increases over time in weight and height/length were significant across all assessment points for all groups (Supplementary Material 3). Stunting z-scores showed no significant gains (decline in HAZ prevalence) for any study group from baseline to endline, with IG1 and IG2 even ending up with lower HAZ scores at $3^{\text {rd }}$ and endline assessment as compared to the baseline and $2^{\text {nd }}$ assessment, respectively. Still IG3 showed the best development in mean scores amonst all study groups, with a significant improvement between the $3^{\text {rd }}$ and endline assessment (Table 3 ). 
Underweight scores significantly improved between baseline and $3^{\text {rd }}$ assessment for IG3; whereas no group showed a significant increase between baseline and endline. Merely IG1 significantly improved their WAZ scores between the $2^{\text {nd }}$ and $4^{\text {th }}$ assessment. All groups except CG experienced significant faltering in mean scores (increase in underweight prevalence) between the $3^{\text {rd }}$ and $4^{\text {th }}$ assessment.

Wasting scores significantly improved between baseline and $3^{\text {rd }}$ assessment for all intervention groups but not CG. Again between baseline and endline no group showed a significant increase. Between the $3^{\text {rd }}$ to endline assessment all groups experienced faltering of scores, with the decrease being significant for IG 1 and IG3. Between $2^{\text {nd }}$ and endline assessment the CG and all intervention groups except IG3 significantly improved the WHZ scores.

MUAC z-scores significantly decreased in the CG between baseline and endline, and showed no change between baseline and $3^{\text {rd }}$ assessment. IG1 showed a significant increase between $2^{\text {nd }}$ and $3^{\text {rd }}$ assessment followed by a significant decrease between $3^{\text {rd }}$ and endline assessment. IG2 and IG3 experienced no significant changes in MUAC zscores. There was a tendency of higher experienced increases in MUAC scores for all intervention groups as opposed to the $C G$ at the $3^{\text {rd }}$ and endline assessment, respectively.

To sum up intra-group effects considering key points of the trial: hemoglobin concentrations showed a significant increase between $1^{\text {st }}$ and $3^{\text {rd }}$ assessment for all intervention groups and CG, with the effect size being smallest for CG. Between baseline and endline all intervention groups but not CG showed significant increases (Table 3).

Weight as well as height/length increases were significant for all groups over the study period. Stunting scores showed no significant changes in any study group between baseline and $3^{\text {rd }} /$ endline assessment. Still, IG3 showed significant improvement in HAZ scores between the $3^{\text {rd }}$ and endline assessment. Similarly, underweight scores significantly increased between $1^{\text {st }}$ and $3^{\text {rd }}$ assessment for IG3. Wasting scores significantly rose between $1^{\text {st }}$ and $3^{\text {rd }}$ assessment for all intervention groups but not CG. MUAC scores significantly decreased between $1^{\text {st }}$ and endline assessment for CG, whereas all intervention groups showed a tendency of increasing MUAC z-scores (Supplementary Material 3).

\section{Table 3 Effect of diversified meals only (IG1), or either enriched with ALP/MLP (IG2), or an adjusted amount of} industrial micronutrient powder (IG3) on $\mathrm{Hb}$ concentrations and the nutritional status (HAZ, WAZ, WHZ) of study children. 


\begin{tabular}{|c|c|c|c|c|c|}
\hline \multirow{3}{*}{$\begin{array}{l}\text { Hemoglobin } \\
\text { (mg/dl) }\end{array}$} & IG1 & IG2 & IG3 & CG & p-value \\
\hline & \multirow[t]{2}{*}{$n=64$} & \multirow[t]{2}{*}{$\mathrm{n}=58$} & \multirow[t]{2}{*}{$n=67$} & \multirow[t]{2}{*}{$n=65$} & $\begin{array}{l}(\mathrm{IG} \mathrm{1,2,3} \\
\mathrm{CG})\end{array}$ \\
\hline & & & & & $\begin{array}{l}\text { ANOVA or } \\
\text { Kruskal- } \\
\text { Wallis test }\end{array}$ \\
\hline Baseline & $9.5 \pm 1.1$ & $9.2 \pm 1.1$ & $9.1 \pm 1.0$ & $9.4 \pm 1.0$ & $p=0.055$ \\
\hline $2^{\text {nd }}$ & $10.1 \pm 1.3$ & $9.5 \pm 1.2$ & $9.7 \pm 1.2$ & $9.6 \pm 1.1$ & $\begin{array}{l}p=0.027 * \\
a, d, f\end{array}$ \\
\hline $3^{\text {rd }}$ & $10.5 \pm 1.2$ & $10.0 \pm 1.2$ & $10.0 \pm 1.1$ & $9.9 \pm 1.1$ & $\begin{array}{l}p=0.021 * \\
a, d, f\end{array}$ \\
\hline Endline $\mathrm{NN}^{*}$ & $10.2 \pm 1.2$ & $10.0 \pm 1.1$ & $9.9 \pm 1.0$ & $9.9 \pm 1.1$ & $p=0.202$ \\
\hline $\begin{array}{l}\text { Difference } \\
\text { 3rd-1st }\end{array}$ & $0.99 \pm 1.04$ & $0.84 \pm 1.3$ & $0.93 \pm 1.17$ & $0.49 \pm 1.06$ & $p=0.064$ \\
\hline $\begin{array}{l}\text { Difference } \\
\text { 4th-2nd }\end{array}$ & $0.11 \pm 1.11$ & $0.52 \pm 0.96$ & $0.23 \pm 1.10$ & $0.28 \pm 1.07$ & $p=0.209$ \\
\hline $\begin{array}{l}\text { Difference } \\
\text { 4th-1 st NN* }\end{array}$ & $0.70 \pm 1.15$ & $0.81 \pm 1.31$ & $0.82 \pm 1.33$ & $0.45 \pm 1.24$ & $p=0.119$ \\
\hline \multirow{11}{*}{$\begin{array}{l}\text { Friedman } \\
\text { baseline to } \\
\text { endline }\end{array}$} & $p<0.001 * \star *$ & $p<0.001 * * *$ & $p<0.001 * \star \star$ & $p=0.007 * \star$ & \\
\hline & $A, D, F(p<0.001)$ & $D, F(p<0.001)$ & $D, F(p<0.001)$ & $F(p=0.009)$ & \\
\hline & \multirow[t]{2}{*}{$\mathrm{B}(\mathrm{p}=0.050$ marginal $)$} & $E(p=0.007)$ & $A(p=0.024)$ & & \\
\hline & & $B(p=0.004)$ & $B(p=0.010)$ & & \\
\hline & Effect size of Dunn- & Effect size of Dunn- & Effect size of Dunn- & \multicolumn{2}{|l|}{ Effect size of Dunn- } \\
\hline & Bonferroni (pairwise & Bonferroni (pairwise & Bonferroni (pairwise & \multicolumn{2}{|l|}{ Bonferroni (pairwise } \\
\hline & comparison of 1 st versa & comparison of 1 st versa & comparison of 1 st versa & \\
\hline & 4th/3rd assessment) & 4th/3rd assessment) & 4th/3rd assessment) & \multicolumn{2}{|l|}{ versa 3rd assessment) } \\
\hline & $D:(z=-4.279, r=0.535)$ & $\begin{array}{l}D:(z=-4.099, \\
r=0.538)\end{array}$ & $D:(z=-4.483, r=0.548)$ & \multirow{2}{*}{\multicolumn{2}{|c|}{$F:(z=-3.159, r=0.392)$}} \\
\hline & \multirow[t]{2}{*}{$F:(z=-6.573, r=0.822)$} & & $F:(z=-6.022, r$ & & \\
\hline & & $F:(z=-4.243, r=0.557)$ & $=0.736)$ & & \\
\hline
\end{tabular}




\begin{tabular}{|c|c|c|c|c|c|}
\hline Height-for-age & IG1 & IG2 & IG3 & CG & p-value \\
\hline \multirow[t]{3}{*}{ z-score (stunting) } & $n=64$ & $n=57$ & $n=67$ & $n=64$ & $(\mathrm{IG} \mathrm{1,2,3,CG)}$ \\
\hline & & & & & ANOVA or Kruskal- \\
\hline & & & & & Wallis test \\
\hline Baseline & $-1.82 \pm 0.99$ & $-1.79 \pm 0.90$ & $-2.05 \pm 1.25$ & $-2.27 \pm 1.09$ & $p=0.040 * d, e$ \\
\hline $2^{\text {nd }}$ & $-1.80 \pm 0.88$ & $-1.92 \pm 0.87$ & $-1.93 \pm 1.12$ & $-2.22 \pm 1.09$ & $p=0.121$ \\
\hline $3 r d$ & $-1.87 \pm 0.88$ & $-1.98 \pm 0.86$ & $-1.99 \pm 1.12$ & $-2.24 \pm 0.99$ & $p=0.168$ \\
\hline Endline & $-1.84 \pm 0.84$ & $-1.95 \pm 0.85$ & $-1.86 \pm 1.02$ & $-2.24 \pm 0.99$ & $p=0.062$ \\
\hline Difference $_{3 \mathrm{rd}-1 \mathrm{st} \mathrm{NN}^{\star \star \star}}$ & $-0.054 \pm 0.572$ & $-0.194 \pm 0.660$ & $0.058 \pm 0.655$ & $0.029 \pm 0.542$ & $p=0.122$ \\
\hline Difference $_{4 \text { th-2nd NN }}{ }^{\star \star \star}$ & $-0.039 \pm 0.446$ & $-0.025 \pm 0.449$ & $0.068 \pm 0.349$ & $-0.023 \pm 0.43$ & $p=0.400$ \\
\hline \multirow[t]{2}{*}{ Difference 4 th-1 st NN ${ }^{\star \star \star}$} & $-0.027 \pm 0.676$ & $-0.158 \pm 0.751$ & $0.188 \pm 0.605$ & $0.035 \pm 0.638$ & $p=0.034^{*}$ \\
\hline & & & & & $\begin{array}{l}\mathrm{b}: \mathrm{p}=0.024 \\
\text { Bonferroni-corr. }\end{array}$ \\
\hline \multirow{2}{*}{$\begin{array}{l}\text { ANOVA repeated } \\
\text { measurements }\end{array}$} & $p=0.630$ & $p=0.076$ & $p=0.032 *$ & $p=0.724$ & \\
\hline & & & $C(p=0.003)$ & & \\
\hline
\end{tabular}




\begin{tabular}{|c|c|c|c|c|c|}
\hline Weight-for-age & IG1 & IG2 & IG3 & CG & $\mathrm{p}$-value \\
\hline \multirow[t]{2}{*}{ z-score (underweight) } & $n=64$ & $n=58$ & $n=67$ & $n=64$ & $(\mathrm{IG} 1,2,3, \mathrm{CG})$ \\
\hline & & & & & $\begin{array}{l}\text { ANOVA or Kruskal- } \\
\text { Wallis test }\end{array}$ \\
\hline Baseline & $-1.91 \pm 0.85$ & $-1.78 \pm 0.98$ & $-1.92 \pm 1.03$ & $-2.01 \pm 1.07$ & $p=0.625$ \\
\hline $2^{\text {nd }}$ & $-2.05 \pm 0.74$ & $-1.95 \pm 0.96$ & $-1.99 \pm 0.94$ & $-2.20 \pm 1.03$ & $p=0.465$ \\
\hline $3^{\text {rd }}$ & $-1.75 \pm 0.76$ & $-1.73 \pm 0.94$ & $-1.68 \pm 0.97$ & $-1.94 \pm 0.95$ & $p=0.390$ \\
\hline Endline & $-1.91 \pm 0.76$ & $-1.84 \pm 0.89$ & $-1.96 \pm 0.89$ & $-2.06 \pm 0.89$ & $p=0.536$ \\
\hline Difference $_{3 r d-1 \text { st }}$ & $0.162 \pm 0.532$ & $0.045 \pm 0.513$ & $0.239 \pm 0.548$ & $0.072 \pm 0.548$ & $p=0.162$ \\
\hline Difference $_{4 \text { th-2nd }}$ & $0.135 \pm 0.297$ & $0.112 \pm 0.345$ & $0.024 \pm 0.387$ & $0.132 \pm 0.408$ & $p=0.254$ \\
\hline Difference $_{4 \text { th-1 }}$ st NN* & $-0.005 \pm 0.559$ & $-0.065 \pm 0.548$ & $-0.041 \pm 0.582$ & $-0.052 \pm 0.611$ & $p=0.831$ \\
\hline \multirow{4}{*}{$\begin{array}{l}\text { ANOVA repeated } \\
\text { measurements }\end{array}$} & $p<0.001^{* * *}$ & $p=0.003 * *$ & $p<0.001 * * *$ & $\mathrm{p}=0.001 * *$ & \\
\hline & $B, C(p<0.001)$ & $A(p=0.037)$ & $B, C(p<0.001)$, & $A(p=0.023)$ & \\
\hline & $E(p=0.003)$ & $B(p<0.001)$ & $F(p=0.004)$ & $B(p<0.001)$ & \\
\hline & & $C(p=0.007)$ & & & \\
\hline
\end{tabular}




\begin{tabular}{|c|c|c|c|c|c|}
\hline Weight-for-height/length & IG1 & IG2 & IG3 & CG & $\mathrm{p}$-value \\
\hline \multirow[t]{2}{*}{ z-score (wasting) } & $n=64$ & $n=57$ & $n=67$ & $n=64$ & $(\mathrm{IG} 1,2,3, \mathrm{CG})$ \\
\hline & & & & & $\begin{array}{l}\text { ANOVA or } \\
\text { Kruskal-Wallis } \\
\text { test }\end{array}$ \\
\hline Baseline & $-1.30 \pm 0.84$ & $-1.10 \pm 0.98$ & $-1.15 \pm 0.88$ & $-1.08 \pm 1.09$ & $p=0.551$ \\
\hline $2^{\text {nd }}$ & $-1.54 \pm 0.75$ & $-1.29 \pm 0.95$ & $-1.34 \pm 0.90$ & $-1.41 \pm 0.93$ & $p=0.438$ \\
\hline $3 r d$ & $-1.00 \pm 0.65$ & $-0.88 \pm 0.92$ & $-0.81 \pm 0.85$ & $-0.98 \pm 0.89$ & $p=0.502$ \\
\hline Endline & $-1.24 \pm 0.75$ & $-1.03 \pm 0.90$ & $-1.30 \pm 0.79$ & $-1.12 \pm 0.87$ & $p=0.250$ \\
\hline Difference $_{3 r d-1 \text { st }}$ & $0.296 \pm 0.684$ & $0.219 \pm 0.594$ & $0.338 \pm 0.704$ & $0.091 \pm 0.751$ & $p=0.188$ \\
\hline \multirow[t]{6}{*}{ Difference $_{4 \text { th-2nd } N N^{\star \star}}$} & $0.293 \pm 0.454$ & $0.264 \pm 0.534$ & $0.032 \pm 0.601$ & $0.288 \pm 0.696$ & $p=0.003^{* \star}$ \\
\hline & & & & & $\begin{array}{l}\mathrm{b}: \mathrm{p}=0.056 \\
\text { marginal }\end{array}$ \\
\hline & & & & & signif., \\
\hline & & & & & Bonferroni-corr. \\
\hline & & & & & $\begin{array}{l}\text { c: } p=0.048 \\
\text { Bonferroni-corr. }\end{array}$ \\
\hline & & & & & $\begin{array}{l}f: p=0.004 \\
\text { Bonferroni-corr. }\end{array}$ \\
\hline Difference $_{4 \text { th-1 st }}$ & $0.056 \pm 0.697$ & $0.075 \pm 0.606$ & $-0.159 \pm 0.747$ & $-0.048 \pm 0.822$ & $p=0.240$ \\
\hline \multirow{4}{*}{$\begin{array}{l}\text { ANOVA repeated measurements } \\
\text { baseline to endline }\end{array}$} & $p<0.001 * * *$ & $p<0.001 * * *$ & $p<0.001 * * *$ & $p<0.001 * * *$ & \\
\hline & $A(p=0.037)$ & $B(p<0.001)$ & $B, C(p<0.001)$ & $A(p=0.002)$ & \\
\hline & $B, C, E(p<0.001)$ & $E(p=0.003)$ & $F(p=0.001)$ & $B(p<0.001)$ & \\
\hline & $F(p=0.006)$ & $F(p=0.044)$ & & $E(p=0.009)$ & \\
\hline
\end{tabular}

Values represent Mean $\pm S D$

NS non significant

Levels of significance ${ }^{*} p<0.05 ; * \star p<0.01 ; * \star \star p<0.001$

Significant difference between groups small letter/between measurement points capital letter: ${ }^{\mathrm{a} / \mathrm{A}}$ I and II; ${ }^{\mathrm{b} / \mathrm{B}} \mathrm{II}$ and III; c/C III and IV; ${ }^{d / D}$ I and IV; e/E II and IV; f/F I and III 
NN not normally distributed tested by Kolmogorov-Smirnov Test, the hypothesis regarding the distributional form is rejected with $*, * \star, * \star \star$.

If the sample size comprises $n>30$ or 40 individuals, the violation of normal distribution is less problematic, as the sampling distribution approaches normality regardless of the shape of the data [48]. The division of the mean by median resulted in a ratio within the range 0.95-1.05 for measured data on anthropometry or $\mathrm{Hb}$, and the graphical distribution by histogram ascertained no serious deviation from normality for none of the variables investigated. Still according to the Kolmogorov-Smirnov Test the decision for parametric or non-parametric tests was performed. However for visual presentation of $\mathrm{Hb}$, and $\mathrm{HAZ}, \mathrm{WAZ}, \mathrm{WHZ}$ scores the means were preferred over the median.

Calculation of effect size (r) using z-value of Dunn-Bonferroni obtained during Friedman-test:

Interpretation of the strength of effect size according to Cohen (1992) [49]:

$0.1 \leq r<0.3$ (weak), $0.3 \leq r<0.5$ (medium), $r>0.5$ (strong).

Prevalence of moderate/severe anemia and stunting, underweight, wasting at the different assessment points

Note: as $\mathrm{Hb}<7 \mathrm{~g} / \mathrm{dl}$ was an exclusion criteria during the nutrition program phase, merely at endline assessment a total of three children suffering from severe anemia $(\mathrm{Hb}<7 \mathrm{~g} / \mathrm{dl})$ were remaining in analysis, one child per IG1, IG3, CG, respectively. At baseline the four study groups were not comparable concerning the prevalence of moderate anemia $(7 \mathrm{~g} / \mathrm{dl} \leq \mathrm{Hb}<10 \mathrm{~g} / \mathrm{dl})(\mathrm{p}=0.007 * *)$. The initial prevalence of moderate anemia was highest for IG2, IG3 $(81.0 \%, 80.6 \%)$, followed by $63.1 \%(C G)$, and $59.4 \%$ in (IG1). Again at $3^{\text {rd }}$ assessment, the comparison of the four study groups showed a significant difference $\left(p=0.021^{\star}\right)$, with IG3 having the highest prevalence of moderate anemia $(49.3 \%)$, followed by IG2 (46.6\%), CG (44.6\%), IG1 (25.0\%). The prevalence of moderate anemia was similar across the groups concerning the remaining assessments $\left(2^{\text {nd }}, 4^{\text {th }}\right)$ (Figure 5).

Figure 5: Prevalence of moderate/severe anemia at different assessment points by study group

To sum up, considering all subjects suffering from moderate anemia at baseline assessment, and improving their $\mathrm{Hb}$ level to mild/or no anemia at $3^{\text {rd }}$ or endline assessment, respectively then no significant differences across the four study groups could be detected. In other words, the proportion of children improving their Hb level from moderate anemia to mild/no anemia between the $1^{\text {st }}$ and $3^{\text {rd }} / 4^{\text {th }}$ assessment, respectively, was similar across all groups, indicating no significant effect of the intervention on the reduction of the prevalence of moderate anemia. Still, the prevalence of moderate/severe anemia between the $1^{\text {st }}$ and $3^{\text {rd }}, 1^{\text {st }}$ and $4^{\text {th }}$ assessment decreased least in the CG $(18.5 \%, 10.8 \%)$, whilst the highest decrease was observed for IG2 (34.4\%, 36.2\%), respectively. IG1 (34.4\%, $26.6 \%)$ and IG3 $(31.3 \%, 26.9 \%)$ similarly showed invariable higher decreases in the rates of moderate/severe anemia as compared to the $C G$, indicating a positive tendency on the reduction of anemia by the intervention measures. 
The Chi-square test (not presented) showed significant differences in regard to the initial stunting prevalence at baseline assessment across the four different study groups ( $p=0.033)$. All remaining comparisons concerning the prevalence of stunting ( 2 2SD), wasting or underweight showed similarity across the four study groups at the different assessment points, indicating no significant effect of the intervention measure on growth indices across the different study groups (Supplementary Material 4).

\section{Regression analysis}

Table 2 presents differences in socio-demographic characteristics across study groups. It has to be considered that meaningful differences in baseline characteristics are often not detected, because studies are not powered for this purpose (type II error). This implies that a non-significant difference still can be a strong prognostic factor causing meaningful confounding and vice versa. Boer et al. [50] conclude that potential confounders should not be selected based on statistical analysis of differences at baseline. Thus, in subsequent regression models, all prognostic factors were taken into account in terms of bivariate analysis to identify meaningful confounders $(p<0.25)$ in relation to the dependent variable.

Regression analysis to define predictors of the highest percentile of hemoglobin increases occurred at endline assessments ( $1^{\text {st }}$ versa $3^{\text {rd }}, 4^{\text {th }}$ assessment, respectively)

A forward regression analysis with a step-wise approach was performed to identify independent predictors on the $\mathrm{Hb}$ response occurred during the $1^{\text {st }}$ and $3^{\text {rd }}$ (Model A, Table 4), as well as the $1^{\text {st }}$ and $4^{\text {th }}$ assessment (Model B, Table 5), respectively. The cutoffs to define the dependent variable were set to select the highest percentile of $\mathrm{Hb}$ increases observed across the different assessment points. First each covariate was examined for the presence of statistical association with the dependent variable $\left(\mathrm{Hb}_{\text {diff }} \geq 1.8 \mathrm{~g} / \mathrm{dl}\right.$ at $3^{\mathrm{rd}} / 1^{\mathrm{st}}$, and $\mathrm{Hb}_{\text {diff }} \geq 1.7 \mathrm{~g} / \mathrm{dl} 4^{\text {th }} / 1^{\text {st }}$ assessment $)$ by logistic binary regression (generation of crude p-values), respectively. Hereby covariates with a $p$-value of $<0.25$ in the bivariate analysis were considered during the process of multiple logistic regression in two models, in order to assess the independent predictors on the $20 \%$ highest $\mathrm{Hb}$ response of valid cases (merely maternal educational level and $\mathrm{HH}$ cash income were included even though not matching a $\mathrm{p}<0.25)$.

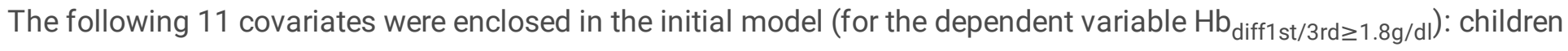
's age, sex, average number of days affected by respiratory disease assessed by 5-weeks morbidity questionnaire, maternal educational level, $\mathrm{HH}$ cash income, intervention group, ethnicity (categorical variables), as well as WHZ at baseline, $\mathrm{Hb}$ concentrations at baseline, count of food groups consumed the day before the interview at baseline assessment, delivery number/birth order of study child (continuous variables).

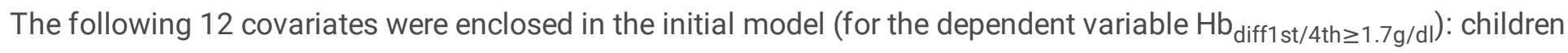
's age, sex, maternal educational level, $\mathrm{HH}$ cash income, intervention group, any land cultivation, ethnicity (categorical variables), as well as age of the main caretaker, $\mathrm{Hb}$ concentrations at baseline, delivery number/birth order of study child, average number of days affected by any morbidity (fever, cold/cough, diarrhea) assessed during the 5-weeks morbidity questionnaire, average number of days mother and child sit together while eating (continuous variables). 
All continuous covariates were assessed for interactions with their logit (log odds), and all relationships were found to be linear (Box-Tidwell Test), further the initial model was assessed for the presence of multi-collinearity [51], and fitness to the data was proofed by the Hosmer-Lemeshow's goodness-of-fit test.

Variables with a p-value below 0.05 assessed during forward regression were declared to be significantly associated with the dependent variable $\mathrm{Hb}$ increase $\geq 1.8 / 1.7 \mathrm{~g} / \mathrm{dl}$ at $3^{\text {rd }}$, and $4^{\text {th }}$ assessment, respectively.

Predictors of the highest percentile of $\mathrm{Hb}$ increases occurred between baseline and $3^{\text {rd }}$ assessment were: low baseline $\mathrm{Hb}$ concentrations, and a diversified diet at baseline, as well as to be amongst the first-borns in a family. Considering the highest percentile of $\mathrm{Hb}$ increases occurred between baseline and endline assessment: then again low baseline $\mathrm{Hb}$ concentrations, were a distinct predictor for high increases in $\mathrm{Hb}$, but also the availability of a higher $\mathrm{HH}$ cash income was associated with higher increases in $\mathrm{Hb}$ over time. The affiliation to any of the study groups was not shown to be significantly associated with the highest $\mathrm{Hb}$ increases occurred during the intervention period.

Table 4: Ratio of odds of $\mathrm{Hb}$ response accounting for $\mathrm{Hb}_{\mathrm{Diff}} \geq 1.8 \mathrm{~g} / \mathrm{dl}$ ( $3^{\text {rd }}$ vs. $1^{\text {st }}$ assessment), ( $\mathrm{n}=44 / 195,22.6 \%$ prevalence), 11 covariates included in the intitial model, $83.1 \%$ of cases were correctly predicted.

\begin{tabular}{|c|c|c|c|c|c|}
\hline \multirow[t]{2}{*}{ Model A: Forward Wald } & \multirow[t]{2}{*}{ Beta } & \multirow[t]{2}{*}{ S.E. } & $\begin{array}{l}\text { Odds } \\
\text { ratio }\end{array}$ & \multirow[t]{2}{*}{ 95\% C.I. } & \multirow[t]{2}{*}{$\begin{array}{l}\text { p- } \\
\text { value }\end{array}$} \\
\hline & & & $\operatorname{Exp}(B)$ & & \\
\hline Hemoglobin concentraions at baseline $(\mathrm{g} / \mathrm{dl})$ & -1.334 & 0.257 & 0.264 & $\begin{array}{l}0.159 \\
0.436\end{array}$ & 0.000 \\
\hline $\begin{array}{l}\text { Count of food groups consumed during previous } 24 \mathrm{~h} \text { at } \\
\text { baseline }\end{array}$ & 0.616 & 0.183 & 1.851 & $\begin{array}{l}1.293 \\
2.650\end{array}$ & 0.001 \\
\hline Delivery number/birth order of study child & -0.560 & 0.278 & 0.571 & $\begin{array}{l}0.331 \\
0.985\end{array}$ & 0.044 \\
\hline
\end{tabular}

Levels of significance ${ }^{*} \mathrm{p}<0.05 ;{ }^{* \star} \mathrm{p}<0.01 ;{ }^{* *} \mathrm{p}<0.001$.

Table 5: Ratio of odds of $\mathrm{Hb}$ response accounting for $\mathrm{Hb}_{\mathrm{Diff}} \geq 1.7 \mathrm{~g} / \mathrm{dl}$ ( $4^{\text {th }}$ vs. $1^{\text {st }}$ assessment), $(\mathrm{n}=46 / 218,21.1 \%$ prevalence), 12 covariates included in the initial model, $83.5 \%$ of cases were correctly predicted.

\begin{tabular}{|lccccc} 
Model B: Forward Wald & Beta & S.E. & $\begin{array}{l}\text { Odds ratio } \\
\text { Exp(B) }\end{array}$ & 95\% C.I. & p-value \\
\hline Hemoglobin concentrations at baseline $(\mathrm{g} / \mathrm{dl})$ & -2.013 & 0.315 & 0.134 & $0.072,0.248$ & 0.000 \\
\hline Cash income (two groups) & 0.916 & 0.435 & 2.498 & $1.066,5.857$ & 0.035 \\
\hline
\end{tabular}

Levels of significance ${ }^{*} p<0.05 ;{ }^{*} p<0.01 ;{ }^{* *} p<0.001$. Note: exclusion of serial No 65 (IG1) in model B (as standardized residual $|z|>3 S D$ in the preliminary model [52], and Box-Tidwell test turned significant). Without exclusion of outliers, 
merely baseline hemoglobin concentrations were assessed as significant predictor for the highest percentile of $\mathrm{Hb}$ increases between $1^{\text {st }}$ and $4^{\text {th }}$ assessment.

In Supplementary Material 5 the mean hemoglobin changes occurred between the respective assessment points are presented by baseline anemia status. To conclude, children with no/mild anemia at baseline $(n=50)$ experienced significant lower mean increases in $\mathrm{Hb}$ than children suffering from moderate anemia at baseline.

General linear model to ascertain the intervention effect on $\mathrm{Hb}$ adjusted for significant confounders

Additionally an univariate general linear model was performed, in order to ascertain the effect of the intervention on $\mathrm{Hb}$ concentrations at $2^{\text {nd }}, 3^{\text {rd }}$ and $4^{\text {th }}$ assessment, respectively, adjusted for selected confounders. Similarly, the $1^{\text {st }}$ assessment was investigated for comparability of groups adjusted for the same confounders (except baseline $\mathrm{Hb}$ concentrations, time period in months between respective assessment points).

First the correlation coefficient for a set of covariates, was assessed by Pearson or Spearman at each assessment. Then those covariates correlating with a $p<0.25$ were further considered in linear Forward regression models to ascertain significant confounders at each assessment point on the dependent variable Hb concentration. Hereby age and $\mathrm{Hb}$ concentrations at baseline were the two covariates significant to all models, thus were selected for designing GLM with the variable intervention group as fixed factor, and the respective $\mathrm{Hb}$ concentration at each assessment as dependent variable. Additional covariates considered as relevant for adjustment were gender, as well as time in months between assessment points. The intervention effect on investigated dependent variables ( $\mathrm{Hb}$ concentrations) was validated by significant differences for any of the intervention groups versa the control group ( $<<0.05)$, according to LSD. Altogether three GLM resulted: GLM A2, A3, A4 (comparison of Hb concentrations at $2^{\text {nd }}, 3^{\text {rd }}, 4^{\text {th }}$ assessment, respectively across intervention groups toward CG) (Supplementary Material 6).

GLM A2, A3, A4 reveal significant higher mean Hb concentrations for IG1 as opposed to the CG, at $2^{\text {nd }}(p=0.029), 3^{\text {rd }}$ $(p=0.006)$, and endline ( $p=0.040$, after exclusion of standardized residual $|z|>3 S D$ [52]) assessment, adjusted for age and $\mathrm{Hb}$ at baseline, time in months between assessment points, gender. When including all valid cases at $4^{\text {th }}$ assessment, no significant differences between any study groups were detected.

Unadjusted and adjusted means of $\mathrm{Hb}$ concentrations are presented in Table 6 (outlier considerations are contained herein). At baseline assessment the unadjusted/adjusted Hb concentrations of IG3 significantly differed from IG1 ( $p=0.028 / 0.016)$, and from CG ( $p=0.037 / 0.004)$, respectively, assessed by LSD post-hoc test. When considering the pairwise comparison of intervention groups versa control group (unadjusted/adjusted), then IG1 had significantly higher $\mathrm{Hb}$ concentrations at $2^{\text {nd }}(p=0.024 / 0.029), 3^{\text {rd }}(p=0.006 / 0.006)$, and $4^{\text {th }}$ assessment $(p=0.046 / 0.040)$, as opposed to the CG.

Table 6: Inter-group comparison of mean $\mathrm{Hb}$ concentrations $(\mathrm{g} / \mathrm{dl})$ at respective assessment points by GLM. Mean $\mathrm{Hb}$ concentrations by study group.

Page 23/62 


\begin{tabular}{|c|c|c|c|c|c|}
\hline Assessment points & Total $(n=254)$ & IG1 $(n=64)$ & IG2 $(n=58)$ & IG3 (n=67) & CG $(n=65)$ \\
\hline Hb measurement & & Mean, 95\% C.I. & Mean, 95\% C.I. & Mean, 95\% C.I. & $\begin{array}{l}\text { Mean, 95\% } \\
\text { C.I. }\end{array}$ \\
\hline $\begin{array}{l}\text { 1st Assessment Hb } \\
(\mathrm{g} / \mathrm{dl})\end{array}$ & $\begin{array}{l}9.29(9.16 \\
9.43)\end{array}$ & $\begin{array}{l}9.47(9.20 \\
9.75)^{\mathrm{a}}\end{array}$ & $\begin{array}{l}9.19(8.89 \\
9.49)^{a, b}\end{array}$ & $\begin{array}{l}9.06(8.82 \\
9.31)^{b}\end{array}$ & $\begin{array}{l}9.45(9.20 \\
9.70)^{\mathrm{a}}\end{array}$ \\
\hline adjusted & $\begin{array}{l}9.30(9.18 \\
9.42)\end{array}$ & $\begin{array}{l}9.42(9.18 \\
9.67)^{\mathrm{a}}\end{array}$ & $\begin{array}{l}9.25(8.99 \\
9.50)^{a, b}\end{array}$ & $\begin{array}{l}9.01(8.77 \\
9.24)^{b}\end{array}$ & $\begin{array}{l}9.51(9.27 \\
9.75)^{\mathrm{a}}\end{array}$ \\
\hline $\begin{array}{l}\text { 2nd Assessment Hb } \\
(\mathrm{g} / \mathrm{dl})\end{array}$ & $\begin{array}{l}9.72(9.57 \\
9.87)\end{array}$ & $\begin{array}{l}10.10(9.77 \\
10.43)^{a}\end{array}$ & $\begin{array}{l}9.48(9.16 \\
9.80)^{b}\end{array}$ & $\begin{array}{l}9.65(9.37 \\
9.94)^{\mathrm{b}}\end{array}$ & $\begin{array}{l}9.62(9.34 \\
9.89)^{b}\end{array}$ \\
\hline adjusted & $\begin{array}{l}9.71(9.60 \\
9.83)\end{array}$ & $\begin{array}{l}9.96(9.73 \\
10.20)^{a}\end{array}$ & $\begin{array}{l}9.57(9.32 \\
9.81)^{b}\end{array}$ & $\begin{array}{l}9.73(9.50 \\
9.96)^{a, b}\end{array}$ & $\begin{array}{l}9.59(9.36 \\
9.83)^{b}\end{array}$ \\
\hline $\begin{array}{l}\text { 3rd Assessment Hb } \\
(\mathrm{g} / \mathrm{dl})\end{array}$ & $\begin{array}{l}10.12(9.97 \\
10.26)\end{array}$ & $\begin{array}{l}10.50(10.19 \\
10.80)^{a}\end{array}$ & $\begin{array}{l}10.03(9.73 \\
10.34)^{b}\end{array}$ & $\begin{array}{l}9.99(9.73 \\
10.26)^{b}\end{array}$ & $\begin{array}{l}9.94(9.67 \\
10.21)^{\mathrm{b}}\end{array}$ \\
\hline adjusted & $\begin{array}{l}10.12(10.00 \\
10.24)\end{array}$ & $\begin{array}{l}10.39(10.16 \\
10.63)^{a}\end{array}$ & $\begin{array}{l}10.08(9.83 \\
10.34)^{a, b}\end{array}$ & $\begin{array}{l}10.06(9.82 \\
10.30)^{a, b}\end{array}$ & $\begin{array}{l}9.93(9.69 \\
10.16)^{\mathrm{b}}\end{array}$ \\
\hline $\begin{array}{l}\text { 4th Assessment } \mathrm{Hb} \\
(\mathrm{g} / \mathrm{dl})\end{array}$ & $\begin{array}{l}10.03(9.89 \\
10.16)\end{array}$ & $\begin{array}{l}10.27(10.00 \\
10.55)^{a}\end{array}$ & $\begin{array}{l}10.00(9.71 \\
10.28)^{a, b}\end{array}$ & $\begin{array}{l}9.94(9.71 \\
10.17)^{a, b}\end{array}$ & $\begin{array}{l}9.90(9.62 \\
10.18)^{b}\end{array}$ \\
\hline adjusted & $\begin{array}{l}10.03(9.91 \\
10.15)\end{array}$ & $\begin{array}{l}10.20(9.95 \\
10.44)^{a}\end{array}$ & $\begin{array}{l}10.08(9.83 \\
10.34)^{a, b}\end{array}$ & $\begin{array}{l}10.00(9.76 \\
10.24)^{a, b}\end{array}$ & $\begin{array}{l}9.83(9.59 \\
10.08)^{\mathrm{b}}\end{array}$ \\
\hline
\end{tabular}

Note: all results are reported as means (95\% confidence interval). Differing superscript letters indicate statistical significant differences $(p<0.05)$ between study groups assessed by GLM, post-hoc tests according to least significant difference (LSD) (unadjusted, adjusted).

Adjusted for: age (months) at baseline and gender (male=1) (1 $1^{\text {st }}$ assessment), age (months) and hemoglobin concentrations $(\mathrm{g} / \mathrm{dl})$ at baseline, time between baseline and investigated assessment point (months), gender (male=1) $\left(2^{\text {nd }}, 3^{\text {rd }}, 4^{\text {th }}\right.$ assessment), respectively.

Outlier considerations for the above presented unadjusted/adjusted means: $\mathbf{1}^{\text {st }}$ Assessment (n=253): exclusion of Serial No 48 (IG1) as z-residual of |z|>3SD. Before as well as after outlier exclusion residuals normally distributed, and same study groups showed significant difference in pairwise comparison (unadjusted, adjusted model). $2^{\text {nd }}$ and $3^{\text {rd }}$ Assessment (n=254): residuals normally distributed and no z-residual of $|z|>3 S D$. Note: $3^{\text {rd }}$ assessment: pairwise comparison in adjusted model revealed significant difference between IG1 vs. CG ( $p=0.006)$, and IG1 vs. IG3 ( $p=0.051$,

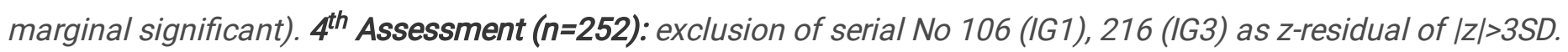
Before as well as after outlier exclusion residuals normally distributed. Before outlier exclusion pairwise comparison found no significant differences between any study groups concerning unadjusted/adjusted mean Hb concentrations. 
GLM, post-hoc test for adjusted model according to Bonferroni (adjustment for multiple comparisons): all pairwise comparisons non-significant ( $p>0.05)$, except $1^{\text {st }}$ Assessment: IG3 vs. CG ( $\left.p=0.024\right), 3^{\text {rd }}$ Assessment: IG1 vs. CG $(p=0.039)$.

In Table 7 the unadjusted/adjusted means of occurred changes in $\mathrm{Hb}$ over time are presented and in Supplementary Material 7 the respective GLM.

Table 7 Inter-group comparison of mean $\mathrm{Hb}$ changes ( $\mathrm{g} / \mathrm{dl}$ ) occurred between indicated assessment points by GLM. Mean $\mathrm{Hb}$ changes by study group.

\begin{tabular}{|c|c|c|c|c|c|}
\hline \multirow[t]{2}{*}{$\begin{array}{l}\text { Mean } \mathrm{Hb} \text { change occurred within } \\
\text { indicated assessment period }\end{array}$} & $\begin{array}{l}\text { Total } \\
(n=254)\end{array}$ & IG1 (n=64) & IG2 (n=58) & IG3 (n=67) & CG $(n=65)$ \\
\hline & & $\begin{array}{l}\text { Mean, 95\% } \\
\text { C.I. }\end{array}$ & $\begin{array}{l}\text { Mean, 95\% } \\
\text { C.I. }\end{array}$ & $\begin{array}{l}\text { Mean, 95\% } \\
\text { C.I. }\end{array}$ & $\begin{array}{l}\text { Mean, 95\% } \\
\text { C.I. }\end{array}$ \\
\hline 2nd_1st Hb change (g/dl) & $\begin{array}{l}0.412 \\
(0.280 \\
0.544)\end{array}$ & $\begin{array}{l}0.588 \\
(0.354 \\
0.821)^{a}\end{array}$ & $\begin{array}{l}0.290 \\
(-0.016, \\
0.595)^{a, b}\end{array}$ & $\begin{array}{l}0.588 \\
(0.319 \\
0.857)^{a}\end{array}$ & $\begin{array}{l}0.168 \\
(-0.086 \\
0.422)^{b}\end{array}$ \\
\hline adjusted & $\begin{array}{l}0.409 \\
(0.293 \\
0.525)\end{array}$ & $\begin{array}{l}0.659 \\
(0.425 \\
0.893)^{a}\end{array}$ & $\begin{array}{l}0.264 \\
(0.019 \\
0.508)^{b}\end{array}$ & $\begin{array}{l}0.424 \\
(0.194, \\
0.653)^{a, b}\end{array}$ & $\begin{array}{l}0.290 \\
(0.057 \\
0.522)^{b}\end{array}$ \\
\hline 3rd_1st Hb change (g/dl) & $\begin{array}{l}0.811 \\
(0.669 \\
0.954)\end{array}$ & $\begin{array}{l}0.986 \\
(0.727 \\
1.245)^{a}\end{array}$ & $\begin{array}{l}0.840 \\
(0.497, \\
1.182)^{a, b}\end{array}$ & $\begin{array}{l}0.930 \\
(0.644 \\
1.216)^{a}\end{array}$ & $\begin{array}{l}0.491 \\
(0.228 \\
0.753)^{b}\end{array}$ \\
\hline adjusted & $\begin{array}{l}0.812 \\
(0.693 \\
0.930)\end{array}$ & $\begin{array}{l}1.090 \\
(0.852 \\
1.327)^{a}\end{array}$ & $\begin{array}{l}0.780 \\
(0.529 \\
1.031)^{a, b}\end{array}$ & $\begin{array}{l}0.755 \\
(0.519, \\
0.992)^{a, b}\end{array}$ & $\begin{array}{l}0.622 \\
(0.385 \\
0.859)^{b}\end{array}$ \\
\hline 4th_1st Hb change (g/dl) & $\begin{array}{l}0.716 \\
(0.564 \\
0.869)\end{array}$ & $\begin{array}{l}0.733 \\
(0.449 \\
1.017)^{a, b}\end{array}$ & $\begin{array}{l}0.807 \\
(0.463 \\
1.150)^{a, b}\end{array}$ & $\begin{array}{l}0.885 \\
(0.586 \\
1.183)^{a}\end{array}$ & $\begin{array}{l}0.448 \\
(0.140 \\
0.755)^{b}\end{array}$ \\
\hline adjusted & $\begin{array}{l}0.719 \\
(0.598 \\
0.841)\end{array}$ & $\begin{array}{l}0.887 \\
(0.643 \\
1.132)^{a}\end{array}$ & $\begin{array}{l}0.772 \\
(0.517, \\
1.027)^{a, b}\end{array}$ & $\begin{array}{l}0.692 \\
(0.450 \\
0.934)^{a, b}\end{array}$ & $\begin{array}{l}0.525 \\
(0.280 \\
0.770)^{b}\end{array}$ \\
\hline
\end{tabular}

Note: all results are reported as means (95\% confidence interval). Differing superscript letters indicate statistical significant differences $(p<0.05)$ between study groups assessed by GLM, post-hoc tests according to least significant difference (LSD) (unadjusted, adjusted).

Adjusted for: age at baseline (months), hemoglobin concentrations ( $\mathrm{g} / \mathrm{dl})$ at baseline, time between respective assessment points (months), gender (male=1).

Outlier considerations for the above presented unadjusted/adjusted means: $2^{\text {nd }} \boldsymbol{1}^{\text {st }}$ assessment period ( $\left.n=254\right)$ : residuals normally distributed and no z-residual of $|z|>3 S D$. $3^{\text {rd }} \eta^{\text {st }}$ assessment period $(\boldsymbol{n}=254)$ : residuals normally 
distributed and no $z$-residual of $|z|>3 S D$. Note: $3^{\text {rd }} 1^{\text {st }}$ assessment: pairwise comparison in adjusted model revealed significant difference between IG1 vs. CG ( $p=0.006)$, and IG1 vs. IG3 ( $p=0.051$, marginal significant). $4^{\text {th }} \boldsymbol{1}^{\text {st }}$ assessment period (n=252): exclusion of serial No 106 (IG1), 216 (IG3) as z-residual of $|z|>3 S D$. Before as well as after outlier exclusion residuals normally distributed. Before outlier exclusion pairwise comparison found no significant differences between any study groups concerning unadjusted/adjusted mean Hb changes.

GLM, post-hoc test for adjusted model according to Bonferroni (adjustment for multiple comparisons): all pairwise comparisons non-significant ( $p>0.05)$, except $3^{\text {rd }} 1^{\text {st }}$ assessment period: IG1 vs. CG ( $\left.p=0.039\right)$.

In Figure 6 the adjusted mean changes in $\mathrm{Hb}$ over time are depicted.

ANCOVA with repeated measurements ( $n=251$, with age as covariate) showed: the within-subjects effects -considering overall $\mathrm{Hb}$ concentrations from baseline, $2^{\text {nd }}, 3^{\text {rd }}$, to endline assessment; to be significantly different within IG1 $(p<0.001,=0.110, f=0.352), I G 3(p<0.001,=0.111, f=0.353), C G(p<0.024,=0.048, f=0.225)$, whereas for IG2 the intragroup comparison of $\mathrm{Hb}$ concentrations over time did not differ significantly $(p=0.119,=0.119, f=0.193)$. The withingroup pairwise comparison of baseline versa $3^{\text {rd }}$ or endline $\left(4^{\text {th }}\right)$ assessment, respectively, was found invariably significant for all study groups with $p<0.001$, merely in case of $1^{\text {st }}$ versa $4^{\text {th }}$ for CG with $p=0.005$. The decline in mean $\mathrm{Hb}$ concentrations between $3^{\text {rd }}$ and endline assessment was found non-significant for all study groups.

On the basis of estimates for age-adjusted means reflecting the total intervention period: $10.06 \mathrm{~g} / \mathrm{dl}$ (IG1), 9.73 (IG2), 9.61 (IG3), 9.80 (CG) the pairwise between-group comparison proved IG1 to be superior toward IG2 ( $p=0.026)$, or IG3 $(p=0.001)$, however with the IG1 versa CG comparison remaining non-significant $(p=0.072)$. The in this section described analysis via ANCOVA with repeated measurements is based on the exclusion of standardized residuals of |z|>3SD (serial No: 048 (IG1), 106 (IG1), 216 (IG3)).

Figure 6 Adjusted mean changes in $\mathrm{Hb}$ concentrations occurred over time, per study group (covariates age and $\mathrm{Hb}$ at baseline, time between baseline and investigated assessment point, gender).

General linear model to ascertain the intervention effect on HAZ, WAZ, WHZ adjusted for baseline age and baseline zscores for stunting, underweight, wasting, respectively

The GLM was performed for the $z$-scores at $2^{\text {nd }}, 3^{\text {rd }}$, endline assessment controlled for age (months) and $z$-scores at baseline, time in months between baseline and investigated assessment point, as well as gender, respectively. The unadjusted/adjusted means are presented in Supplementary Material 8, Supplementary Material 9, Supplementary Material 10 (outlier considerations are contained herein).

For adjusted HAZ (including all valid cases) merely at endline $\left(4^{\text {th }}\right)$ assessment a significant effect has been assessed with IG3 achieving best mean scores amongst all study groups and being found significantly superior to IG2 ( $p=0.018)$. 
With the exclusion of outliers -standardized residual |z|>3SD (serial No: 051 (IG1), 163 (IG2), 349 (CG)) this superiority remained $(p=0.026)$.

For adjusted WAZ at the $2^{\text {nd }}$ assessment -only after exclusion of outliers (serial No: 202 (IG2), 349 (CG), 378 (CG), 424 (CG), 439 (CG)); significant higher $z$-scores were assessed for IG3 versa CG ( $p=0.049)$. At $3^{\text {rd }}$ assessment IG3 was found superior toward CG ( $p=0.043)$, and IG2 was assessed to be significantly inferior toward IG3 ( $p=0.024)$; after the exclusion of outliers (serial No: 069 (IG1), 349 (CG), 439 (CG)) these differences in mean adjusted WAZ-scores increased in significance (IG3 vs. CG ( $p=0.005)$, IG2 vs. IG3 ( $p=0.014)$ ); and additionally IG1 versa CG $(p=0.044)$ turned significant.

For adjusted WHZ-scores at $3^{\text {rd }}$ assessment IG3 was sigificantly better than CG $(p=0.026)$, this superiority increased after excluding outliers (serial No: $439(\mathrm{CG})$ ) ( $\mathrm{p}=0.010)$. At $4^{\text {th }}$ assessment IG2 achieved significant better WHZ-scores than IG3 ( $p=0.024)$, this superiority increased after exclusion of outliers (serial No: 051 (IG1), 327 (IG3), 379 (CG)) $(p=0.004)$.

To conclude, tendencies revealed by the LSD post-hoc test for the adjusted model showed: IG3 to be significant better in scores for WAZ at $2^{\text {nd }}, 3^{\text {rd }}$ assessement and for WHZ at $3^{\text {rd }}$ assessment as opposed to the CG, and showed best development amongst all study groups in overall HAZ scores. IG3 showed superiority toward IG2 at $3^{\text {rd }}$ assessment (WAZ) and at endline (HAZ). IG2 failed to show significant higher Z-scores as opposed to the CG, however at endline assessment IG2 had the best scores for WHZ amongst all study groups and significantly higher than IG3 (which experienced unexpected decreases in WAZ/WHZ scores at endline). IG1 showed similar positive trends concerning WAZ scores as IG3, being equally superior to $C G$ at $3^{\text {rd }}$ checkup.

The Bonferroni post-hoc test for the adjusted model confirmed IG3 being superior to CG at $3^{\text {rd }}$ assessment for WAZ $(p=0.029), W H Z$ ( $p=0.059$, marginal significant). Moreover at endline IG2 was found superior toward IG3 $(p=0.027)$ in WHZ scores (IG3 experienced excessive faltering at endline), but remained comparable to CG (subtext Supplementary Material 8, Supplementary Material 9, Supplementary Material 10).

The adjusted mean z-score changes occurred, were highest for WHZ, followed by WAZ, with HAZ showing the slightest changes over time. It is observed that stunting scores show reziprocal curve processing to WAZ or WHZ (Figure 7, Figure 8, Figure 9). Moreover clear effects on season are palpable determining growth patterns.

Figure 7 Adjusted mean changes in HAZ scores occurred over time, per study group (covariates age and HAZ scores at baseline, time between baseline and investigated assessment point, gender).

Figure 8 Adjusted mean changes in WAZ scores occurred over time, per study group (covariates age and WAZ scores at baseline, time between baseline and investigated assessment point, gender). 
Figure 9 Adjusted mean changes in WHZ scores occurred over time, per study group (covariates age and WHZ scores at baseline, time between baseline and investigated assessment point, gender).

\section{Size of feeding center}

The participants per feeding center ranged from 7 to 29 children. No significant correlation between number of participants and $\mathrm{Hb}$ increases between different assessment points could be detected. Also the increases in $\mathrm{Hb}$ over time between centers with less than 20 children versa centers with 20 or more children were found similar. Altogether this finding indicates the size of feeding center having no influence on program delivery. Size of feeding center, attendance or consumption rates were not considered during regression models as being variables not applicable to the CG.

\section{Attendance and portion sizes consumed}

The primary objective of this research was to determine the effect of diversified meals in the scope of community nutrition programs on the nutritional, hematological and health status of study children. The analysis followed an intention-to-treat approach investigating all participants according to their allocation status to the intervention, whether they received it or not. Thereby the non-compliance and treatment changes that are likely to occur in practice are considered, without the risk of attrition bias [53]. Still, the attendance was recorded to validate the program. Hereby, the respective four weeks before each follow-up assessment $\left(2^{\text {nd }}, 3^{\text {rd }}\right.$, endline) were analyzed to picture the attendance rate and consumption rate of the three half-yearly intervention periods (IP) (compare Figure 1). Thereby, each analyzed attendance period consists of 12 supplementary feeding program days, as the program was conducted three times per week. Consequently a total of 36 feedings were analyzed to estimate the attendance and consumption rates over the total study period of 18 months. The attendance rate is expressed in percent of possible feeding days, and the consumption rate as percent of the age-dependent portion size served. Additionally the attendance rate (but not consumption rate) was analyzed for the total 78 weeks (18 months).

The overall attendance rate in the periods IP1-3 (36 feedings) for total IG was $81.5 \%$, and the overall consumption rate $90.8 \%$ ranging from no consumption up to $141 \%$ of the reference portion. The attendance rate over the total intervention period of 78 weeks accounted for $80.3 \%$ for total IG. Throughout all IPs and for the overall study period IP1-3, IG2 had the lowest consumption rates amongst all study groups. Significant differences were detected for IG1 having higher consumption rates than IG2 at IP1 (102.3\% versa 85.4\%) and IP3 (85.7\% versa 82.3\%), respectively. For attendance rates no significant differences were detected across the study groups.

Boys and girls had similar attendance rates at the program (81.9\% versa $80.9 \%$ ), however the average consumption rate assessed was significantly higher for boys $(94.2 \%$ versa $85.8 \%)(p=0.017)$.

\section{Correlation of attendance and hemoglobin}

The Spearman correlation between attendance rates over the three IPs with the Hb concentrations at the $2^{\text {nd }}, 3^{\text {rd }}, 4^{\text {th }}$ assessment, respectively, as well as of the 78 weeks attendance rate with $\mathrm{Hb}$ at the $4^{\text {th }}$ assessment showed no 
significant association. Similarly, when testing for associations between changes occurred in $\mathrm{Hb}$ (during $1^{\text {st }} / 3^{\text {rd }}$ and $1^{\text {st }} / 4^{\text {th }}$ assessment, respectively) and attendance rates, adjusted for consumption rates, no significant association was found. However when testing for the effect of attendance rates during all three IPs at once (36 feeding days) on $\mathrm{Hb}$ concentrations at the $4^{\text {th }}$ assessment, and controlling for consumption rates, then a negative association was detected $(r=-0.155, p=0.034)$.

\section{Correlation of portion size and hemoglobin}

Correlations between portion size and $\mathrm{Hb}$ concentrations at the $2^{\text {nd }}, 3^{\text {rd }}, 4^{\text {th }}$ assessment, respectively, showed no significant association, with or without adjustment for attendance rates. Similarly, when testing for the effect of consumption rates during all three IPs at once (36 feeding days) on $\mathrm{Hb}$ at the $4^{\text {th }}$ assessment, and controlling for attendance rates, merely a marginal positive association was detected $(r=0.143, p=0.050)$. However, when testing for the association of the occurred changes in $\mathrm{Hb}$ concentration (during $1^{\text {st }} / 3^{\text {rd }}$ assessment, and $1^{\text {st }} / 4^{\text {th }}$ assessment, respectively) and consumption rates, then a slight association was found for the changes occurred in $\mathrm{Hb}\left(1^{\mathrm{st}} / 3^{\mathrm{rd}}\right.$ assessment) and portion sizes consumed $\left(r=0.154^{*}, p=0.034\right)$, the significance increased after adjusting for attendance rates $(r=0.169, p=0.020)$. None of the tested associations between the changes in $\mathrm{Hb}\left(1^{\text {st }} / 4^{\text {th }}\right.$ assessment $)$ and consumption rates proofed to be significant.

\section{Morbidity throughout the study period and assessed by morbidity questionnaire}

The morbidity analysis concerning fever or diarrhea prevalence revealed no significant differences between the study groups at $1^{\text {st }}, 2^{\text {nd }}, 3^{\text {rd }}$ assessment point, respectively. Merely the prevalence of respiratory infections (comparable across groups at baseline) was significantly different between the study groups at $2^{\text {nd }}(p=0.006)$, and $3^{\text {rd }}(p=0.002)$ assessment (Figure 6), respectively. Baseline data ([24]) revealed the morbidity prevalence (fever, respiratory infections, diarrhea) to be highly age-dependent, with children aged 12 to 23 months being most vulnerable to morbidity, with continuous decline thereafter. As the age distribution was comparable across study groups, the observed higher decreases in the prevalence of respiratory infections (from 69.7\% to 33.3\%) for IG3 may be related to the higher zinc intakes amongst beneficiaries of this intervention arm. Similarly, comparing all study groups IG3 showed the highest decreases in fever prevalence (from $27.3 \%$ to $6.1 \%$ ) or diarrhea rates $\left(19.7 \%\right.$ to $7.6 \%$ ) between the $1^{\text {st }}$ to the $3^{\text {rd }}$ assessment. By comparing $1^{\text {st }}$ versa $3^{\text {rd }}$ assessment, effects of season are considered. In general, no clear trends related to seasonality were visible, probably due to the confounding factor age. Yet, for respiratory infections and diarrhea prevalence some flattening or even positive slope of the line could be observed between the $2^{\text {nd }}$ and $3^{\text {rd }}$ assessment, indicating the winter season having increased the rates of infectious diseases in this study. The trend of fever rates however showed a continuous decrease for all study groups across all assessment points.

Figure 10 Prevalence of morbidity across different assessment points by study group

\section{Discussion}


The recommended iron densities of complementary foods (CF) for infants $12-23$ months are 1.6 and $0.8 \mathrm{mg} / 100 \mathrm{kcal}$ assuming low and average bioavailability, for 6-11 months these densities rank invariably higher $(4.6-7.7 \mathrm{mg} / 100 \mathrm{kcal}$ and $2.4-4 \mathrm{mg} / 100 \mathrm{kcal}$, respectively) [54]. The iron provided in IG1 accounted for an iron density of $0.86 \mathrm{mg}$ iron per $100 \mathrm{kcal}$, and for IG2/IG3 $2.33 \mathrm{mg}$ iron per $100 \mathrm{kcal}$, respectively. Iron and zinc are considered to be the limiting nutrients in family nutrition in developing countries. Recommended intakes of iron and to a lesser extent of zinc are still unlikely to be provided by improved traditional CF in the first year of life, when portion size is limited and iron gap is biggest. During a child's first year of life, growth and therewith blood creation is particular high in the child, so are iron needs [55]; [56]. The special iron needs of children under age two get palpable by the increased prevalence of anemia among children aged 6 to 23 months as elaborated by Kotecha based on the data of the Indian NFHS-3, and similarly confirmed by baseline data of the current trial [24]. Kotecha suggests low-birth weights infants, premature infants, and infants of mothers with anemia to require additional iron from two months of age on, otherwise iron stores remain insufficient and iron demands for rapid growth are not met [57]. Ruel et al. concluded that the densities for iron and zinc in traditional complementary recipes in resource-constraint environments remain highly inadequate for children younger than one year, even after inclusion of locally available fortified corn-soy blend (CSB) and optimal combination of locally available, acceptable and affordable foods. An overall challenge remains for targeted beneficiaries to meet appropriate infant feeding practices by adequate nutrient density, consistency and texture, as well as frequency of feeding [58].

In the current study mothers were informed that the feeding program has a supplementary purpose to enhance child's nutrient intake, still at endline assessment of 189 mothers the majority (74.1\%) reported that the meal offered at the nutrition program replaced a meal at home, with one mother stating that only due to the rare attendance of her child (due to disliking the ALP/MLP taste) the meal did not replace a meal at home, and merely $25.4 \%$ indicated that the meal supplemented the dietary routine of the child. The reason for meal replacement $(n=137)$, was "the time of nutrition program was the same time when child would receive food at home anyway" (89.8\%), thus "children had full stomach after program, could not eat extra food at home" $(2.2 \%)$, or "because other family members can eat more at home, if one child eats outside" (8.0\%). The hosting of the nutrition program in the late afternoon was intentionally chosen, in order that caretakers may be free after work to bring their child to the nutrition program. Still, observations showed children were frequently accompanied by older siblings or even came alone to the program. Altogether the practice of replacing a meal at home is likely to have diminished the possible effect of the low-dose feeding trial. Still, the locally produced supplementary meals were composed of affordable and available ingredients, thus constitute a sustainable complementary food option to be adapted by caregivers after closure of the feeding program. Accordingly, at endline assessment of 188 mothers, more than every fourth $(28.2 \%)$ indicated that they have modified their cooking behavior at home -inspired by the nutrition program. Of these 53 mothers, $32.1 \%$ improved their hygienic behavior (proper cleaning of utensils, intensified washing of vegetables, using food cover, serving spoon), and $83.0 \%$ changed composition of their diet (add more vegetables/leafy vegetables, started to use or to add more Amaranthus/Moringa leaves, use more frequently egg or soybean). 157 mothers indicated reasons for not having changed anything or problems faced when trying to change something (no money $(70.1 \%)$, husband did not like a change (40.1\%), mother felt unable to change something (8.3\%), time constraints $(1.9 \%)$, and $55.5 \%$ of cases stated they felt no need to change anything e.g. as home food is perceived to be of very good quality). To conclude economic as well as social limitations stand out as main reasons; combined with lack of awareness of the need for modifications. 
The Copenhagen Consensus 2008 concluded that nutrition-focused interventions (micronutrient supplementation, fortification as well as community-based nutrition promotion) generate highest economic returns [59], thus are of priority when advancing the well-being of people in developing countries.

The WHO recommends a daily dose of $10-12.5 \mathrm{mg}$ elemental iron amongst infants aged 6 to 23 months when the prevalence of anemia is $40 \%$ or higher [60]. The absolute absorption efficiency depends on intestinal factors (hostrelated factors), individual's iron status or infection state (systemic factors), the dose and form of iron compounds and absorption modifiers consumed with the food vehicle (diet-related factors) [34].

\section{Food synergies in diversified study meals}

Food synergy is considered as a key to healthy diet with food components deemed "to act in concert on health" implying additive effects, this means the whole is more than the sum of its parts. Food consists of a biological complexity developed under evolutionary control, that cannot be imitated by single nutrients. The focus on isolated nutrients in nutrition research may be counterproductive and less-beneficial [61], thus this study investigates the effect of diversified meals only (IG1), and either enriched with whole-food leaf powder (IG2) or an adjusted amount of industrially synthesized isolated micronutrients (IG3). Between IG2 and IG3 no significant differences in Hb concentrations at different assessment points were observed (Table 6, Table 7).

The bioavailability of iron is increased by small amounts of animal-protein "meat factor", or by ascorbic acid [62]. The latter however may experience substantial losses during storage or preparation, in particular in the presence of oxygen, metals, humidity and/or high temperatures if the food is not appropriately packaged or the vitamin $\mathrm{C}$ not encapsulated [63].

Proteins from other food sources in particular eggs, milk and dairy products (especially casein) inhibit iron absorption. Serum ferritin was reported to be positively associated with flesh foods intake and negatively related to dairy product consumption [34]. Still, in the current trial iron absorption may be equally impaired by the egg or milk proteins across all study groups, as the only variation is the ALP/MLP (IG2) or adjusted amount of TopNutri (IG3).

Zinc and iron were found to show competitive interactions, similarly calcium may have an acute inhibitory effect on iron absorption [34]. The adverse effect is dependent on the calcium amount administered rather than the Ca:Fe molar ratio [64]. Negative effects have been shown with the addition of $165 \mathrm{mg}$ calcium from milk products [65]. The maximum inhibitory effect is suggested to be achieved at calcium doses of $300 \mathrm{mg}$ ( $77 \%$ inhibition) in a meal, but already starts at 40mg (39\% inhibition) [64]. Still, reported negative effects of calcium on iron absorption are predominantly assessed in single-meal studies; whereas multiple-meal studies -embracing a huge amount of other inhibitors and promoters, suggest calcium to have merely a limited effect [65]. Moreover it remains uncertain if the observed adverse effects are due to the increased calcium or rather related to inhibitory milk proteins of dairy products commonly applied as primary source of calcium in single-meal studies [64]. The calcium content per 100g Halwa including half egg/Khechuri was highest for IG3 (148.1 mg/117.4mg), followed by IG2 (119.8mg/88.8mg), with IG1 providing lowest calcium amounts $(70.8 \mathrm{mg} / 40.1 \mathrm{mg})$. Thus, a potential inhibitory effect of calcium on iron absorption is conceivable with the decrease in absorption rate to be considered highest for IG3. 
Measuring the molar ratio of phytate/minerals in the diet predicts bioavailability of minerals in the body. Phytate (PA):mineral molar ratios (PA:Fe, PA:Zn, PA:Ca, Ca*PA/Zn, Ca:P, Oxalate:Ca, Zn:Fe) were calculated based on the Indian Food Composition [66] and Annex 1 for the study recipes (results not shown). Hereby, for PA:Fe the critical ratio of 1:1 as suggested by Hurrel for plain cereal or legume-based meals [67], has been exceeded by all study groups. For an exemplified serving size of 100g, the highest PA:Fe ratio was assessed for diversified study meals only (IG1, PA:Fe ratio: 3.97, 2.96), followed by diversified meals plus ALP/MLP (IG2, PA:Fe ratio: 1.41, 1.35), with diversified meals plus an adjusted amount of TopNutri (IG3, PA:Fe ratio: 1.37, 1.31) having the lowest ratio for Halwa including half egg/Khechuri, respectively. Moreover for IG3 the Ca*PA/Zn ratio highly exceeded the critical value of 0.5 , -as suggested by Ferguson [68], with 8.98 and 9.47 for Halwa including half egg and Khechuri, respectively. The latter indicates that calcium may influence zinc absorption for IG3.

Foods considered as being high in PA are defined to contain $>400 \mathrm{mg}$ PA/100g food [69]. Yet, the dose-dependent inhibitory effect of phytate on iron absorption is reported to start at low concentrations of $10 \mathrm{mg} / \mathrm{meal}$ [70]. The PA contents of all study meals were $<65 \mathrm{mg} / 100 \mathrm{~g}$ serving size of Halwa/Khechuri. According to Hurrel [67], [71] for composite meals, containing ascorbic acid from vegetables or meat as enhancers, a PA:Fe ratio of 6:1 may be acceptable. Thus, the PA content in the current study meals may not be a major inhibitory factor.

The benefits and limitations of food-based approaches for combating iron-deficiency and malnutrition by dietary diversification are discussed in detail by reports of the FAO [15], [72]. Evaluations of the efficacy of multi-sectoral approaches for dietary diversification is challenging and remains inconclusive, due to the complexity of holistic foodbased strategies, the variety of nutritional components contained in food, large number of confounders and difficulties for study design in regard to short-term and long-term effects. Food-based approaches for dietary diversification focus on food and livelihood-based models (e.g. home gardening and crop-diversification, the increased availability and consumption of animal-sourced foods, education and training, access to sanitary facilities, social services and health care), thereby strive for prevention and sustainability.

In the current trial altogether diversified meals alone (IG1) were found to have most effectively increased the $\mathrm{Hb}$ concentrations as opposed to the CG at $2^{\text {nd }}, 3^{\text {rd }}$, and endline assessment. Leaf-powder enriched meals (IG2), or meals with an adjusted amount of MNP showed no superior effect toward the CG. The superiority of IG1 vs. CG in regard to $\mathrm{Hb}$ concentrations was also affirmed by the conservative Bonferroni-post-hoc test at $3^{\text {rd }}$ assessment (subtext Table 6, Table 7). Concerning growth indices the effect of IG1 appears less conclusive. At $3^{\text {rd }}$ assessment IG 1 showed superiority toward CG concerning WAZ scores. Moreover IG1 showed highest mean time investment in caring activities, and at home mothers were sitting next to their child during eating on significant more days during a five-week assessment as compared to the other study groups (Table 2). This increased caring may promote increased food ingestion in the child, thus may positively contribute to anemia reduction or growth development in this study.

\section{Leaf powder and bioavailability studies}

Moringa oleifera is especially promoted due to its satisfying iron content. Gallaher et al [73] investigated the iron bioavailability of dried Moringa leaf powder (MLP) ( $0.5 \%$ dry weight basis diet) in rats, and came to the conclusion that 
the high phytic acid content of the leaves implies not only a low bioavailability of iron from the Moringa supplement itself but also inhibits the absorption of iron provided from the general diet. Rats receiving commercial animal feed and MLP at $10 \%$, experienced significant lower increases in $\mathrm{Hb}$ and weight as compared to another experimental group being fed MLP at 5\% [74].

Equally, researches of the University of Pretoria [75], [76] concluded that the in vitro iron and zinc bioaccessibility of adding MLP in the weight amount of $5 \%$ to a standardized pearl millet porridge (dry weight basis) was superior to the adding of $15 \%$ of Moringa with regard to the fulfillment of physiological reference intake levels. As compared to other dried food-to-food fortifications e.g. hibiscus leaves, baobab fruit pulp, mango-carrot premix; MLP resulted in the lowest increases of iron and zinc accessibility attributable to the high calcium, phenolic, phytic and organic acid content. MLP increased (due to its high iron content) but also decreased bioaccessibilies, altogether a negative impact on the bioaccessibility of the porridge itself has to be considered due to the high levels of iron and zinc inhibitors. All studies used a realistic single-meal food matrix, which suggests that there is no amplified impact on iron absorption as it may be in studies utilizing isolated plant products. Still, it has to be noted that studies on single-meals versa whole diets tend to exaggerate the effect of nutrient interactions involving iron absorption [34]. In the current trial the applied overall leaf powder dose of ALP/MLP was rather low accounting for $3 \%$ in total (wet weight basis of overall served study meal), and in regard to MLP $1 \%$. Without cooking water and not considering the served egg, fortification levels rank at maximum double. Still, a theoretical low dosage of $<1 \%-5 \%$ MLP could exceed the critical amount according to investigations by Gallaher et al [73], however still may be an enrichment according to considerations of Merwe et al. [75] as outlined above. Tessera et al. [77] reported the bioavailability of iron to be highest for $5 \%$ MLP blending while zinc and calcium were found to be well available in blending up to $20 \%$ MLP with wheat flour on the basis of molar ratios of minerals and antinutrients.

According to analysis by the LA Chemie University of Hohenheim the phytate contents in dried ALP/MLP were $<0.05 \%$, thus not exactly detectable. According to the Indian Food Composition Table [66] fresh Amaranthus leaves contain less phytic acid than fresh Moringa leaves e.g. (4.89mg/100g vs. $128 \mathrm{mg} / 100 \mathrm{~g})$. Other analysis published revealed phytic acid contents accounting for $234 \mathrm{mg}$ in $100 \mathrm{~g}$ of Amaranthus leaf powder [78]; or ranging from $0.265 \mathrm{mg}$ [18] to 2100mg [79] in $100 \mathrm{~g}$ of dried Moringa leaves (Supplementary Material 1).

In the current trial the mean adjusted $\mathrm{Hb}$ concentrations assessed in IG2 showed no significant differences toward the CG across all assessment points (Table 6, Table 7). Moreover IG2 was slightly worse than the CG and significantly inferior to IG1 concerning $\mathrm{Hb}$ concentrations at $2^{\text {nd }}$ assessment (Table 6) or in regard to the Hb changes occurred between baseline and $2^{\text {nd }}$ assessment (Table 7), possibly attributable to antinutrients (phytic acid, polyphenols, oxalate) or nutrient-to-nutrient interactions. Still, at the $3^{\text {rd }}$ and endline assessment IG2 remained comparable to all intervention groups.

Similarly, in regard to adjusted means of growth indices (HAZ, WAZ, WHZ); IG2 failed to show significant differences as opposed to the CG. Concerning adjusted HAZ scores IG2 was significantly inferior to IG3 at endline, and showed most poor changes in scores over time amongst all study groups (Figure 7). For adjusted WAZ-scores IG2 was found significantly inferior to IG3 at $3^{\text {rd }}$ assessment. In regard to adjusted WHZ scores at endline the highest scores were found for IG2 (lowest WHZ prevalence), moreover IG2 showed significant better WHZ scores than IG3 at endline, also confirmed by the conservative Bonferroni-post-hoc test (subtext, Supplementary Material 10). It has to be noted that IG3 experienced excessive faltering in WHZ scores at endline, but showed the best performance at $3^{\text {rd }}$ assessment 
(Figure 9). The positive effect on reduction of wasting prevalence may be attributable to the holistic amino acid composition present in ALP/MLP (IG2) (Supplementary Material 2), and TopNutri (IG3) equally containing high quality protein (amino acid score of 100 [80]).

IG2 showed lowest consumption rates throughout the trial as compared to the other intervention groups, significantly inferior to IG1 during IP1 and IP3. Similarly mothers were significantly less sitting next to their child during eating at home, in IG2 versa IG1 (Table 2). Altogether the lower consumption rates during the program and less attentive eating athmosphere at home, may have negatively affected the reduction in anemia rates or growth development.

\section{Acceptability of MLP and left-over rate of distributed portions}

The feasibility and acceptability of using dried Moringa leaves as nutrition supplement was rated to be high by several studies. In India, a pilot study on children aged 1-5 years over one month found the adding of 5-7g leaf powder /100g food as well accepted. A maximum left-over of $30 \%$ of distributed portion size was reported, equally observed in the control group consuming regular recipes [81]. Similarly Boateng et al. 2017 reported the daily MLP-supplementation of $5 \mathrm{~g}$ MLP sprinkled over usual foods or incorporated in a $35 \mathrm{~g}$ cereal-legume blend ( $15 \%$ fortification, dry weight) to be well-accepted in Ghanian infants aged 8-12 months, with a daily left-over rate of $13.8 \%$ or $28.5 \%$, respectively during a 14-day period [82]. Boateng et al. [83] reviewed common MLP fortification levels applied in complementary food blends ranging from 1 to $25 \%$, with the authors' recommendation of acceptable MLP fortification levels being 1 to $15 \%$ (the minimum amount of MLP to significantly improve nutritional value was estimated with $10 \%)$. In the current trial the general acceptability of ALP/MLP application was perceived as good among children (as no child was recorded to reject the food -probably due to the young age). Few caretakers however seemed more critical towards the greenish color and uncommon "leafy" taste. Moreover the belief/fear that Moringa may decrease the blood pressure in a harmful way guides the skepticism amongst Adivasis (as being named in the baseline survey by 10 out of 43 caretakers as reason for not consuming Moringa at home). The lowest rate of consumption was assessed for IG2, possibly an indirect consequence of caretaker's influence on the feeding process or directly on child's appetite due to discomfort in taste. Few pregnant women (also entitled to participate in the nutrition program) mentioned to suffer from nausea when smelling the ALP/MLP-enriched meal.

Nutrition intervention studies including the feeding of green leafy vegetables (GLV) amongst others different Amaranthus species

Studies on the consumption of GLV are diverse in their results. Nawiri et al. [84] provided $80 \mathrm{~g}$ fresh/re-hydrated sundried cowpea and Amaranthus tricolor leaves to Kenian pre-school children over a period of 13 weeks (IG1/IG2, $\mathrm{n}=56 / 20$, baseline $\mathrm{Hb}$ 11.5/11.6g/dl), versa fresh/re-hydrated sun-dried white cabbage (CG1/CG2, n=51/25, baseline $\mathrm{Hb} 12.4 / 12.3 \mathrm{~g} / \mathrm{dl}$ ). A non-significant but positive intra-group pre-post increase for $\mathrm{Hb}$ concentrations in the IG $(0.7 / 0.6 \mathrm{~g} / \mathrm{dl})$ was reported, with CG showing no increases $(-0.1 /-0.1 \mathrm{~g} / \mathrm{dl})$, (descriptive study analysis). Similarly Egbi et al. [85] (inferential study) supplemented Ghanian children aged 4 to 9 years (IG, n=53, baseline Hb 11.8g/dl; CG, n=51, baseline $\mathrm{Hb} 11.7 \mathrm{~g} / \mathrm{dl}$ ) with beans/tomato stews and groundnut soup (CG) enriched with dried composite GLV powder including Amaranthus cruentes (IG) five times a week over a period of three months, and found a significant higher increase in $\mathrm{Hb}(0.43 \mathrm{~g} / \mathrm{dl}$ versa $-0.35 \mathrm{~g} / \mathrm{dl})$ as well as higher decrease in anemia prevalence $(\mathrm{Hb}<11.5 \mathrm{~g} / \mathrm{dl})$ from $41.5 \%$ to $33.3 \%$ in IG versa $37.3 \%$ to $57.5 \%$ in $\mathrm{CG}$, respectively.

Page $34 / 62$ 
Two other inferential studies however could not show a positive effect of GLV on Hb: Hoeven et al. [86] found no significant differences in $\mathrm{Hb}$ increases between IG ( $n=86, \mathrm{Hb}$ baseline $12.8 \mathrm{~g} / \mathrm{dl}, \mathrm{Hb}$ increase $0.3 \mathrm{~g} / \mathrm{dl})$ and CG $(n=81, \mathrm{Hb}$ baseline $12.7 \mathrm{~g} / \mathrm{dl}, \mathrm{Hb}$ increase $0.4 \mathrm{~g} / \mathrm{dl}$ ) in school-children aged 6-12 years receiving a starchy school meal including either $300 \mathrm{~g}$ cooked leafy vegetables with Amaranthus cruentes accounting for $80-100 \%$ of GLV, versa only small amounts of cabbage or a teaspoon legumes or meat/soya mince over a period of 62 school days. The authors conclude that the regular consumption of GLV showed no effect on micronutrient status $(\mathrm{Hb}$, serum ferritin, serum zinc and serum retinol) in South African children with mild deficiencies. Pee et al. [87] investigated potential differences in the provision of dietary sources rich in carotene/retinol. Hereby either meals predominantly based on GLV including three Amaranthus types (IG1, n=45, baseline $\mathrm{Hb} 11.1 \mathrm{~g} / \mathrm{dl}$ ) versa meals based on carotene-rich fruits $(I G 2, n=49$, baseline $\mathrm{Hb} 11.1 \mathrm{~g} / \mathrm{dl}$ ), retinol-rich foods (IG3, $\mathrm{n}=48$, baseline $\mathrm{Hb} 11.1 \mathrm{~g} / \mathrm{dl})$ or foods low in carotene or retinol $(C G, n=46$, baseline $\mathrm{Hb} 11.2 \mathrm{~g} / \mathrm{dl}$ ) were fed to anemic school-children with two meals a day over a period of nine weeks in Indonesia. The subjects fed on GLV experienced the smallest increase in $\mathrm{Hb}(0.1 \mathrm{~g} / \mathrm{dl})$ amongst all four study groups, which was significant lower as compared to IG2 $(0.5 \mathrm{~g} / \mathrm{dl})$ and IG3 $(0.5 \mathrm{~g} / \mathrm{dl})$ possibly attributable to the low bioavailability of non-haem iron.

The effectiveness of leaf concentrates in improving the human nutritional status has been reviewed by Davys et al. [72] relating to studies in the more distant past. Positive effects on height and weight development, Hb concentration, vitamin A status, and diminished morbidity were observed as opposed to control groups, however the statistical relevance has not been discussed in detail.

\section{Nutrition intervention studies including the feeding of Moringa oleifera}

Indigenous nutrient-rich plant sources like Moringa oleifera are increasingly discussed as potential sustainable solution to combat malnutrition in children [88], [89], [90], [91], [92], [93], [94], [95], [96], [97], [98], [99], [100], [101], [102]. Descriptive studies (intra-group comparisons) comment positively on MLP application as preventive or treatment approach however bear distinct limitations: Isingoma et al [99] reported the application of a fermented millet porridge with $7 \% \operatorname{MLP}(\mathrm{IG}, \mathrm{n}=26$, baseline $\mathrm{Hb} 9.6 \mathrm{~g} / \mathrm{dl})$ to be comparable to $\mathrm{F}-100$ (CG, n=25, baseline $\mathrm{Hb} 9.8 \mathrm{~g} / \mathrm{dl})$ in the rehabilitation of SAM children aged 7 to 36 months, Uganda. By reaching discharge criteria after 5 to 7 days children achieved significant increases in $\mathrm{Hb}$ of $0.6 \mathrm{~g} / \mathrm{dl}(\mathrm{IG})$ versa $0.2 \mathrm{~g} / \mathrm{dl}(\mathrm{CG})$, respectively. The wasting z-scores similarly improved by a comparable rate of 1.4 versa 0.9 within the study groups. Srikanth et al [100] successfully treated Indian children suffering from protein energy malnutrition grade (PEM) I or II (aged < 5 years), with the application of 30g MLP added to child's daily diet $(n=30)$ over a study duration of two months. There was a trend of higher weight gains for children of the IG as compared to the CG $(n=30)$, however no report on compliance (mothers were in charge to administer the MLP to their children), nor a description of daily diet in the CG. Asante et al [102] reported an $\mathrm{Hb}$ increase of $0.9 \mathrm{~g} / \mathrm{dl}$ (baseline $\mathrm{Hb} 9.3 \mathrm{~g} / \mathrm{dl}$ ) after application of $15 \mathrm{~g} \mathrm{MLP} \mathrm{(IG,} \mathrm{n}=25)$ over a study period of four weeks, however neither baseline $\mathrm{Hb}$ concentrations nor increases observed in the CG ( $F-100, n=10)$ were presented. During the rehabilitation of Ghanian children (aged 6 to 36 months and suffering from PEM), there was a clear trend of higher weight increases for IG, with the authors of the study concluding MLP to have the potential to significantly contribute to the management of malnutrition. Nnam et al [101] conducted a study in Nigeria on children aged 6 to 12 months (unclear inclusion/exclusion criteria, baseline $\mathrm{Hb} 10.7 \mathrm{~g} / \mathrm{dl}$ in IG/CG, respectively) over a period of four weeks. Children in the IG $(n=20)$ received a fermented maize porridge with MLP $(3.67 \mathrm{mg}$ iron/day), with the CG $(n=20)$ receiving the same porridge without MLP. Merely for the IG significant increases in $\mathrm{Hb}(2.3 \mathrm{~g} / \mathrm{dl})$ as well as serum ferritin $(26.2 \mu \mathrm{g} / \mathrm{l})$ could be observed, with zero increase in CG, respectively. 
Two inferential studies (inter-group comparisons) commented positively on the effects of MLP application on $\mathrm{Hb}$ : Andrew [88] fed a with 25g MLP enriched maize porridge (IG, $n=64$, baseline $\mathrm{Hb} 7.4 \mathrm{~g} / \mathrm{dl}$ ) to SAM children aged 6 to 24 months attending nutrition rehabilitation in Tanzania over a period of three months. A significant higher Hb increase was observed for IG $(4.1 \mathrm{~g} / \mathrm{dl})$ as opposed to CG $(0.2 \mathrm{~g} / \mathrm{dl})(\mathrm{n}=76$, baseline $\mathrm{Hb} 7.1 \mathrm{~g} / \mathrm{dl})$. Similarly gains in weight, MUAC (cm), WAZ and WHZ were significantly higher in IG versa CG. Moreover a reduction on diarrhea prevalence from $13 \%$ at baseline to $1.4 \%$ at endline assessment was reported for IG.

Saturnin et al. [94] provided $10 \mathrm{~g} \mathrm{MLP} / \mathrm{d}(\mathrm{IG}, \mathrm{n}=44$, baseline $\mathrm{Hb} 10.3 \mathrm{~g} / \mathrm{dl})$ to moderately acute malnourished (MAM) children which was applied to usual diet of the 6 to 30 months old children in Benin. A significant higher increase in $\mathrm{Hb}$ of $1.6 \mathrm{~g} / \mathrm{dl}$ was assessed for IG as compared to CG $(-0.6 \mathrm{~g} / \mathrm{dl})(\mathrm{n}=40$, baseline $\mathrm{Hb} 10.4 \mathrm{~g} / \mathrm{dl})$ after six months.

A range of other inferential studies showed no significant increases in $\mathrm{Hb}$ in IG versa CG: in a study in Burkina Faso conducted by Zongo et al [98] the addition of $10 \mathrm{~g} \mathrm{MLP} / \mathrm{d}$ to standard care diet (IG, $\mathrm{n}=52$, baseline $\mathrm{Hb} 9.7 \mathrm{~g} / \mathrm{dl}$ ) was efficient to increase weight gains but not $\mathrm{Hb}$ concentrations $(-0.1 \mathrm{~g} / \mathrm{dl}(\mathrm{IG})$ versa $-1.0 \mathrm{~g} / \mathrm{dl}(\mathrm{CG}))$ when compared to CG $(n=58$, baseline $\mathrm{Hb} 10.5 \mathrm{~g} / \mathrm{dl})$. Hereby the admission period for SAM children aged 6 to 59 months accounted for an average of 36 days (IG) and 57 days (CG) due to significant higher weight gains in IG (8.9g/kg/d) versa CG (5.7 $\mathrm{g} / \mathrm{kg} / \mathrm{d}$ ), respectively. Another trial by Zongo et al [97] conducted in Burkina Faso on pre-school children aged 12 to 59 months was ineffective in changing the nutritional status (HAZ, WHZ) by applying $30 \mathrm{~g}$ MLP over the day for 12 weeks (IG $n=60, C G n=59$ ). A study on the Philippines conducted by Serafico et al. [96] found no significant effects of snack foods enriched with $3 \mathrm{~g}$ MLP on $\mathrm{Hb}$, weight or height after 120 days in 8 to 10 year old underweight school children (mean baseline $\mathrm{Hb}$ of $12.5 \mathrm{~g} / \mathrm{dl}$ for IG $\mathrm{n}=61 / \mathrm{CG} \mathrm{n}=60$, respectively). Similarly, in a trial by Menasria et al [95] (assigning its subjects during analysis in the categories "actual intervention received" and "non-compliers", thus not following the intention-to-treat approach), the application of $16 \mathrm{~g}$ MLP over six months showed no significant effects on Hb, Ferritin, HAZ or WHZ in Cambodian children aged 6 to 23 months as opposed to the CG (baseline Hb 10.1g/dl, n=39 (IG) versa $9.9 \mathrm{~g} / \mathrm{dl}, \mathrm{n}=79$ (CG)). Hb increases accounted for $0.5 \mathrm{~g} / \mathrm{dl}(\mathrm{IG})$ and $0.4 \mathrm{~g} / \mathrm{dl}$ (CG). Equally a study by Glover-Amengor et al [93] found no significant increase in $\mathrm{Hb}$ in Ghanian school children aged 5 to 12 years by applying $2.4 \mathrm{~g}$ up to $5.1 \mathrm{~g} \mathrm{MLP}$ (depending on body weight) along with study meals three times a week over nine weeks as compared to CG (baseline $\mathrm{Hb} 10.6 \mathrm{~g} / \mathrm{dl}$ for IG $\mathrm{n}=69 / \mathrm{CG} \mathrm{n}=76$, respectively). Another trial conducted in Ghana by Boateng et al [92] failed to show significant effects of a daily dose of $5 \mathrm{~g}$ MLP - either as part of cereal-legume blend (IG1, $n=80$ ) or as a supplement sprinkled on infant's usual home-based diet (IG2, n=74), on $\mathrm{Hb}$ concentrations or growth indicators of children aged 8 to 12 months after a total trial period of 16 weeks (baseline Hb n.a.) as compared to CG $(n=83)$ receiving the cereallegume blend without enrichments. Also Perlas et al [90] could not proof any significant increases in $\mathrm{Hb}$, serum ferritin, weight or height as compared to the CG, after providing snacks enriched with $3 \mathrm{~g}$ MLP on a daily basis over 120 days to Filipino school children (WAZ<-2SD) aged eight to ten years (baseline Hb $12.5 \mathrm{~g} / \mathrm{dl}$ for IG $n=61 / C G \mathrm{n}=60$, respectively). Lonati et al [91] concluded the application of 3 to $5 \mathrm{~g} \operatorname{MLP}(\mathrm{IG}, \mathrm{n}=88)$ to have no significant effects on the prevalence of anemia $(\mathrm{Hb}<11.5 \mathrm{~g} / \mathrm{dl})$ in Cameroon school children aged 5 to 8 years as compared to placebo meal without MLP (CG, $\mathrm{n}=95$ ). Merely the increase in height/HAZ was reported as significantly higher for IG than CG after 18 weeks.

Yet, there is no general agreement on an outstanding nutritional benefit of local plant sources in terms of preventing or treating malnutrition. Due to the inconsistency in the quality of human intervention studies it is difficult to come to a conclusive judgment. 
The bioavailability of nutrients from supplements/fortificants when taken along with a meal is affected by the same factors as those present in food, with the net effect depending on the ratio of promoters and inhibitors [34]. Among reviewed complementary food supplements by Pee et al. TopNutri provides the most complex mix of micronutrients along with high quality protein. TopNutri contains iron as ferric sodium ethylenediaminetetraacetate (NaFeEDTA) [103], which shows for food vehicles high in phytate a relative bioavailability of $>100 \%$ (two to three times better absorbed) as compared to ferrous sulfate, with concurrent improvement of the iron, zinc and possibly copper absorption from foods [63], [104], [105]. Iron absorption from NaFeEDTA containing food products - unlike zinc, is reported not to be influenced by higher calcium levels [106]. The authors of the study assume the indicated $7.7 \mathrm{mg}$ iron/7.5g recommended dose TopNutri per day [80] to relate to the compound NaFeEDTA (no information available by the company), thus in the current trial the applied dose of $3.68 \mathrm{~g}$ TopNutri/200g portion may provide 3.8mg NaFeEDTA $(\approx 0.5 \mathrm{mg}$ elemental iron [107]) The company GC Rieber Compact reviews TopNutri to have positive effects on stunting and underweight rates, to increase discharge rates of formerly severely malnourished children as compared to milkbased treatment, as well as to decrease anemia rates [108] from $63.8 \%$ to $17.6 \%$ in children aged 6 to 35 months with an increase in $\mathrm{Hb}$ of $1.3 \mathrm{~g} / \mathrm{dl}$ after four months of daily supplementation in a trial in Myanmar [109]. A small increase in iron status (reduction of soluble transferrin receptor), but no increase in $\mathrm{Hb}$ concentrations and similarly no decreased rates of anemia could be observed in a trial applying $2.5 \mathrm{mg} \mathrm{NaFeEDTA}(\approx 0.33 \mathrm{mg}$ elemental iron [107]) to women and children aged 6 to 59 months in a Kenyan refugee camp over a period of 13 months [110]. Similiarly, a South African trial on school children aimed to investigate the efficacy of a low-iron MNP containing 2.5mg NaFeEDTA, applied $5 \mathrm{~d} /$ week for 23 weeks to a high-phytate maize porridge in the intervention group. Compared with the control, the MNP was effectively increasing serum ferritin, body iron stores, $\mathrm{WHZ}$, and decreased transferrin receptor, also the prevalenc of iron deficiency fell significantly. However $\mathrm{Hb}$ concentrations and rates of anemia were not changed during the intervention [111]. Apart from the latter low-dose trials the effectiveness of MNP in increasing $\mathrm{Hb}$ is well investigated. Ying Yang Bao (2.5mg iron-EDTA, 5mg ferrous fumarate; $\approx 2 \mathrm{mg}$ elemental iron [28], [107]) - a MNP similar to TopNutri, has been shown in a non-controlled trial to increase $\mathrm{Hb}$ of Chinese children aged 6 to 23 months by $0.9 \mathrm{~g} / \mathrm{dl}$ over a total period of 18 months [112]. A Cochrane database systematic review [113] including eight controlled trials (Ghana, Cambodia, India, Kyrgyz Republic, Haiti, Pakistan, Kenya) lasting two to twelve months, concluded home fortification with MNP (containing $12.5 \mathrm{mg}$ of iron as ferrous fumarate $\approx 4.2 \mathrm{mg}$ elemental iron [28], $5 \mathrm{mg}$ zinc, and $300 \mu \mathrm{g}$ of vitamin A) to be effective in improving haematological indices, and stated MNP to be possibly comparable to daily iron supplementation (as drops or syrups). All included trials applied at least $12.5 \mathrm{mg}$ ferrous fumarate on a daily basis. The review also relates to studies providing intermittend or flexible MNP allocation with a lower overall daily dose (e.g. $30 \mathrm{mg}$ ferrous fumarate per week [114]) which have been found to be as effective on haematological response. Hereby, Hyder et al. supplemented anemic Bangladeshi children aged 12 to 24 months with either $12.5 \mathrm{mg}$ iron daily versa $30 \mathrm{mg}$ weekly $(\approx 1.4 \mathrm{mg} / \mathrm{d}$ elemental iron [28]) over 8 weeks, and reported no significant differences among the groups in the $\mathrm{Hb}$ increases occurred $(16.1 \mathrm{~g} / \mathrm{l}$ versa $12.3 \mathrm{~g} / \mathrm{l})$, respectively [114]. Reviewed studies significantly reduced anaemia on average by $31 \%$, and iron deficiency by $51 \%$ as compared to no intervention or placebo in children aged 6 to 23 months. Thereby the decrease in anemia rates was equally effective in populations with different anemia prevalence, in all children aged 6 to 23 months, and independent of duration of intervention. In regard to Hb concentrations, six trials had a $5.87 \mathrm{~g} / \mathrm{l}$ higher mean $\mathrm{Hb}$ concentration at follow-up, as compared to studies with no treatment or placebo however with no obvious differences among subgroups. Two trials, that assessed effects on growth (HAZ, WAZ, WHZ), could not detect significant effects after six to twelve months of intervention, respectively. Effects on morbidity could not sufficiently be assessed, however in one trial there was a tendency of children supplemented with MNP to be more susceptiple to diarrhea or recurrent respiratory infections during the first month of intervention, whilst another trial found upper respiratory infections to be similar in MNP group (7.6\%) versa placebo group (6.5\%) [113]. Similarly a 
review including 13 studies on pre-school and school-age children found MNP to significantly reduce anemia and iron deficiency but concluded that effects on morbidity and mortality remain scarce, with no significant effects on diarrhea prevalence [115]. Hirve et al. stated sprinkles containing $12.5 \mathrm{mg}$ ferrous fumarate $(\approx 4.2 \mathrm{mg}$ elemental iron [28]) to be similarly efficacious as compared to higher iron doses in sprinkles or drops in improving $\mathrm{Hb}$ in moderately anemic Indian children aged 6 to 18 months over a period of 8 weeks (mean Hb increase $1.5 \mathrm{~g} / \mathrm{dl}$ ) [116]. The integration of MNP sprinkles in ICDS programs similarly has been found to effectively increase $\mathrm{Hb}$ concentrations and decrease rates of anemia from $50 \%$ to $33 \%$ in boys and from $47.4 \%$ to $34.2 \%$ in girls [27].

Findings in this trial are in conformity with studies reporting an increase in hemoglobin by MNP supplementation, however this increase was found for IG3 to be non-significant as compared to the control group.

Altogether, IG3 was not found to significantly increase Hb concentrations when compared to the CG (Table 6, Table 7). Still, IG3 remained comparable to IG1 and all other study groups throughout the intervention period. However in order to explain the lower increases in $\mathrm{Hb}$ or in other words the absence of the expected added value of IG3 toward IG1; probably unfavorable ratios of nutrients in the enriched supplementary meals may have had a negative impact on overall bioavailability. The risk of antagonistic interactions is deemed to be low in fortified diets, as micronutrients become chelated to dietary ligands during food digestion, implying an absorption by different pathways. Competitive interactions appear rather critical if amounts of micronutrient supplements are high and consumed without food [34].

Still, e.g. the calcium content may have possibly implied detrimental effects on iron absorption from total study meal in IG3 as outlined above. Interestingly, confirmed by the Bonferroni post-hoc test IG3 showed significant/marginal significant effects on WAZ and WHZ scores at $3^{\text {rd }}$ assessment when compared to the CG. Moreover IG3 showed the best trends on reducing stunting prevalence (Supplementary Material 4), or concerning mean gains in HAZ-scores (Table 3, Figure 7). Moreover the LSD post-hoc test found IG3 superior to IG2 concerning better stunting z-scores at endline assessment $(p=0.026)$ (Supplementary Material 8). This observation supports research that stresses the importance of an adequate supply of both, Type I and Type II nutrients for growth promotion, hereby TopNutri may provide the most holistic mix of isolated micronutrients [117]. Also for prevention or treatment of diarrhea or respiratory infections the higher zinc or vitamin A content provided may be conducive, still studies on the general application of industrial MNP remain controversial as recent studies even suggest an increased risk of diarrhea [118], [119] -probably attributable to iron promoting the growth of gastro-intestinal pathogens. The gut microbiome is increasingly discussed as crucial actor in the pathogenesis of intestinal imflammatory diseases negatively affecting iron availability [120]. Iron deficiency anemia was associated with microbiota dysbalance, and is discussed to impair the programming of infant's physiologic systems with long-term host effects on metabolism and alteration of immunological response [121]. Moreover alterations in the mircobiome are reported to be implicated in childhood malnutrition in a mutually enhancing relationship [122]. The practical effects of interventions e.g. the current diversified study meals, on the gut microbiome need further investigation.

\section{Predictors for the response size of hemoglobin increases}

In this low-iron dose trial $\mathrm{Hb}$ concentrations at baseline were associated with age (baseline data previously published [24]), and over the intervention period children with lower $\mathrm{Hb}$ baseline values showed a better $\mathrm{Hb}$ response to the supplementary meals as compared to children with higher $\mathrm{Hb}$ baseline levels (Table 4, Table 5). Similarly, a study on 
pre-school children in Zanzibar reported $\mathrm{Hb}$ at baseline to be strongly positively associated with age, and found $\mathrm{Hb}$ increases to be inversely related to baseline $\mathrm{Hb}$ concentrations after a low-dose iron treatment (10mg ferrous sulfate $\approx$ $2 \mathrm{mg}$ elemental iron [28]) for one year [123]. A trial on Bangladeshi children 6 to 12 months found a weekly supplementation of $20 \mathrm{mg}$ elemental iron ineffective to increase $\mathrm{Hb}$ concentrations in predominantly mildly anemic children, implying the conclusion that mild anemia may have other causes than iron deficiency [124], or requires higher iron doses. The current low-dose trial seems to be much more effective for treating moderate anemia than mild anemia. The decreases observed for children with baseline $\mathrm{Hb} \geq 11.0 \mathrm{~g} / \mathrm{dl}$ (Supplementary Material 5) have to be interpreted in consideration of the small number of children in this subsample, still the prevention of anemia seems to require more holistic approaches.

In this trial, equally an increased food group consumption at baseline was associated with higher increases in $\mathrm{Hb}$ during the trial (Table 4, Table 5), indicating that caretakers who practice a more diversified diet at baseline may be more likely to maintain this behavior throughout the trial or even to adopt new ideas of healthy diets possibly inspired by study meals.

Aside low $\mathrm{Hb}$ concentrations, and an increased dietary diversity at baseline, also to be among the first-borns in a family was associated with higher increases in $\mathrm{Hb}$ over intervention time. This increase may be not attributable to baseline $\mathrm{Hb}$ in this trial, as no clear association between baseline $\mathrm{Hb}$ and birth order was detectable. In contrast, birth order $\geq 2$ was associated with poor growth and anemia in children aged 10 to 18 months, living in urban slums of Mumbai [125].

Moreover a cash income $>5000$ INR was associated with higher $\mathrm{Hb}$ increases over time, suggesting that a higher cash flow improves the nutritional outcomes for children early in life. This is in line with published evidence that household wealth status is associated with dietary diversity and nutritional status of Bangladeshi children [126], as well as with hemoglobin concentration of Bangladeshi women due to increased iron intake from animal sources [127].

\section{Weight gain}

No significant differences in weight gains across the study groups were found. At the endline assessment (after 548 days) the mean weight increase for total IG $(2.7 \mathrm{~kg})$ (not presented) matched the observed weight gain for the CG $(2.7 \mathrm{~kg}$ ) (Supplementary Material 3), being equal to a mean growth velocity of $0.52 \mathrm{~g} / \mathrm{kg} / \mathrm{d}$ and $0.55 \mathrm{~g} / \mathrm{kg} / \mathrm{d}$, respectively. During nutrition rehabilitation a daily weight gain is suggested with $5 \mathrm{~g} / \mathrm{kg} / \mathrm{d}$ to validate the treatment in children suffering from moderate acute malnutrition [128]. Jilcott et al. conducted a five weeks feeding trial with locally produced ready-to-use food (RUF) on moderately malnourished Ugandan children aged 6-59 months and reported a mean growth velocity of $2.5 \mathrm{~g} / \mathrm{kg} / \mathrm{d}$. The peanut-soybean porridge enriched with $13.5 \mathrm{~g} \mathrm{MLP}$, provided $682 \mathrm{kcal} / \mathrm{d}$, if consumed as intended, however caretakers practiced dilution [129]. Moderately malnourished Malawian children aged 42 to 60 months gained on average $2.7 \mathrm{~g} / \mathrm{kg} / \mathrm{d}$, when being fed a maize/soy flour supplementation (500kcal/d) over 12 weeks [130]. Andrew achieved with a daily supplementation of a maize porridge either enriched with $25 \mathrm{~g} \mathrm{MLP}$ (IG) or served plain (CG) over three months, a weight gain of $2.96 \mathrm{~g} / \mathrm{kg} / \mathrm{d}$ versa $0.55 \mathrm{~g} / \mathrm{kg} / \mathrm{d}$ in SAM children aged 6 to 24 months, respectively [88]. Purwestri et al. reported weight gains of mildly wasted Indonesian children (aged 6-59 months) in a ready-to-use food (RUF) rehabilitation program for 6 weeks with $3.1 \mathrm{~g} / \mathrm{kg} / \mathrm{bw}$ (daily distribution of RUFNias biscuits with supervision of consumption for one-third of the daily portion) and $2.0 \mathrm{~g} / \mathrm{kg} / \mathrm{bw}$ (weekly distribution of full ration of RUF-Nias biscuits and weekly compliance check) [131]. Scherbaum et al. found weight gains of 
$1.01 \mathrm{~g} / \mathrm{kg} / \mathrm{bw}$ (peanut/milk-based spread), 1.76g/kg/bw (cereal/nut/legume-based biscuits (CNL-B)), $2.31 \mathrm{~g} / \mathrm{kg} / \mathrm{bw}$ (CNL-B and intensive nutrition eduction) among moderately to mildy wasted Indonesian children in a daily feeding program for an average of treatment days of $25,33,30$ days, respectively [132].

Therewith, the observed weight gain in our study is rather low, however is in line with other trials not achieving the proposed daily weight gain of $5 \mathrm{~g} / \mathrm{kg} / \mathrm{bw}$. Moreover the lower feeding frequency and long trial duration in the current study have to be taken into account.

Higher weight gains during the first year of life have been reported to have negative effects on iron status indices [133], [134] or to be not conducive to significant changes in Hb showing even negative correlation [98]. In contrast, findings of the current study suggest a positive association of weight gains and $\mathrm{Hb}$ changes (controlled for age and baseline $\mathrm{Hb}$ concentrations) at endline assessment $(r=0.146, p=0.020)$.

Relationship between linear growth and wasting, as well as interrelations of nutritional status, morbidity, and seasonal change

At baseline assessment of this study, increasing age in the child was reflected in decreasing HAZ- and WAZ-scores (increasing prevalence), but increasing mean WHZ-scores [24]. This positive association of age with stunting, or negative association with wasting is also reflected in the worldwide timing of growth faltering [135].

Data by Helen Keller International on children 0-59 months showed acute malnutrition to highly vary by season in Bangladesh, with the highest peak occurring in August when rice storage is getting scarce [136]. Similarly Brown et al. reported greatest nutritional deficits during monsoon season persisting until subsequent harvest. Hereby the anthropometric indicator used to define malnutrition and detect seasonal change was important to be distinguished; i.e. in the discussed study on Bangladeshi children the highest prevalence of stunting occurred several months after the periods of greatest malnutrition identified by other indicators. Food availability and rate of infectious diseases are discussed as major determinants of children's growth in less developed countries [137]. The multi-factorial etiology of the relationship between the acute and chronic form of undernutrition (wasting and stunting) is poorly understood. Repeated episodes of wasting are discussed to imply stunting, as periods of lowest weight acquisition are followed by periods of lowest linear growth. Linear growth is reported to merely occur when the body has a minimum of energy reserves, in other words when the weight-for-height is high. Wasting reflects a condition of depleted fat and muscle mass. Leptin - produced by fat tissue, stimulates bone density, catch-up growth and the immune system. Aside a lack of micronutrients -that are required for skeletal growth rather than growth of lean tissue [138], the reason how wasting leads to stunting may be partly explained by low fat stores, however the relation remains inconclusive [139], [140], [141]. Wasting was found predictive for stunting in a study on Gambian children, confirming stunting to be an adaptation process to undernutrition [142]. Birth weight and household wealth index are reported to be negatively related to both stunting and wasting. Other common predictors for stunting were low maternal height, low maternal BMI, low frequency of antenatal care visits, higher birth order, low maternal educational level, children of mothers without decision making power regarding food, lack of minimum meal frequency, no feeding of eggs, dairy products, fruits and/or vegetables, or the delayed introduction of complementary foods, increasing age of child, and households without access to improved sanitation [139], [143], [144], [145], [146]. Acute respiratory infection was predictive for underweight, whereas diarrhea was a major driver for stunting among Indian children below five years [147]. Hence, 
multi-sectoral approaches have to be taken to avert underlying causes of stunting (child feeding, women's nutrition, household sanitation), but also the distal and inter-generational drivers (adolescent marriage, women's poor decision making power, low educational level, social exclusion and household poverty). South-Asia bears the highest global burden of child stunting (40\%) [148]. Scaling-up the year-round food security by enhanced homestead food production programs already showed impact with reductions in stunting of 18\% in Bangladesh [149]. Dewey reviews options for improved women's and children's diets and their positive impact on child growth. Still the linear growth response to improved nutrition remains heterogenous, highlighting the multi-factoral mechanisms of prenatal and post-natal growth restriction [150], also explaining why nutrition interventions alone are not necessarily implying a positive impact on growth.

Moreover rapid and simulataneous decrease in stunting and wasting rates may be challenging to achieve as any decline in stunting and underweight prevalence is commonly accompanied by a temporary increase or stagnancy in wasting [151].

Consistent with the above outlined considerations, in this study (Figure 7, Figure 8, Figure 9) underweight and wasting scores were found highest during baseline (t0), and $3^{\text {rd }}$ assessment (t12) in Feb2015/16 (laggards measured in months Mar, Apr); and lowest scores were assessed at $2^{\text {nd }}$ (t6), and endline assessment (t18) in Aug 2015/16 (laggards measured in months Sep, Oct), when rice storages are getting scarce close to the next harvest. Moreover during rainy season lasting from June to September, children may be more prone to infectious diseases [152], which is associated with additional nutrient requirements for the immune response. Infant feeding practices in South Asia have been shown to be highly inadequate during illness which contributes to a further deterioration of the nutritional status [153].

The prevalence of sickness at baseline was rated as high in this study as opposed to data of the NFHS-4 [24], with a perceived increase during winter season over the intervention period (Figure 10). Prevalences of sickness were invariably lower at $3^{\text {rd }}$ assessment versa baseline, indicating a combined positive impact of intervention and increasing age over time on morbidity reduction in particular for IG3.

\section{Correlation of attendance and hemoglobin}

Although merely very weak correlations were detected between attendance rates throughout the study period and hemoglobin concentrations at endline assessment, the association of the effect of the attendance on the hemoglobin status of children was negative, suggesting an issue of reverse causality. Children deemed as more vulnerable by the caretakers were probably taken more often to the supplementary feeding program. The vulnerability may have been characterized by common signs of iron deficiency anemia like fatigue, pallor, or lassitude. This assumption is supported when allocating children according to their anemia status at baseline in two groups (no/mild versa moderate anemia) and considering mean rates of attendance during the 78 weeks. Children suffering from moderate anemia had a higher rate of program attendance than children with no/mild anemia (82.1\% versa $75.2 \%)$, however this finding was not significant. Similarly children suffering from severe anemia were more likely to attend a feeding program in Burkina Faso, than children without severe anemia [154], altogether indicating that being more vulnerable is associated with higher attendance, and not vice versa. Reverse causality has also been suggested in other studies on breastfeeding and nutritional status, hereby mothers tended to breastfeed longer if their child was small and/or seemed to be ill [155], [156]. Besides frequent child's illness may have implied increased program attendance. The

Page $41 / 62$ 
morbidity questionnaire revealed the number of days of cold/cough being associated with the attendance rates until $3^{\text {rd }}\left(r=0.289^{\star *}, p<0.001\right)$ and $4^{\text {th }}$ assessment $\left(r=0.292^{\star *}, p<0.001\right)$.

\section{Correlation of baseline hemoglobin concentrations or portion size with hemoglobin}

The overall consumption rate over the three IPs showed a very weak positive correlation with the $\mathrm{Hb}$ at the $4^{\text {th }}$ assessment after adjusting for attendance rates. Moreover a very weak association was detected between the $\mathrm{Hb}$ changes occurred during $1^{\text {st }}$ to $3^{\text {rd }}$ assessment and portion sizes consumed, adjusted for attendance. Both findings

indicate the intervention having a positive effect on $\mathrm{Hb}$. The $\mathrm{Hb}$ response (during $1^{\mathrm{st}} / 3^{\text {rd }}$ and $1^{\text {st }} / 4^{\text {th }}$ assessment) proofed to be negatively associated $(r=-0.459 * *, r=-0.539, p<0.001)$ with baseline $\mathrm{Hb}$, respectively. Similarly, oral medicinal iron supplementation and lower baseline $\mathrm{Hb}$ concentrations were predictors of a greater $\mathrm{Hb}$ response in a systematic review of 55 controlled trials with iron supplementation interventions in children [157], or the number of micronutrient sachets consumed per week was associated with increases in $\mathrm{Hb}$ in a home-based fortification program of complementary foods [112].

\section{Limitations}

A general limitation to the study is the unknown exact amount of nutrient losses occurred on the way from market/storage, during cooking and finally to the plate, still a careful chain of action was adhered to. Lack of $\mathrm{Hb}$ response in individuals may be a consequence of multiple micronutrient deficiencies, and not limited to iron supply [158]. Variant types of anemia with different etiologies like thalassemia, sickle-cell anemia, could be a major confounding factor for the current study, which were not assessed in this research. In particular in countries where the pevalence of anemia exceeds $40 \%$, the previously assumed anemia proportion of $50 \%$ amenable to iron deficiency [159] (42\% of anemia in children and $50 \%$ of anemia in women [5]) might rank much lower e.g. suggested with $14 \%$ for pre-school children, and $16 \%$ for non-pregnant women in reproductive age [159]. A holistic clinical assessment (e.g. ferritin, transferrin saturation) would do better than $\mathrm{Hb}$ estimation alone, still HemoCue201+ remains the suitable method to the field to diagnose anemia. Moreover the re-examination of a race specific cut-off for mild anemia is discussed due to potential genetic determinants related to the heritability of $\mathrm{Hb}$, partly explaining an unchanging high burden of anemia among Indian women [160]. Several studies assessed the distribution of $\mathrm{Hb}$ to be lower in black people [16]. Similarly anemia during infancy is suggested as common, thus lower cutoffs may be more representative to diagnose anemia in children aged 8 months [161].

\section{Conclusion and recommendations}

After adjusting for age, baseline $\mathrm{Hb}$ concentrations, time between assessment points, and gender; study findings suggest the application of diversified traditional diets (IG1) to be superior toward the enrichments of $3 \mathrm{~g}$ leaf powder/100g meal in the ratio ALP 2:1 MLP (IG2) or a for the iron content of IG2 adjusted amount of industrial MNP (1.84g TopNutri/100g meal) (IG3), in significantly increasing Hb concentrations as compared to the CG analyzed by GLM LSD post-hoc test at $2^{\text {nd }}, 3^{\text {rd }}$, and endline assessment (confirmed by Bonferroni post-hoc at $3^{\text {rd }}$ assessment) (Table 6, Table 7). Still, at $3^{\text {rd }}$ and endline assessment all intervention groups showed a tendency of higher increases in $\mathrm{Hb}$ as opposed to the CG, with IG2 and IG3 being comparable to IG1 but also to the CG indicating a positive impact of 
all interventions on $\mathrm{Hb}$ concentrations (Figure 6). The diminished effect on $\mathrm{Hb}$ observed in IG2 and IG3 may be attributable to undesired nutrient interactions decreasing the bioavailability of the additionally enriched diets.

Adjusted for age, baseline z-scores, time between assessment points and gender; significant effects related to growth indices are less consistent (Supplementary Material 8, Supplementary Material 9, Supplementary Material 10). IG3 seemed to be most succeeding in improving growth indices (WAZ, WHZ) as opposed to the CG (confirmed by the conservative Bonferroni post-hoc test at $3^{\text {rd }}$ checkup). Moreover IG3 showed as only intervention group tendencies of slight improvements in HAZ scores after one year of intervention (however without statistical relevance); as well as most efficiently reduced morbidity prevalence (in particular respiratory infection, but also fever and diarrhea rates).

Observed mean changes in $\mathrm{Hb}$ (Figure 4) have to be interpreted in relation to the low iron dose applied in this trial. Thus, the rather low increases in Hb over a long period of time are still deemed to be beneficial by the authors of this study, in particular when striving for sustainable solutions to combat anemia. The serving of a minimum of three diversified meals per week may be likely to be adopted by most caretakers on household level after nutrition counseling and interactive cooking trainings. Thus, diversified meals are a local possibility to decrease rates of anemia. Moreover to modify caregiver's feeding practices and strengthen their resources for healthy meal preparation e.g. by maintaining kitchen garden programs which may be more cost-efficient as compared to hosting a long-term community feeding trial requiring extensive monitoring and being less appealing to caretaker's own responsibility to make behavioral modifications. Still, for treatment of anemia therapeutic iron doses are recommended in the first line, as a rapid improvement in $\mathrm{Hb}$ concentrations is of priority for proper physical and mental development of the child, but still bears own limitations as outlined by the Indian National Iron Plus Initiative [162]. Moreover the enrichment with an adjusted amount of the MNP TopNutri (IG3) showed beneficial effects concerning growth indices, thus MNP may have to be considered as additional treatment approach for undernutrition. The absent effect on $\mathrm{Hb}$ and the inconsistency of IG3effects on growth across different study assessment points has to be interpreted in relation to the applied dose (which was lower than recommended by GC Rieber Compact). Moreover some effects on e.g. HAZ scores which reflect the status of chronic undernutrition; need long-term interventions for improvement, thus the absence of significant effects on HAZ during the first year of study is not decisive. At endline for IG3 the beneficial impact of a holistic nutrient composition on improving stunting scores seems to slightly emerge, however without statistical relevance as opposed to the CG.

The $\mathrm{Hb}$ response was inversely related to baseline anemia status (Table 4, Table 5, Supplementary Material 5), suggesting low-dose trials to be most effective for treating moderate forms of anemia, with beneficial effects on mildly anemic children. For interpretation of the preventive effects of this trial on anemia the sample size was limited.

In order to alleviate micronutrient deficiencies a holistic food-based strategy -as suggested by Thompson and Amoroso [15], will embrace agricultural incentives to promote increased availability and consumption of diets composed of a variety of foods, nutrition education, implications for public health and disease control, as well as further enrichments through supplementation.

To conclude diversified supplementary meals of this trial (IG1) (dietary diversification) proofed to be a successful foodbased approach to increase $\mathrm{Hb}$ concentrations in particular in moderately anemic Adivasi children. The enrichment of diversified diets with MNP (IG3) showed best effects on growth indices and reduction of morbidity prevalence amongst 
all study groups. Yet, more research is needed to particularly investigate holistic approaches for sustainable treatment and prevention of anemia and undernutrition with locally available resources.

\section{Declarations}

Ethics approval and consent to participate: The intervention trial is registered with the study code: 014/1763 at the Freiburg Ethics Commission International (10 th Nov 2014), and approved by the local Child Development Office in Bolpur, Birbhum District (1 $11^{\text {th }}$ July 2014). Before enrolment, a full explanation of the study purpose was given to the communities, and informed consent was obtained either by signature or thumbprint.

Consent for publication: Not applicable

Availability of data and materials: The datasets used and/or analyzed during the current study are available from the corresponding author on reasonable request.

Competing interests: The authors declare that they have no competing interests.

Author Contributions: C.K.S., S.K.E.G. and V.S. designed the study. C.K.S., S.K.E.G. and V.S. drafted, completed and submitted the study proposal for funding of the baseline assessment and the main intervention phase (Feb 2015 to Feb 2016, foundation FIAT Panis). C.K.S., S.K.E.G., M.G. and S.M. organized, implemented and supervised the study in the field. C.K.S. and S.K.E.G. entered and analyzed all data obtained in the field. D.G.R. supported the entry of attendance and portion size data into the software SPSS, analyzed the compliance data in the scope of her Master thesis in Clinical Nutrition, and performed awareness sessions on-site during final follow-up phase after completion of the intervention trial. C.K.S. conceptualized and wrote the original draft of the manuscript. C.K.S., S.K.E.G., W.S. and V.S. reviewed and finalized the manuscript of the present research article. W.S. assisted with statistical advise and analyzed the vitamins (water-soluble: B, C, and fat-soluble: carotenes, E) of leaf powder samples (ALP/MLP) at the FriedrichSchiller University, Jena. M.G. and H.K.B. helped with the study design and the funding for prolongation of intervention phase (Feb 2016 to Aug 2016) including the endline assessment, as well as the follow-up awareness/ kitchen garden program (Rotary Club), and gave valuable comments for implementation of the study and completion of the manuscript. All authors read and approved the final manuscript for publication.

Funding: The study was funded by Shining Eyes e.V., the foundation FIAT Panis, and the Rotary Club. The authors gratefully acknowledge financial support from Shining Eyes e.V., and the foundation FIAT Panis, both enabling the medical baseline assessment and socio-economic data collection on household level. The holistic implementation of the long-term nutritional trial, lasting 1.5 years was made possible by Shining Eyes e.V., Fiat Panis (05/2015) and Rotary Club (GG1525036), altogether. A short-term grant program (57044996) by DAAD supported two stays of the researchers C.K.S. and S.K.E.G. on-site for field research purposes.

Acknowledgements: The authors are deeply grateful to PhD Semaw Ferede Abera, and sc. agr. Ratna Chrismiari Purwestri for statistical advise and constructive comments during preparation of this manuscript. Great thanks goes to the LA Chemie of the University of Hohenheim, which performed the mineral, phytate, and amino acid analysis of a range of different Amaranthus leaf types, as well as Moringa leaf powder samples. Valuable information for sample size calculation of the intervention study was provided by Prof. Dr. Iris Zöllner, whose support we highly appreciated. Moreover the authors are greatly obliged to the cooperation of all women and children in the intervention area having participated in this trial, further to all voluntary international workers and the staff members of Shining Eyes India and the NGO Bolpur Manab Jamin (implementing partner). Sincere thanks also goes to the 
company GC Rieber Compact for providing TopNutri free-of-cost. Moreover special thanks goes to the horticulturists Anne and Rolf Bucher who coordinated and performed the local Moringa leaf powder production, as well as again to the NGO Bolpur Manab Jamin for producing the Amaranthus leaf powder and coordinating kitchen garden activities during the follow-up phase of the trial.

\section{References}

1. UNICEF; WHO; World Bank; UN-DESA Population Division Levels and trends in child mortality 2015.

2. UNICEF Children: reducing mortality 2016.

3. Unicef The State of the World's children 2019: children, food and nutrition - growing well in a changing world; New York, 2019; ISBN 978-92-806-5003-7.

4. UNICEF The State of the World's Children 2016: A Fair Chance for Every Child; New York, USA, 2016; ISBN 978-92806-4838-6.

5. WHO The global prevalence of anaemia in 2011; World Health Organisation, 2015; ISBN 9789241564960.

6. The World Bank Prevalence of anemia among children (\% of children under 5) Available online: https://data.worldbank.org/indicator/SH.ANM.CHLD.ZS.

7. IIPS India Fact Sheet. National Family Health Survey (NFHS-4) 2015-16; International Institute for Population Sciences: Mumbai;

8. IIPS District fact sheet, Birbhum, West Bengal (NFHS-4); International Institute for Population Sciences, Mumbai, 2015;

9. Sachdev, Y.; Dasgupta, J. Integrated Child Development Services (ICDS) Scheme. Med J Armed Forces India 2001, 57, 139-143, doi:10.1016/S0377-1237(01)80135-0.

10. Kubde, S.; Kokiwar, P. Anemia among 0-6 Years of Children in ICDS and Non ICDS areas. Annals of International Medical and Dental Research 2016, 2, 238-242.

11. Biswas, S.; Bose, K.; Mukhopadhyay, A. High prevalence of stunting among integrated child development services (ICDS) scheme children aged 1-5 years of Chapra Block, Nadia District, West Bengal, India. Internet Journal of Biological Anthropology 2009, 3, 1-7.

12. Mandal G.C.; Bose K.; Bisai S.; Ganguli S. Undernutrition among Integrated Child Development Services (ICDS) Scheme Children aged 2-6 years of Arambag, Hooghly District, West Bengal, India: A serious public health problem. Italian Journal of Public Health 2008, 5, 28-33.

13. Gibson, R.S. Technological approaches to combatting iron deficiency. Eur J Clin Nutr 1997, 51 Supp/ 4, S25-27.

14. Begum, P.S.; Manjula, K. Food to food fortification - a novel approach to mitigate iron deficiency anemia. International Jounal of food, agriculture and veterinary sciences 2015, 5, 55-58.

15. Thompson, B. Food-based approaches for combating iron deficiency (Chapter 21). In Kraemer K, Zimmermann MB; editors. Nutritional anemia. Sight and Life Press; Food and Agricultural Organization of the United Nations, Rome, 2007; pp. 337-358.

16. Balarajan, Y.; Ramakrishnan, U.; Ozaltin, E.; Shankar, A.H.; Subramanian, S.V. Anaemia in low-income and middleincome countries. Lancet 2011, 378, 2123-2135, doi:10.1016/S0140-6736(10)62304-5.

17. Johns, T. Plant Biodiversity and Malnutrition: Simple Solutions to Complex Problems. African Journal of Food, Agriculture, Nutrition and Development 2003, 3, 45-52.

18. Gidamis, A.B.; Panga, J.T.; Sarwatt, S.V.; Chove, B.E.; Shayo, N.B. Nutrient and Antinutrient Contents in Raw and Cooked Young Leaves and Immature Pods Of Moringa oleifera, Lam. Ecology of Food and Nutrition 2003, 42, 
399-411, doi:10.1080/03670240390268857.

19. Platel, K.; Srinivasan, K. Bioavailability of Micronutrients from Plant Foods: An Update. Critical reviews in food science and nutrition 2015, 56, doi:10.1080/10408398.2013.781011.

20. Al-Mekhlafi, H.M.; Al-Zabedi, E.M.; Al-Maktari, M.T.; Atroosh, W.M.; Al-Delaimy, A.K.; Moktar, N.; Sallam, A.A.; Abdullah, W.A.; Jani, R.; Surin, J. Effects of vitamin A supplementation on iron status indices and iron deficiency anaemia: a randomized controlled trial. Nutrients 2013, 6, 190-206, doi:10.3390/nu6010190.

21. Garcia-Casal, M.N.; Layrisse, M.; Solano, L.; Baron, M.A.; Arguello, F.; Llovera, D.; Ramirez, J.; Leets, I.; Tropper, E. Vitamin $A$ and beta-carotene can improve nonheme iron absorption from rice, wheat and corn by humans. J Nutr 1998, 128, 646-650, doi:10.1093/jn/128.3.646.

22. Pawson, R.; Mehta, A. Review article: the diagnosis and treatment of haematinic deficiency in gastrointestinal disease. Aliment Pharmacol Ther 1998, 12, 687-698, doi:10.1046/j.1365-2036.1998.00368.x.

23. Jansen van Rensburg, W.S.; Venter, S.L.; Netshiluvhi, T.R.; van den Heever, E.; Vorster, H.J.; de Ronde, J.A.; Bornman, C.H. Role of indigenous leafy vegetables in combating hunger and malnutrition. South African Journal of Botany 2004, 70, 52-59, doi:10.1016/S0254-6299(15)30268-4.

24. Stiller, C.K.; Golembiewski, S.KE.; Golembiewski, M.; Mondal, S.; Biesalski, H.K.; Scherbaum, V. Prevalence of Undernutrition and Anemia among Santal Adivasi Children, Birbhum District, West Bengal, India. IJERPH 2020, 17, doi:10.3390/ijerph17010342.

25. Michaelsen, K.F.; Hoppe, C.; Roos, N.; Kaestel, P.; Stougaard, M.; Lauritzen, L.; Molgaard, C.; Girma, T.; Friis, H. Choice of foods and ingredients for moderately malnourished children 6 months to 5 years of age. Food Nutr Bull 2009, 30, S343-404, doi:10.1177/15648265090303S303.

26. Allen, J. Sample Size Calculation for Two Independent Groups: A Useful Rule of Thumb; 2011; Vol. 20;.

27. Hirve, S.; Martini, E.; Juvekar, S.K.; Agarwal, D.; Bavdekar, A.; Sari, M.; Molwane, M.; Janes, S.; Haselow, N.; Yeung, D.L.; et al. Delivering Sprinkles Plus through the Integrated Child Development Services (ICDS) to reduce anemia in pre-school children in India. Indian J Pediatr 2013, 80, 990-995, doi:10.1007/s12098-013-1063-2.

28. WHO WHO recommendations on antenatal care for a positive pregnancy experience. Summary. 2016.

29. Adams, G.; Gulliford, M.C.; Ukoumunne, O.C.; Eldridge, S.; Chinn, S.; Campbell, M.J. Patterns of intra-cluster correlation from primary care research to inform study design and analysis. J Clin Epidemiol 2004, 57, 785-794, doi:10.1016/j.jclinepi.2003.12.013.

30. Green, S.B. How Many Subjects Does It Take To Do A Regression Analysis. Multivariate Behav Res 1991, 26, 499510, doi:10.1207/s15327906mbr2603_7.

31. R. Wilson Van Voorhis, C.; Morgan, B. Understanding Power and Rules of Thumb for Determining Sample Size; 2007; Vol. 3;.

32. Foidl, N.; Makkar, H.; Becker, K. The potential of Moringa oleifera for agricultural and industrial uses Moringa oleifera.; 2001;

33. ICMR Nutrient requirements and recommended dietary allowances for Indians, -A report of the Expert Group of the Indian Council of Medical Research. National Institute of Nutrition. Indian Council of Medical Research JamaiOsmania PO, Hyderabad 2009.

34. Gibson, R.S. The role of diet- and host-related factors in nutrient bioavailability and thus in nutrient-based dietary requirement estimates. Food Nutr Bull 2007, 28, S77-100, doi:10.1177/15648265070281S108.

35. IOM Dietary Reference Intakes (DRIs): Recommended Dietary Allowances and Adequate Intakes, Vitamins.

Summary Tables. Food and Nutrition Board, Institute of Medicine, National Academies 1997. 
36. Shaheen, N.; Rahim, ATM.; Mohiduzzaman, MD.; Banu, CP.; Bari, L.; Tukun, AB.; Bhattacharjee, L.; Stadlmayr, B. Food Composition Table for Bangladesh; Institute of Nutrition and Food Science; Centre for Advanced Research in Sciences; University of Dhaka, Dhaka-1000, Bangladesh, 2013;

37. USDA USDA Food Composition Databases. National Nutrient Database for Standard Reference Release 28; United States Department of Agriculture. National Agricultural Library., 2016;

38. Parlesak Biologische Eigenschaften und Inhaltsstoffe von Kolostrum und reifer Frauenmilch. In Scherbaum, $V$., Perl, F.M., Kretschmer, U. (2003): Stillen - Frühkindliche Ernährung und reproductive Gesundheit. Deutscher Ärzteverlag, Köln.; 2003.

39. Dewey, KG; Brown, KH Update on technical issues concerning complementary feeding of young children in developing countries and implications for intervention programs. Food and Nutrition Bulletin 2003, 24.

40. Piroth, I Assessing the Gap of Local Diets for Prevention of Malnutrition among Young Children in Rural Villages in West Bengal, India. Master's thesis, University of Hohenheim, Institute of Biological Chemistry and Nutrition (140c); 1 st supervisor professor H.K. Biesalski, Centre of Gender and Nutrition (430b); 2nd supervisor PD Dr. rer. nat. $V$ Scherbaum; 2014;

41. O'Connell, N.S.; Dai, L.; Jiang, Y.; Speiser, J.L.; Ward, R.; Wei, W.; Carroll, R.; Gebregziabher, M. Methods for Analysis of Pre-Post Data in Clinical Research: A Comparison of Five Common Methods. J Biom Biostat 2017, 8, 1-8, doi:10.4172/2155-6180.1000334.

42. Laird, N. Further Comparative Analyses of Pretest-Posttest Research Designs. The American Statistician 1983, 37, 329-330, doi:10.1080/00031305.1983.10483133.

43. Liu, G.F.; Lu, K.; Mogg, R.; Mallick, M.; Mehrotra, D.V. Should baseline be a covariate or dependent variable in analyses of change from baseline in clinical trials? Stat Med 2009, 28, 2509-2530, doi:10.1002/sim.3639.

44. Finch, B.K.; Beck, A.N. Socio-economic status and z-score standardized height-for-age of U.S.-born children (ages 2-6). Econ Hum Biol 2011, 9, 272-276, doi:10.1016/j.ehb.2011.02.005.

45. Saville, D.J. Multiple Comparison Procedures: The Practical Solution. The American Statistician 1990, 44, 174180, doi:10.2307/2684163.

46. Saville, D. Multiple Comparison Procedures-Cutting the Gordian Knot. Agronomy Journa/ 2013, 0, 0, doi:10.2134/agronj2012.0394.

47. Lee, S.; Lee, D.K. What is the proper way to apply the multiple comparison test? Korean J Anesthesio/ 2018, 71, 353-360, doi:10.4097/kja.d.18.00242.

48. Ghasemi, A.; Zahediasl, S. Normality tests for statistical analysis: a guide for non-statisticians. Int J Endocrinol Metab. 2012, 10, 486-9.

49. Cohen, J. A power primer. Psychol Bull 1992, 112, 155-159.

50. de Boer, M.R.; Waterlander, W.E.; Kuijper, L.D.; Steenhuis, I.H.; Twisk, J.W. Testing for baseline differences in randomized controlled trials: an unhealthy research behavior that is hard to eradicate. The International Journal of Behavioral Nutrition and Physical Activity 2015, 12, 4, doi:10.1186/s12966-015-0162-z.

51. Hair, J.F. Multivariate Data Analysis; 5th ed.; Pearson Education Limited, 1998; ISBN 978-0-13-930587-0.

52. Field AP Outliers and residuals (Chapter 8.3.1.1), p. 305. In: Discovering statistics using IBM SPSS Statistics: and sex and drugs and Rock ' $n$ 'Roll; 4th ed.; SAGE publications Ltd, 2012; ISBN 978-1-4462-4917-8.

53. EPHPP Effective public health practice project (EPHPP): Quality assessment tool for quantitative studies dictionary 2008.

54. WHO Programme of Nutrition Complementary feeding of young children in developing countries: a review of current scientific knowledge. 1998, 96. 
55. PAHO/WHO Guiding principles for complementary feeding of the breastfed child 2003.

56. WHO Complementary feeding: family food for breastfed children 2000.

57. Kotecha, P.V. Nutritional anemia in young children with focus on Asia and India. Indian J Community Med 2011, 36, 8-16, doi:10.4103/0970-0218.80786.

58. Ruel, M.T.; Menon, P.; Loechl, C.; Pelto, G. Donated fortified cereal blends improve the nutrient density of traditional complementary foods in Haiti, but iron and zinc gaps remain for infants. Food Nutr Bull 2004, 25, 361-376, doi:10.1177/156482650402500406.

59. Copenhagen Consensus Center Copenhagen Consensus 2008 - Results Available online: http://www.copenhagenconsensus.com/sites/default/files/cc08_results_final_0.pdf.

60. WHO Guideline: daily iron supplementation in infants and children; World Health Organization: Geneva, 2016; ISBN 9789241549523.

61. Jacobs, D.R.; Tapsell, L.C. Food synergy: the key to a healthy diet. Proc Nutr Soc 2013, 72, 200-206, doi:10.1017/S0029665112003011.

62. Nair, M.K.; Augustine, L.F.; Konapur, A. Food-Based Interventions to Modify Diet Quality and Diversity to Address Multiple Micronutrient Deficiency. Front Public Health 2016, 3, 277-277, doi:10.3389/fpubh.2015.00277.

63. Allen, L.; Benoist, B.; Dary, O.; Hurrell, R. Guidelines on food fortification with micronutrients, World Health Organization, Food and Agricultural Organization of the United Nations: Geneva, Switzerland, 2006; ISBN 92-4159401-2.

64. Lynch, S.R. The effect of calcium on iron absorption. Nutr Res Rev 2000, 13, 141-158, doi:10.1079/095442200108729043.

65. Abbaspour, N.; Hurrell, R.; Kelishadi, R. Review on iron and its importance for human health. Journal of Research in Medical Sciences: The Official Journal of Isfahan University of Medical Sciences 2014, 19, 164-174.

66. Longvah, T.; Ananthan, R.; Bhaskar, K.; Venkaiah, K. Indian Food Composition Tables. Available on: FAO/INFOODS: Databases; 2017; ISBN 978-93-5267-677-4.

67. Hurrell, R.F. Phytic acid degradation as a means of improving iron absorption. Int J Vitam Nutr Res 2004, 74, 445452, doi:10.1024/0300-9831.74.6.445.

68. Ferguson, E.L.; Gibson, R.S.; Thompson, L.U.; Ounpuu, S.; Berry, M. Phytate, zinc, and calcium contents of 30 East African foods and their calculated phytate:Zn, Ca:phytate, and [Ca][phytate]/[Zn] molar ratios. Journal of Food Composition and Analysis 1988, 1, 316-325, doi:10.1016/0889-1575(88)90031-2.

69. Gibson, R.; Ferguson, E. An Interactive 24-Hour Recall for Assessing the Adequacy of Iron and Zinc Intakes in Developing Countries. 2008.

70. Hurrell, R.F.; Juillerat, M.A.; Reddy, M.B.; Lynch, S.R.; Dassenko, S.A.; Cook, J.D. Soy protein, phytate, and iron absorption in humans. Am J Clin Nutr 1992, 56, 573-578, doi:10.1093/ajcn/56.3.573.

71. Hurrell, R.; Egli, I. Iron bioavailability and dietary reference values. Am J Clin Nutr 2010, 91, 1461S-1467S, doi:10.3945/ajcn.2010.28674F.

72. Thompson, B.; Amoroso, L. Combating micronutrient deficiencies: Food-based approaches 2010.

73. Gallaher, D.D.; Gallaher, C.M.; Natukunda, S.; Schoenfuss, T.C.; Mupere, E.; Cusick, S.E. Iron Bioavailability from Moringa oleifera Leaves Is Very Low. The FASEB Journal 2017, 31, 786.13-786.13, doi:10.1096/fasebj.31.1_supplement.786.13.

74. Madukwe, E.U.; Ugwuoke, A.L.; Ezeugwu, J.O. Effectiveness of dry Moringa oleifera leaf powder in treatment of anaemia. International Journal of Medicine and Medical Sciences 2013, 5, 226-228, doi:10.5897/IJMMS2013.0884.

Page $48 / 62$ 
75. van der Merwe, R.; Taylor, J.R.N.; Kruger, J. Mineral-rich plant foods have the potential to increase iron and zinc bioavailabilities from an instant cereal-based porridge 2017.

76. Renée, van der M. Pearl millet porridge: improvement in iron and zinc bioaccessibilities through fortification with micronutrient- rich plant food components 2017.

77. Tessera, G.M.; Haile, A.; Kinfe, E. Bioavailability of Minerals in Cookies Developed from Blend of Moringa Leaf Powder and Wheat Flour for Iron Deficient Lactating Mothers. International Journal of Food Science and Nutrition Engineering 2015, 5, 226-232, doi:10.5923/j.food.20150506.02.

78. Yadav, S.K.; Sehgal, S. Effect of domestic processing and cooking on selected antinutrient contents of some green leafy vegetables. Plant Foods for Human Nutrition 2003, 58, 1-11, doi:10.1023/B:QUAL.0000040359.40043.4f.

79. Makkar, H.P.S.; Becker, K. Nutrients and antiquality factors in different morphological parts of the Moringa oleifera tree. The Journal of Agricultural Science 1997, 128, 311-322.

80. TopNutri Datasheet Available online: https://medeor.de/images/medeormarket/spezialnahrung/topnutri_datenblatt.pdf.

81. Nambiar, V.S.; Bhadalkar, K.; Daxini, M. Drumstick leaves as source of vitamin A in ICDS-SFP. Indian J Pediatr 2003, 70, 383-387.

82. Boateng, L.; Nyarko, R.; Asante, M.; Steiner-Asiedu, M. Acceptability of Complementary Foods That Incorporate Moringa oleifera Leaf Powder Among Infants and Their Caregivers. Food Nutr Bull 2017, 39, 137-148, doi:10.1177/0379572117708656.

83. Boateng, L.; Nortey, E.; Ohemeng, A.N.; Asante, M.; Steiner-Asiedu, M. Sensory attributes and acceptability of complementary foods fortified with Moringa oleifera leaf powder. Nutrition \& Food Science 2018, 49, 393-406, doi:10.1108/NFS-07-2018-0192.

84. Nawiri, M.P.; Nyambaka, H.; Murungi, J.I. Sun-dried cowpeas and amaranth leaves recipe improves beta-carotene and retinol levels in serum and hemoglobin concentration among preschool children. Eur J Nutr 2013, 52, 583589, doi:10.1007/s00394-012-0360-2.

85. Egbi, G.; Gbogbo, S.; Mensah, G.E.; Glover-Amengor, M.; Steiner-Asiedu, M. Effect of green leafy vegetables powder on anaemia and vitamin-A status of Ghanaian school children. BMC Nutrition 2018, 4, 27, doi:10.1186/s40795018-0235-x.

86. van der Hoeven, M.; Faber, M.; Osei, J.; Kruger, A.; Smuts, C.M. Effect of African leafy vegetables on the micronutrient status of mildly deficient farm-school children in South Africa: a randomized controlled study. Public Health Nutr 2016, 19, 935-945, doi:10.1017/S1368980015002037.

87. de Pee, S.; West, C.E.; Permaesih, D.; Martuti, S.; Muhilal; Hautvast, J.G. Orange fruit is more effective than are darkgreen, leafy vegetables in increasing serum concentrations of retinol and beta-carotene in schoolchildren in Indonesia. Am J Clin Nutr 1998, 68, 1058-1067, doi:10.1093/ajcn/68.5.1058.

88. Andrew, A. Effect of Moringa oleifera leaf powder supplement to improve nutritional status of severely malnourished children aged 6-24 months in Arusha Region, Human Nutrition of Sokoine University of Agriculture: Morogor, Tanzania, 2010.

89. Saleh, S.M.; Abdel Salam, H.A. Effectiveness of Moringa oleifera in combating mild and moderate malnutrition in pediatric age group. New Yourk Science Journal 2014, 7, 69-79.

90. Perlas, L.A.; Magsadia, C.R.; Desnacido, J.A.; Serafico, M.E.; Viajar, R.V.; Rongavilla, E. O.; Azana, G.P.; Trinidad, T.P. The Efficacy of Malunggay Leaves Sprinkle in Improving the Iron, Vitamin A, B-vitamins and Calcium Status of 810 Years Old Schoolchildren. Research and Development 2014.

91. Lonati, A. Moringa nutritional intervention study on a school-age children population 2016. 
92. Boateng, L.; Quarpong, W.; Ohemeng, A.; Asante, M.; Steiner-Asiedu, M. Effect of complementary foods fortified with Moringa oleifera leaf powder on hemoglobin concentration and growth of infants in the Eastern Region of Ghana. Food Sci Nutr 2018, 7, 302-311, doi:10.1002/fsn3.890.

93. Glover-Amengor, M.; Aryeetey, R.; Afari, E.; Nyarko, A. Micronutrient composition and acceptability of Moringa oleifera leaf-fortified dishes by children in Ada-East district, Ghana. Food Sci Nutr 2017, 5, 317-323, doi:10.1002/fsn3.395.

94. Saturnin, HBV.; Mamatchi, M.; Eunice, K.N.; Balbine, F.A.; Lumo, A.K. Pharmacological Effects of Moringa oleifera (Lam.) Leaves Powder in the Treatment of Anaemia in Children Aged from 6 to 30 Months in Lissezoun in Central Benin. Biochemistry \& Physiology 2018, 7, doi:10.4172/2168-9652.1000239.

95. Menasria, L.; Blaney, S.; Main, B.; Vong, L.; Hun, V.; Raminashvili, D.; Chhea, C.; Chiasson, L.; Leblanc, C.P. Mitigated Impact of Provision of Local Foods Combined with Nutrition Education and Counseling on Young Child Nutritional Status in Cambodia. Nutrients 2018, 10, 1450, doi:10.3390/nu10101450.

96. Serafico, M.E.; Perlas, L.A.; Magsadia, C.R.; Desnacido, J.A.; Viajar, R.V.; Rongavilla, E. O.; Azana, G.P.; Trinidad, T.P. Efficacy of Malunggay (Moringa oleifera) leaves in improving the iron and vitamins $A$ and $B$ status of Filipino schoolchildren; Acta Horticulturae; 2017; Vol. 1158;.

97. Zongo, U.; Savadogo, B.; Zoungrana, S.L.; Sanou, D.; Savadogo, A.; Dicko, M.H.; SababenedyoTraore, A. Effect of Moringa Leaves Powder Consumption on Young Children Nutritional and Serum Retinol Status in Burkina Faso Rural Area. International Journal of Nutrition and Food Sciences 2018, 7, 148.

98. Zongo, U.; Léonce Zoungrana, S.; Savadogo, A.; Traore, A. Nutritional and Clinical Rehabilitation of Severely Malnourished Children with Moringa oleifera Lam. Leaf Powder in Ouagadougou (Burkina Faso). Food and Nutrition Sciences 2013, 4, 991-997, doi:10.4236/fns.2013.49128.

99. Isingoma, B.; Mbugua, S.; Edward, K.; Wamuyu-Maina, G. Performance of Nutritionally Optimized Millet Porridges in the Rehabilitation of Severely Malnourished Children at Mulago National Referral Hospital, Uganda. Journal of Advances in Medicine and Medical Research 2016, 18, 1-12, doi:10.9734/BJMMR/2016/28355.

100. Srikanth, V.S.; Mangala, S.; Subrahmanyam, G. Improvement of Protein Energy Malnutrition by Nutritional Intervention with Moringa Oleifera among Anganwadi Children in Rural Area in Bangalore, India. International Jourmal of Scientific Study 2014, 2, 32-35.

101. Nnam, N. Moringa oleifera leaf improves iron status of infants 6-12 months in Nigeria. Int J Food Saf Nutr Publ Health 2009, 2, 158-164, doi:10.1504/IJFSNPH.2009.029281.

102. Asante, R. The use of Moringa Oleifra leaf powder in the management of sub-clinical protein energy malnutrition in childen between the ages of 6-36 months, Kwame Nkrumah University of Science and Technology: Kumasi, Ghana, 2011.

103. de Pee, S.; Bloem, M.W. Current and potential role of specially formulated foods and food supplements for preventing malnutrition among 6- to 23-month-old children and for treating moderate malnutrition among 6- to 59month-old children. Food Nutr Bull 2009, 30, S434-463, doi:10.1177/15648265090303S305.

104. Bothwell, T.H.; MacPhail, A.P. The potential role of NaFeEDTA as an iron fortificant. Int J Vitam Nutr Res 2004, 74, 421-434, doi:10.1024/0300-9831.74.6.421.

105. Davidsson, L.; Almgren, A.; Hurrell, R.F. Sodium Iron EDTA [NaFe(III)EDTA] as a Food Fortificant Does Not Influence Absorption and Urinary Excretion of Manganese in Healthy Adults. The Journal of Nutrition 1998, 128, 1139-1143, doi:10.1093/jn/128.7.1139.

106. Mendoza, C.; Peerson, J.M.; Brown, K.H.; Lönnerdal, B. Effect of a micronutrient fortificant mixture and 2 amounts of calcium on iron and zinc absorption from a processed food supplement. The American Journal of Clinical Nutrition 2004, 79, 244-250, doi:10.1093/ajcn/79.2.244. 
107. Scientific Opinion on the use of ferric sodium EDTA as a source of iron added for nutritional purposes to foods for the general population (including food supplements) and to foods for particular nutritional uses. EFSA Journal. EFSA Panel on Food Additives and Nutrient Sources added to Food (ANS). European Food Safety Authority (EFSA), Parma, Italy 2010, 8, 1414.

108. Dossier: TopNutri for complete food fortification, What is TopNutri, Why use TopNutri, How to use TopNutri, TopNutri in the field.

109. Initial trial on Multiple Micronutrient sprinkle among children in Myanmar. Department of Medical Research (Lower Myanmar) Bulletin. 41st Myanmar Health Research Congress 2013, 25.

110. Ndemwa, P.; Klotz, C.L.; Mwaniki, D.; Sun, K.; Muniu, E.; Andango, P.; Owigar, J.; Rah, J.H.; Kraemer, K.; Spiegel, P.B.; et al. Relationship of the availability of micronutrient powder with iron status and hemoglobin among women and children in the Kakuma Refugee Camp, Kenya. Food Nutr Bull 2011, 32, 286-291, doi:10.1177/156482651103200314.

111. Troesch, B.; van Stuijvenberg, M.E.; Smuts, C.M.; Kruger, H.S.; Biebinger, R.; Hurrell, R.F.; Baumgartner, J.; Zimmermann, M.B. A micronutrient powder with low doses of highly absorbable iron and zinc reduces iron and zinc deficiency and improves weight-for-age Z-scores in South African children. J Nutr 2011, 141, 237-242, doi:10.3945/jn.110.129247.

112. Huo, J.; Sun, J.; Fang, Z.; Chang, S.; Zhao, L.; Fu, P.; Wang, J.; Huang, J.; Wang, L.; Begin, F.; et al. Effect of HomeBased Complementary Food Fortification on Prevalence of Anemia Among Infants and Young Children Aged 6 to 23 Months in Poor Rural Regions of China. Food Nutr Bull 2015, 36, 405-414, doi:10.1177/0379572115616001.

113. De-Regil, L.M.; Suchdev, P.S.; Vist, G.E.; Walleser, S.; Pena-Rosas, J.P. Home fortification of foods with multiple micronutrient powders for health and nutrition in children under two years of age. Cochrane Database Syst Rev 2011, CD008959, doi:10.1002/14651858.CD008959.pub2.

114. Hyder, S.M.Z.; Haseen, F.; Rahman, M.; Tondeur, M.C.; Zlotkin, S.H. Effect of daily versus once-weekly home fortification with micronutrient Sprinkles on hemoglobin and iron status among young children in rural Bangladesh. Food Nutr Bull 2007, 28, 156-164, doi:10.1177/156482650702800204.

115. De-Regil, L.M.; Jefferds, M.E.D.; Pena-Rosas, J.P. Point-of-use fortification of foods with micronutrient powders containing iron in children of preschool and school-age. Cochrane Database Syst Rev 2017, 11, CD009666, doi:10.1002/14651858.CD009666.pub2.

116. Hirve, S.; Bhave, S.; Bavdekar, A.; Naik, S.; Pandit, A.; Schauer, C.; Christofides, A.; Hyder, Z.; Zlotkin, S. Low dose 'Sprinkles'- an innovative approach to treat iron deficiency anemia in infants and young children. Indian Pediatr 2007, 44, 91-100.

117. Golden, M.H. Specific deficiencies versus growth failure: type I and type II nutrients. SCN News 1995, 10-14.

118. Lazzerini, M. Micronutrients for the Prevention and Treatment of Diarrhea in Children in Low- and Middle-Income Countries. Current Tropical Medicine Reports 2014, 1, 106-110, doi:10.1007/s40475-014-0014-y.

119. Aggarwal, R.; Sentz, J.; Miller, M.A. Role of zinc administration in prevention of childhood diarrhea and respiratory illnesses: a meta-analysis. Pediatrics 2007, 119, 1120-1130, doi:10.1542/peds.2006-3481.

120. Yilmaz, B.; Li, H. Gut Microbiota and Iron: The Crucial Actors in Health and Disease. Pharmaceuticals (Basel) 2018, 11, doi:10.3390/ph11040098.

121. Muleviciene, A.; D’Amico, F.; Turroni, S.; Candela, M.; Jankauskiene, A. Iron deficiency anemia-related gut microbiota dysbiosis in infants and young children: A pilot study. Acta Microbiol Immunol Hung 2018, 65, 551-564, doi:10.1556/030.65.2018.045.

122. Kane, A.V.; Dinh, D.M.; Ward, H.D. Childhood malnutrition and the intestinal microbiome. Pediatr Res 2015, 77, 256-262, doi:10.1038/pr.2014.179. 
123. Stoltzfus, R.J.; Kvalsvig, J.D.; Chwaya, H.M.; Montresor, A.; Albonico, M.; Tielsch, J.M.; Savioli, L.; Pollitt, E. Effects of iron supplementation and anthelmintic treatment on motor and language development of preschool children in Zanzibar: double blind, placebo controlled study. BMJ 2001, 323, 1389-1393, doi:10.1136/bmj.323.7326.1389.

124. Black, M.M.; Baqui, A.H.; Zaman, K.; Ake Persson, L.; El Arifeen, S.; Le, K.; McNary, S.W.; Parveen, M.; Hamadani, J.D.; Black, R.E. Iron and zinc supplementation promote motor development and exploratory behavior among Bangladeshi infants. Am J Clin Nutr 2004, 80, 903-910, doi:10.1093/ajcn/80.4.903.

125. Huey, S.L.; Finkelstein, J.L.; Venkatramanan, S.; Udipi, S.A.; Ghugre, P.; Thakker, V.; Thorat, A.; Potdar, R.D.; Chopra, H.V.; Kurpad, A.V.; et al. Prevalence and Correlates of Undernutrition in Young Children Living in Urban Slums of Mumbai, India: A Cross Sectional Study. Front Public Health 2019, 7, 191-191, doi:10.3389/fpubh.2019.00191.

126. Ali, N.B.; Tahsina, T.; Hoque, D.M.E.; Hasan, M.M.; Iqbal, A.; Huda, T.M.; El Arifeen, S. Association of food security and other socio-economic factors with dietary diversity and nutritional statuses of children aged 6-59 months in rural Bangladesh. PLoS One 2019, 14, e0221929-e0221929, doi:10.1371/journal.pone.0221929.

127. Bhargava, A.; Bouis, H.E.; Scrimshaw, N.S. Dietary Intakes and Socioeconomic Factors Are Associated with the Hemoglobin Concentration of Bangladeshi Women. The Journal of Nutrition 2001, 131, 758-764, doi:10.1093/jn/131.3.758.

128. World Health Organisation Management of severe malnutrition: a manual for physicians and other senior health workers 1999.

129. Jilcott, S.B.; Ickes, S.B.; Ammerman, A.S.; Myhre, J.A. Iterative design, implementation and evaluation of a supplemental feeding program for underweight children ages 6-59 months in Western Uganda. Matern Child Health J 2010, 14, 299-306, doi:10.1007/s10995-009-0456-3.

130. Maleta, K.; Kuittinen, J.; Duggan, M.B.; Briend, A.; Manary, M.; Wales, J.; Kulmala, T.; Ashorn, P. Supplementary feeding of underweight, stunted Malawian children with a ready-to-use food. J Pediatr Gastroenterol Nutr 2004, 38, 152-158, doi:10.1097/00005176-200402000-00010.

131. Purwestri, R.C.; Scherbaum, V.; Inayati, D.A.; Wirawan, N.N.; Suryantan, J.; Bloem, M.A.; Pangaribuan, R.V.; Stuetz, W.; Hoffmann, V.; Qaim, M.; et al. Supplementary feeding with locally-produced Ready-to-Use Food (RUF) for mildly wasted children on Nias Island, Indonesia: comparison of daily and weekly program outcomes. Asia Pac J Clin Nutr 2012, 21, 374-379.

132. Scherbaum, V.; Purwestri, R.C.; Stuetz, W.; Inayati, D.A.; Suryantan, J.; Bloem, M.A.; Biesalski, H.K. Locally produced cereal/nut/legume-based biscuits versus peanut/milk-based spread for treatment of moderately to mildly wasted children in daily programmes on Nias Island, Indonesia: an issue of acceptance and compliance? Asia Pac J Clin Nutr 2015, 24, 152-161, doi:10.6133/apjcn.2015.24.1.15.

133. Georgieff, M.K.; Wewerka, S.W.; Nelson, C.A.; Deregnier, R.-A. Iron status at 9 months of infants with low iron stores at birth. J Pediatr 2002, 141, 405-409, doi:10.1067/mpd.2002.127090.

134. Thorsdottir, I.; Gunnarsson, B.S.; Atladottir, H.; Michaelsen, K.F.; Palsson, G. Iron status at 12 months of age -effects of body size, growth and diet in a population with high birth weight. Eur J Clin Nutr 2003, 57, 505-513, doi:10.1038/sj.ejcn.1601594.

135. Victora, C.G.; de Onis, M.; Hallal, P.C.; Blossner, M.; Shrimpton, R. Worldwide timing of growth faltering: revisiting implications for interventions. Pediatrics 2010, 125, e473-480, doi:10.1542/peds.2009-1519.

136. CDC A Manual: Measuring and Interpreting Malnutrition and Mortality. Centers for Disease Control and Prevention and the World Food Programme. 2005.

137. Brown, K.H.; Black, R.E.; Becker, S. Seasonal changes in nutritional status and the prevalence of malnutrition in a longitudinal study of young children in rural Bangladesh. Am J Clin Nutr 1982, 36, 303-313. 
138. Golden, M.H. Proposed Recommended Nutrient Densities for Moderately Malnourished Children. Food Nutr Bull 2009, 30, S267-S342, doi:10.1177/15648265090303S302.

139. Saaka, M.; Galaa, S.Z. Relationships between Wasting and Stunting and Their Concurrent Occurrence in Ghanaian Preschool Children. J Nutr Metab 2016, 2016, 4654920-4654920, doi:10.1155/2016/4654920.

140. Briend, A.; Khara, T.; Dolan, C. Wasting and stunting-similarities and differences: policy and programmatic implications. Food Nutr Bull 2015, 36, S15-23, doi:10.1177/15648265150361S103.

141. Dewey, K.G.; Hawck, M.G.; Brown, K.H.; Lartey, A.; Cohen, R.J.; Peerson, J.M. Infant weight-for-length is positively associated with subsequent linear growth across four different populations. Matern Child Nutr 2005, 1, 11-20, doi:10.1111/j.1740-8709.2004.00004.x.

142. Schoenbuchner, S.M.; Dolan, C.; Mwangome, M.; Hall, A.; Richard, S.A.; Wells, J.C.; Khara, T.; Sonko, B.; Prentice, A.M.; Moore, S.E. The relationship between wasting and stunting: a retrospective cohort analysis of longitudinal data in Gambian children from 1976 to 2016. The American Journal of Clinical Nutrition 2019, 110, 498-507, doi:10.1093/ajcn/nqy326.

143. Dhami, M.V.; Ogbo, F.A.; Osuagwu, U.L.; Ugboma, Z.; Agho, K.E. Stunting and severe stunting among infants in India: the role of delayed introduction of complementary foods and community and household factors. Global Health Action 2019, 12, 1638020, doi:10.1080/16549716.2019.1638020.

144. Fenske, N.; Burns, J.; Hothorn, T.; Rehfuess, E.A. Understanding child stunting in India: a comprehensive analysis of socio-economic, nutritional and environmental determinants using additive quantile regression. PLoS One 2013, 8 , e78692-e78692, doi:10.1371/journal.pone.0078692.

145. Sarkar, S. Cross-sectional study of child malnutrition and associated risk factors among children aged under five in West Bengal, India. International Journal of Population Studies 2016, 2, doi:10.18063/IJPS.2016.01.003.

146. Aguayo, V.M.; Nair, R.; Badgaiyan, N.; Krishna, V. Determinants of stunting and poor linear growth in children under 2 years of age in India: an in-depth analysis of Maharashtra's comprehensive nutrition survey. Matern Child Nutr 2016, 12 Supp/ 1, 121-140, doi:10.1111/mcn.12259.

147. Sinha, R.K.; Dua, R.; Bijalwan, V.; Rohatgi, S.; Kumar, P. Determinants of Stunting, Wasting, and Underweight in Five High-Burden Pockets of Four Indian States. Indian J Community Med 2018, 43, 279-283, doi:10.4103/ijcm.IJCM_151_18.

148. Aguayo, V.M.; Menon, P. Stop stunting: improving child feeding, women's nutrition and household sanitation in South Asia. Matern Child Nutr 2016, 12 Suppl 1, 3-11, doi:10.1111/mcn.12283.

149. Haselow, N.J.; Stormer, A.; Pries, A. Evidence-based evolution of an integrated nutrition-focused agriculture approach to address the underlying determinants of stunting. Matern Child Nutr 2016, 12 Suppl 1, 155-168, doi:10.1111/mcn.12260.

150. Dewey, K.G. Reducing stunting by improving maternal, infant and young child nutrition in regions such as South Asia: evidence, challenges and opportunities. Matern Child Nutr 2016, 12 Suppl 1, 27-38, doi:10.1111/mcn.12282.

151. Sachdev, H. Undersized Indian Children: Nutrients-Starved or Hungry for Development? Proceedings of the Indian National Science Academy 2018, 84, doi:10.16943/ptinsa/2018/49438.

152. Rousham, E.; Mascie-Taylor, C. Seasonality and child morbidity in rural Bangladesh. American Journal of Human Biology 1995, 7, 369-379, doi:10.1002/ajhb.1310070313.

153. Paintal, K.; Aguayo, V.M. Feeding practices for infants and young children during and after common illness. Evidence from South Asia. Matern Child Nutr 2016, 12 Suppl 1, 39-71, doi:10.1111/mcn.12222.

154. Ouedraogo, H.Z.; Traore, T.; Zeba, A.; Dramaix-Wilmet, M.; Hennart, P.; Donnen, P. A local-ingredient-based, processed flour to improve the energy, iron and zinc intakes of young children: a community-based intervention. Int 
J Food Sci Nutr 2009, 60 Supp/ 4, 87-98, doi:10.1080/09637480802502548.

155. Scherbaum, V.; Srour, M.L. The Role of Breastfeeding in the Prevention of Childhood Malnutrition. World Rev Nutr Diet 2016, 115, 82-97, doi:10.1159/000442075.

156. Filteau, S. Role of breast-feeding in managing malnutrition and infectious disease. Proc Nutr Soc 2000, 59, 565572.

157. Gera, T.; Sachdev, H.P.S.; Nestel, P.; Sachdev, S.S. Effect of iron supplementation on haemoglobin response in children: systematic review of randomised controlled trials. J Pediatr Gastroenterol Nutr 2007, 44, 468-486, doi:10.1097/01.mpg.0000243440.85452.38.

158. Allen, L.H.; Rosado, J.L.; Casterline, J.E.; López, P.; Muñoz, E.; Garcia, O.P.; Martinez, H. Lack of hemoglobin response to iron supplementation in anemic Mexican preschoolers with multiple micronutrient deficiencies. The American Journal of Clinical Nutrition 2000, 71, 1485-1494, doi:10.1093/ajcn/71.6.1485.

159. Petry, N.; Olofin, I.; Hurrell, R.F.; Boy, E.; Wirth, J.P.; Moursi, M.; Donahue Angel, M.; Rohner, F. The Proportion of Anemia Associated with Iron Deficiency in Low, Medium, and High Human Development Index Countries: A Systematic Analysis of National Surveys. Nutrients 2016, 8, doi:10.3390/nu8110693.

160. Varghese, J.S.; Thomas, T.; Kurpad, A.V. Evaluation of haemoglobin cut-off for mild anaemia in Asians - analysis of multiple rounds of two national nutrition surveys. Indian J Med Res 2019, 150, 385-389, doi:10.4103/ijmr.IJMR_334_18.

161. Emond, A.M.; Hawkins, N.; Pennock, C.; Golding, J. Haemoglobin and ferritin concentrations in infants at 8 months of age. Arch Dis Child 1996, 74, 36-39.

162. Kapil, U.; Kapil, R.; Gupta, A. National Iron Plus Initiative: Current status \& future strategy. Indian J Med Res 2019, 150, 239-247, doi:10.4103/ijmr.IJMR_1782_18.

163. Dhakar, R.C.; Maurya, S.; K. Pooniya, B.; Bairwa, N.; Gupta, M.; Sanwarmal Moringa: The herbal gold to combat malnutrition. Chronicles of Young Scientists 2011, 2, 119, doi:10.4103/2229-5186.90887.

164. Witt, K.A. The nutrient content of moringa oleifera leaves. ECHO Research Notes 2013, 1.

165. Gupta, S.; Jyothi Lakshmi, A.; Manjunath, M.N.; Prakash, J. Analysis of nutrient and antinutrient content of underutilized green leafy vegetables. LWT - Food Science and Technology 2005, 38, 339-345, doi:10.1016/j.Iwt.2004.06.012.

166. Alegbejo, J. Nutritional Value and Utilization of Amaranthus (Amaranthus spp.) - A Review. Bajopas 2014, 6, 136143, doi:10.4314/bajopas.v6i1.27.

167. Gupta, S.; Gowri, B.S.; Lakshmi, A.J.; Prakash, J. Retention of nutrients in green leafy vegetables on dehydration. Journal of Food Science and Technology 2013, 50, 918-925, doi:10.1007/s13197-011-0407-z.

168. Pradeepkumar, T.; Indira, V.; Sankar, M. Nutritional Evaluation of Wild Leafy Vegetables Consumed by Tribals in the Wayanad District of Kerala. Proceedings of the National Academy of Sciences, India Section B: Biological Sciences 2015, 85, 93-99, doi:10.1007/s40011-013-0271-x.

169. Saha, J.; Biswal, A.; Deka, S. Chemical composition of some underutilized green leafy vegetables of Sonitpur district of Assam, India. J Food Sci Tech 2015, 22, 1466-1473.

170. Bechthold, A. Moringa: Sinn und Unsinn des „Superfoods“. Ernährungsumschau - Ernährungslehre \& Praxis 2016, 43-46.

171. Yang, R.-Y.; Chang, L.-C.; Hsu, J.-C.; Weng, B.-C.; Palada, M.; Chadha, M.; Levasseur, V. Nutritional and Functional Properties of Moringa Leaves - From Germplasm, to Plant, to Food, to Health 2006.

172. Yang, R.-Y.; Keding, G. Chapter 4: Nutritional Contributions of Important African Indigenous Vegetables. In: African Indigenous Vegetables in Urban Agriculture Editors: C. M. Shackleton, W. M. Pasquini, A. W. Drescher, Earthscan, 
2009; ISBN 978-1-84407-715-1.

173. Noonan, S.C.; Savage, G.P. Oxalate content of foods and its effect on humans. Asia Pac J Clin Nutr 1999, 8, 6474.

174. Price, M.L. THE MORINGA TREE. In ECHO Technical Note; ECHO Staff, 2007.

175. Agbaire, P. Levels of anti-nutritional factors in some common leafy edible vegetables of southern Nigeria. Afr. J. Food Sci. Technol. 2012, 3, 99-101.

176. Nouman, W.; Basra, S.; Tahir Siddiqui, M.; Yasmeen, A.; Gull, T.; Angelica Cervantes Alcayde, M. Potential of Moringa oleifera L. as livestock fodder crop: A review. Turk J Agric For 2014, 38, 1-14, doi:10.3906/tar-1211-66.

177. Moyo, B.; Masika, P.J.; Hugo, A.; Muchenje, V. Nutritional characterization of Moringa (Moringa oleifera Lam.) leaves; 2011; Vol. 10;

178. FAO Dietary protein quality evaluation in human nutrition. Table 5: Recommended amino acid scoring patterns for infants, children and older children, adolescents and adults. 2011.

179. Lakens, D. Calculating and reporting effect sizes to facilitate cumulative science: a practical primer for t-tests and ANOVAs. Front Psychol 2013, 4, 863, doi:10.3389/fpsyg.2013.00863.

\section{Figures}




\begin{tabular}{|c|c|c|c|}
\hline Intervention Group 1 & Intervention Group 2 & Intervention Group 3 & Control Group \\
\hline Diversified meals & $\begin{array}{c}\text { Diversified meals + } \\
\text { Amaranthus } \\
\text { tricolor/Moringa oleifera } \\
\text { leaf powder }\end{array}$ & $\begin{array}{c}\text { Diversified meals + } \\
\text { adjusted amount } \\
\text { micronutrient sprinkle }\end{array}$ & $\begin{array}{c}\text { No nutrition } \\
\text { intervention but equally } \\
\text { medical checkups }\end{array}$ \\
\hline \multicolumn{3}{|c|}{307 children (aged 6m-39m) } \\
\hline
\end{tabular}

\begin{tabular}{|c|c|c|c|c|}
\hline $\begin{array}{l}\text { Baseline (1st) Assessment, Feb } 2015 \text { (winter season) } \\
\text { medical checkup, morbidity/anthropometric assessment }\end{array}$ & $\mathrm{n}=78$ & $n=73$ & $\mathrm{n}=76$ & $\mathrm{n}=80$ \\
\hline Intervention Period 1 (IP1), 6 months & $-(n=5, H b<7 g / d)$ & $\begin{array}{r}-(n=4, H b<7 / / d l)) \\
-(n=1, \text { child death })\end{array}$ & $\begin{array}{r}-(n=2, H b<7 g / d l) \\
-(n=1, \text { child death })\end{array}$ & $-(n=3, H b<7 / / d l)$ \\
\hline $\begin{array}{l}\text { 2nd Assessment (Follow-up), Aug } 2015 \text { (monsoon season) } \\
\text { medical checkup, morbidity/anthropometric assessment }\end{array}$ & $\begin{array}{c}n=68 \\
\text { (out of a possible } n=73 \text { ) }\end{array}$ & $\begin{array}{c}n=64 \\
\text { (out of a possible } 68 \text { ) }\end{array}$ & $\begin{array}{c}n=70 \\
\text { (out of a possible } 73 \text { ) }\end{array}$ & $\begin{array}{c}\mathrm{n}=69 \\
\text { (out of a possible 77) }\end{array}$ \\
\hline Intervention Period 2 (IP2), 6 months & $-(n=1, H b<7 g / d)$ & $-(n=2, H b<7 g / d d)$ & $\begin{array}{r}-(n=1, H b<7 g / d) \\
-(n=1, \text { child death })\end{array}$ & $-(n=2, H b<7 g / d)$ \\
\hline $\begin{array}{l}\text { 3rd Assessment (Follow-up), Feb } 2016 \text { (winter season) } \\
\text { medical checkup, morbidity/anthropometric assessment }\end{array}$ & $\begin{array}{c}n=71 \\
\text { (out of a possible } n=72 \text { ) }\end{array}$ & $\begin{array}{c}n=66 \\
\text { (out of a possible } n=66 \text { ) }\end{array}$ & $\begin{array}{c}n=70 \\
\text { (out of a possible } n=71 \text { ) }\end{array}$ & $\begin{array}{c}n=75 \\
\text { (out of a possible } n=75 \text { ) }\end{array}$ \\
\hline \multicolumn{5}{|l|}{ Intervention Period 3 (IP3), 6 months } \\
\hline \multirow[t]{8}{*}{$\begin{array}{l}\text { Endline (4th) Assessment, Aug } 2016 \\
\text { anthropometric assessment }\end{array}$} & $\begin{array}{c}n=68 \\
\text { (out of a possible } n=72 \text { ) }\end{array}$ & $\begin{array}{c}n=60 \\
\text { (out of a possible } n=66 \text { ) }\end{array}$ & $\begin{array}{c}n=70 \\
\text { (out of a possible } n=71 \text { ) }\end{array}$ & $\begin{array}{c}n=72 \\
\text { (out of a possible } n=75 \text { ) }\end{array}$ \\
\hline & $\begin{array}{r}-(n=8), \\
\text { number of children at least } \\
\text { once absent } \\
\text { Note: }(n=10), \\
\text { total frequency of absence }\end{array}$ & $\begin{array}{r}-(n=8), \\
\text { number of children at least once } \\
\text { absent } \\
\text { Note: }(n=10), \\
\text { total frequency of absence }\end{array}$ & $\begin{array}{r}-(n=4), \\
\text { number of children at least once } \\
\text { absent } \\
\text { Note: }(n=5), \\
\text { total frequency of absence }\end{array}$ & $\begin{array}{r}-(n=10), \\
\text { number of children at least once } \\
\text { absent } \\
\text { Note: }(n=11), \\
\text { total frequency of absence }\end{array}$ \\
\hline & $\begin{array}{c}\mathrm{n}=64 \\
\text { (valid for all four assessments) } \\
\end{array}$ & $\begin{array}{c}\mathrm{n}=58 \\
\text { (valid for all four assessments) }\end{array}$ & $\begin{array}{c}\mathrm{n}=67 \\
\text { (valid for all four assessments) } \\
\end{array}$ & $\begin{array}{c}\mathrm{n}=65 \\
\text { (valid for all four assessments) }\end{array}$ \\
\hline & \multicolumn{4}{|c|}{ Drop-out Considerations } \\
\hline & $\begin{array}{l}\mathrm{n}=6(\mathrm{Hb}<7 \mathrm{~g} / \mathrm{dl}) \\
\text { (at baseline assessment, } \\
\text { 1st or, 2nd follow-up) }\end{array}$ & $\begin{array}{l}\mathrm{n}=6(\mathrm{Hb}<7 \mathrm{~g} / \mathrm{dl}) \\
\text { (at baseline assessment, } \\
\text { 1st or, 2nd follow-up) }\end{array}$ & $\begin{array}{l}\mathrm{n}=3(\mathrm{Hb}<7 \mathrm{~g} / \mathrm{dl}) \\
\text { (at baseline assessment, } \\
\text { 1st or, 2nd follow-up) }\end{array}$ & $\begin{array}{l}\mathrm{n}=5(\mathrm{Hb}<7 \mathrm{~g} / \mathrm{dl}) \\
\text { (at baseline assessment, } \\
\text { 1st or, 2nd follow-up) }\end{array}$ \\
\hline & $\begin{array}{l}\mathrm{n}=8 \\
\text { (number of children absent) }\end{array}$ & $\begin{array}{l}n=1 \text { (child death) } \\
n=8 \\
\text { (number of children absent) }\end{array}$ & $\begin{array}{l}\mathrm{n}=2 \text { (child death) } \\
\mathrm{n}=4 \\
\text { (number of children absent) }\end{array}$ & $\begin{array}{l}\mathrm{n}=10 \\
\text { (number of children absent) }\end{array}$ \\
\hline & drop-out $n=14$ & drop-out $n=15$ & drop-out $n=9$ & drop-out $n=15$ \\
\hline & & $\begin{array}{l}n=20 \quad(H b<7 g / d l) \\
n=3 \quad \text { (child death) } \\
n=30 \text { (absent) }\end{array}$ & $\begin{array}{l}\text { (investigator-caused disco } \\
\text { (drop-out) } \\
\text { (lost-to-follow-up or refus }\end{array}$ & sedinuation) \\
\hline
\end{tabular}

$\mathrm{n}=53$ children total drop-out from baseline assessment before applying inclusion criteria $(17.3 \%)$ $\mathrm{n}=39$ children drop-out from inclusion to endline assessment (13.3\%)

\section{Figure 1}

Flow chart on enrolment, follow-up and drop-out in the trial 


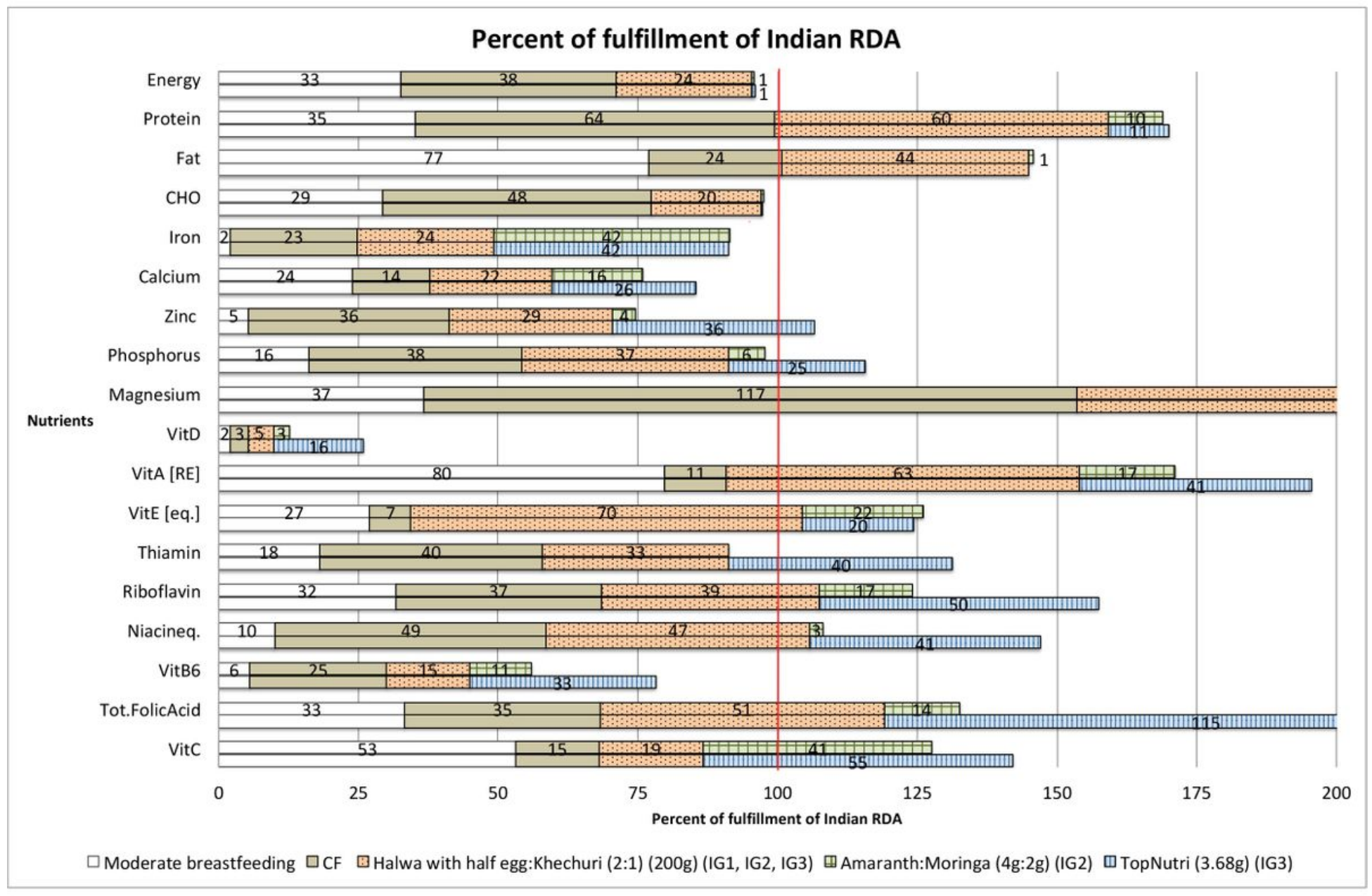

\section{Figure 2}

Percent of fulfillment of Indian RDA by assumed moderate frequency of breastfeeding, by complementary feeding (CF) over the day, as well as Halwa:Khechuri (2:1) supplemented with either Amaranthus:Moringa (2:1) leaf powder mixture or an adjusted amount of TopNutri. 


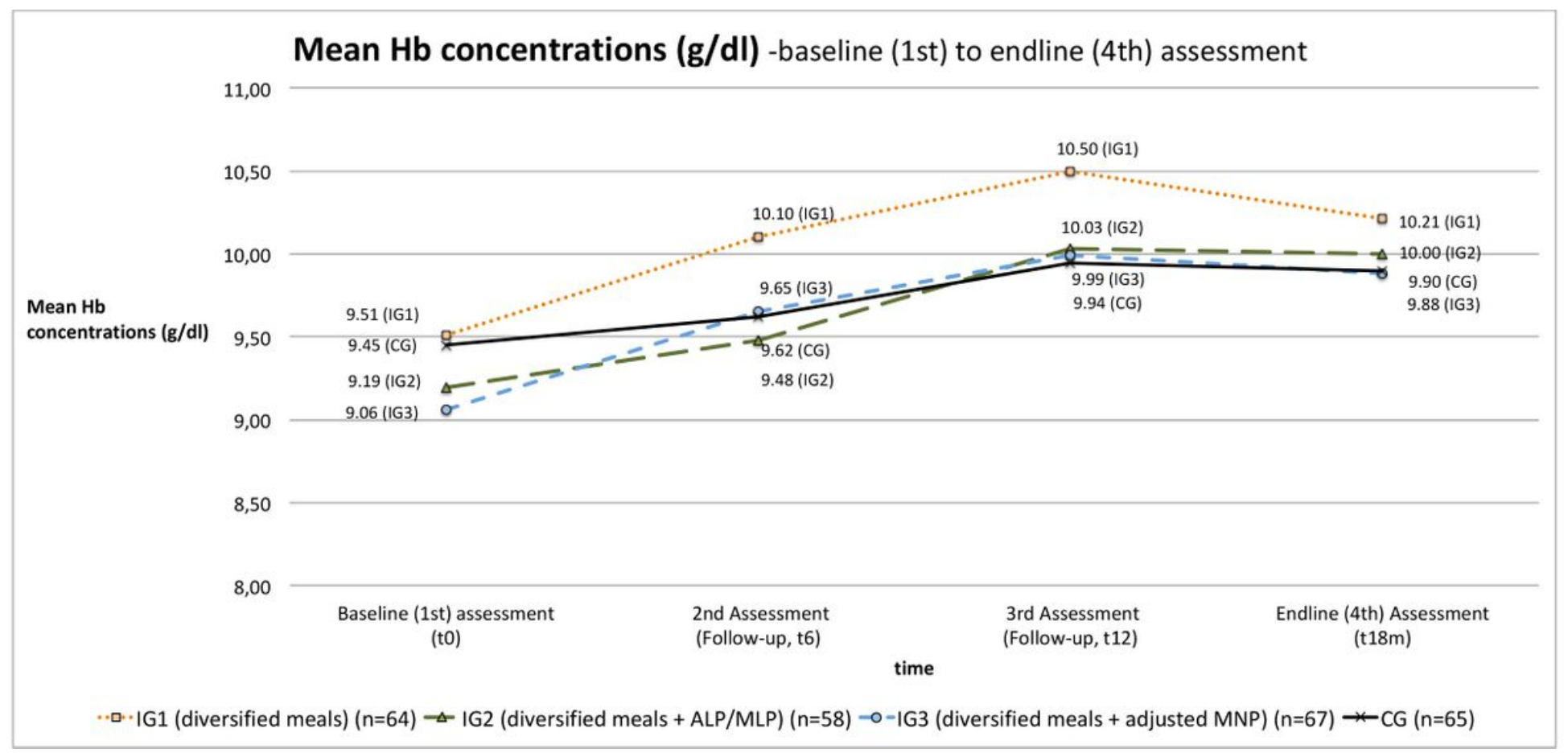

\section{Figure 3}

Mean $\mathrm{Hb}$ concentrations at baseline, 2nd, 3rd, endline assessment $(n=254)$, per study group.

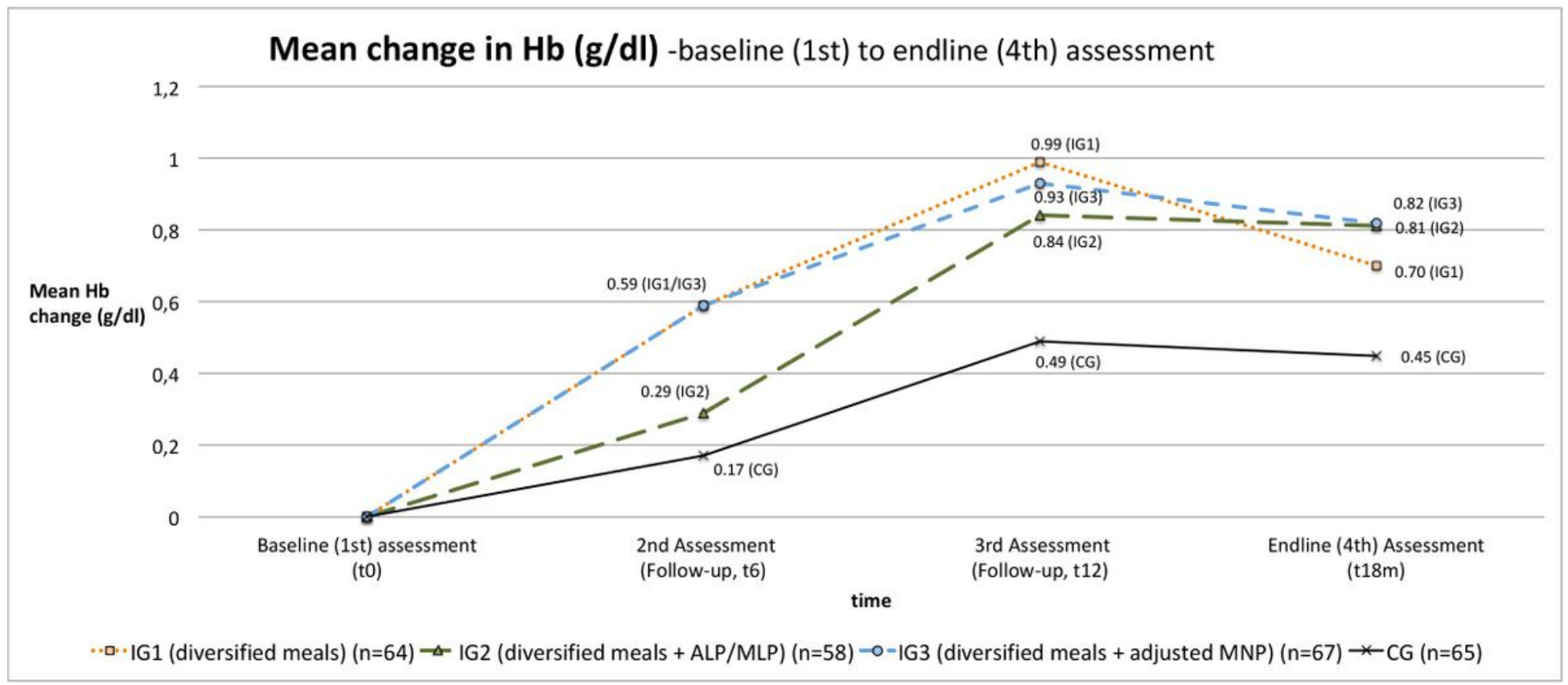

Figure 4

Mean changes in $\mathrm{Hb}$ concentrations occurred over time $(\mathrm{n}=254)$, per study group. 


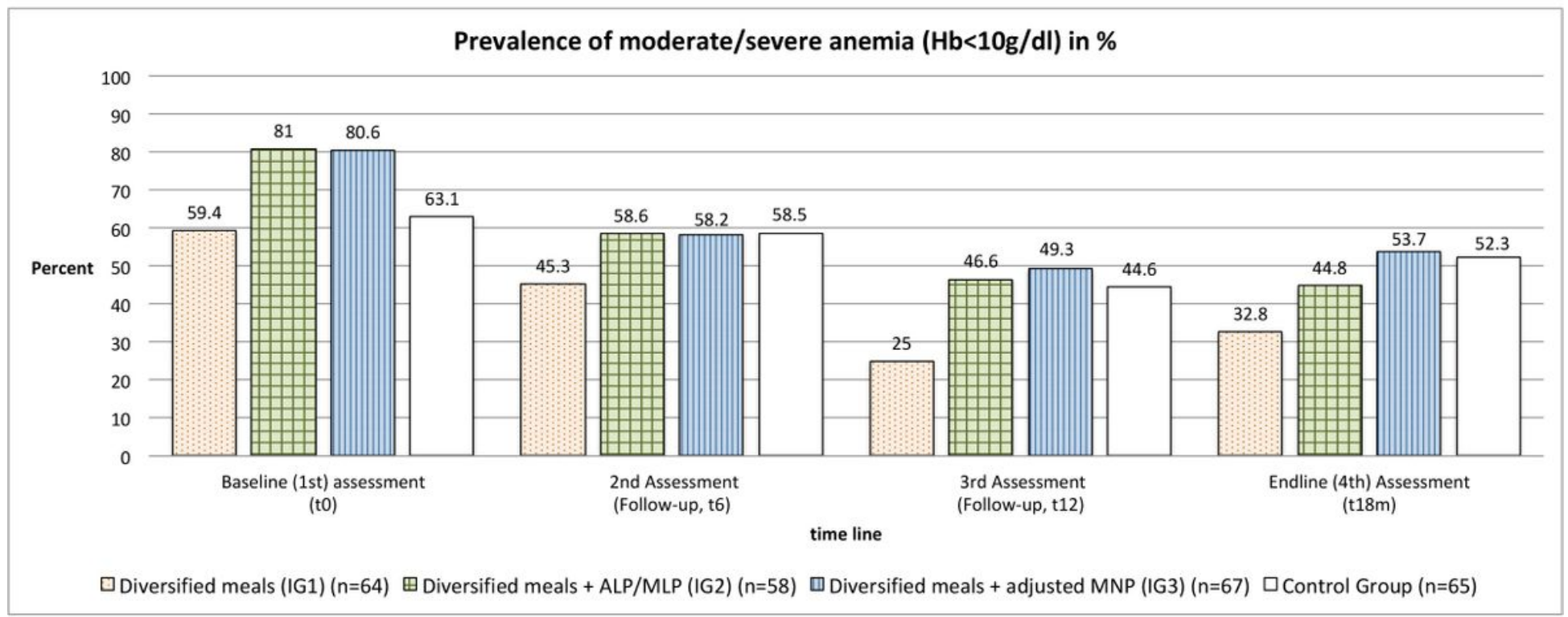

Figure 5

Prevalence of moderate/severe anemia at different assessment points by study group

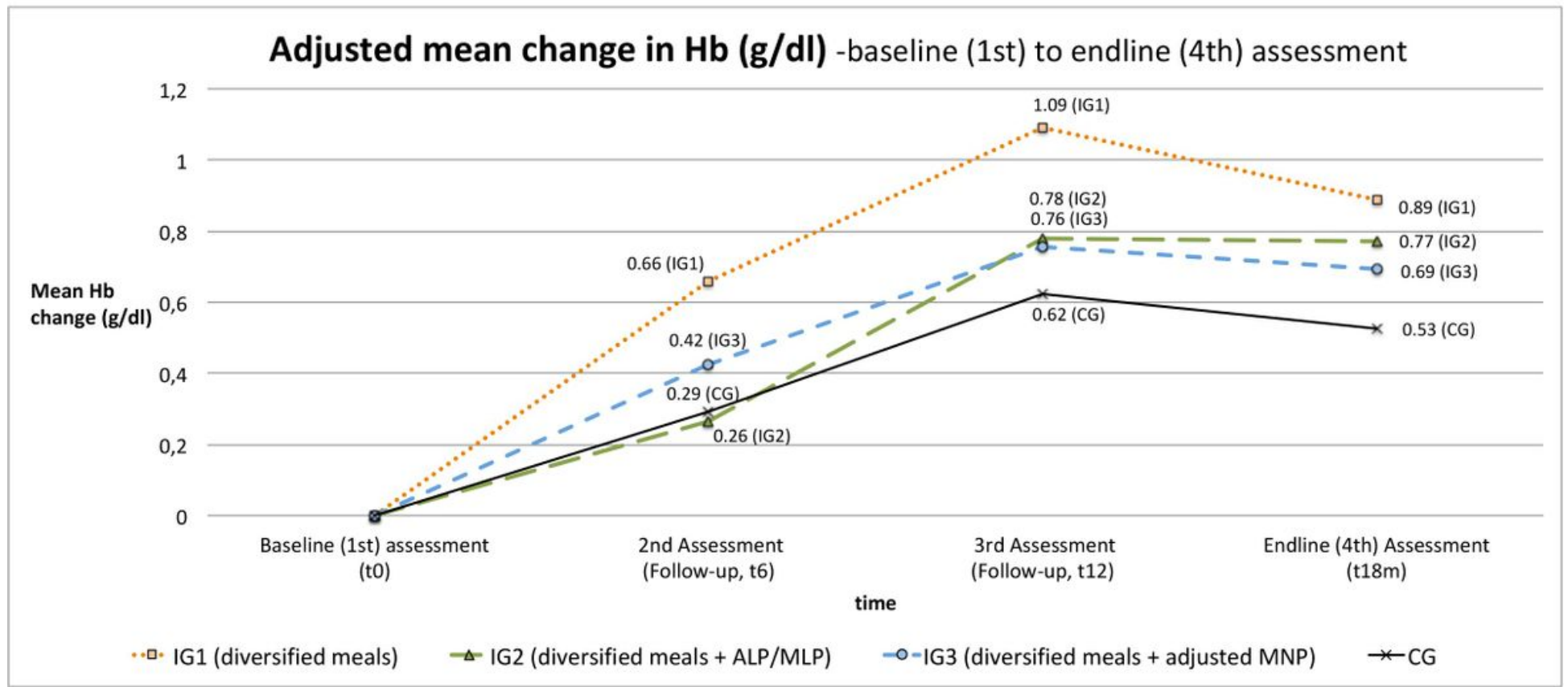

\section{Figure 6}

Adjusted mean changes in $\mathrm{Hb}$ concentrations occurred over time, per study group (covariates age and $\mathrm{Hb}$ at baseline, time between baseline and investigated assessment point, gender). 


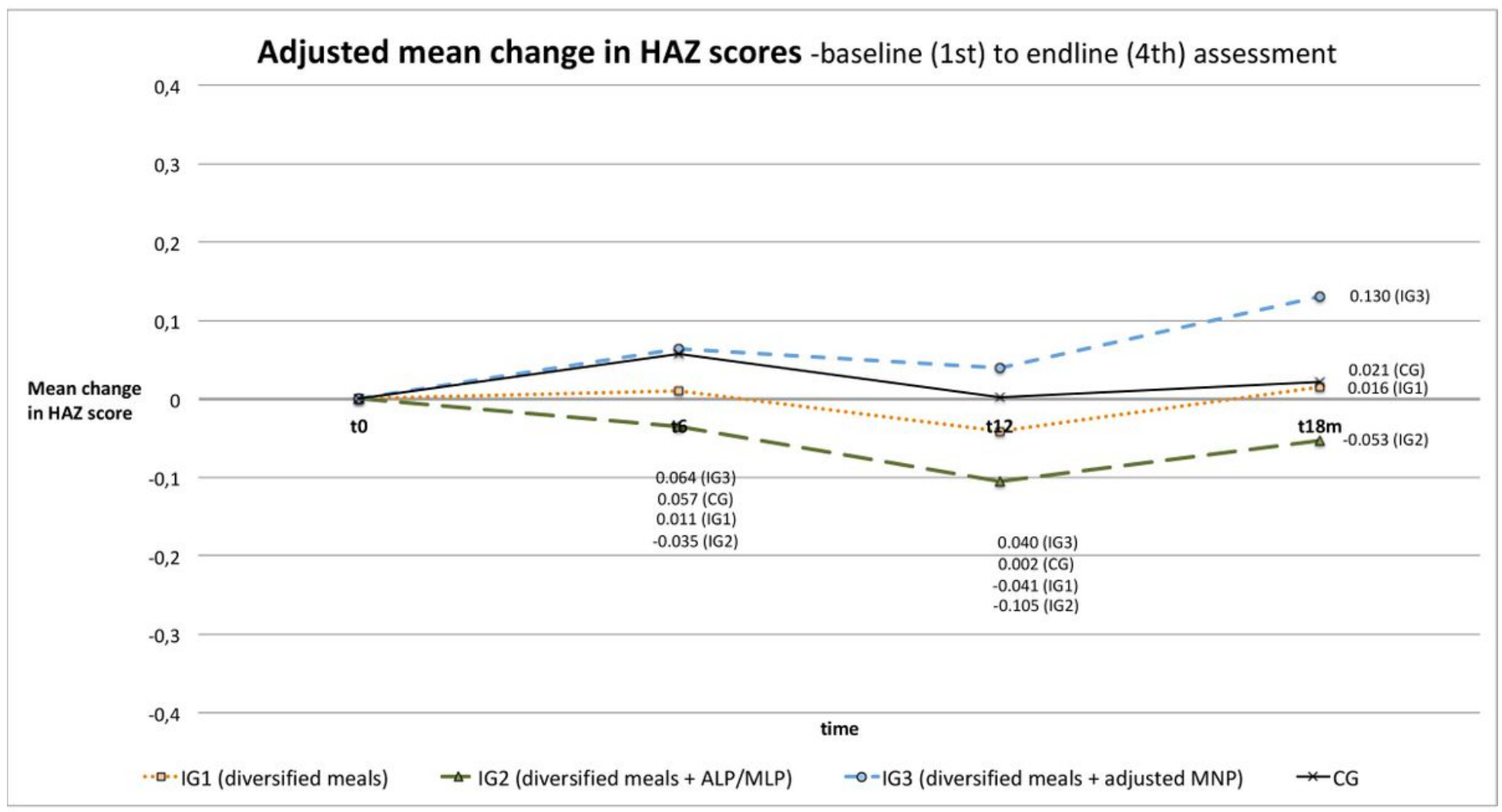

Figure 7

Adjusted mean changes in HAZ scores occurred over time, per study group (covariates age and HAZ scores at baseline, time between baseline and investigated assessment point, gender).

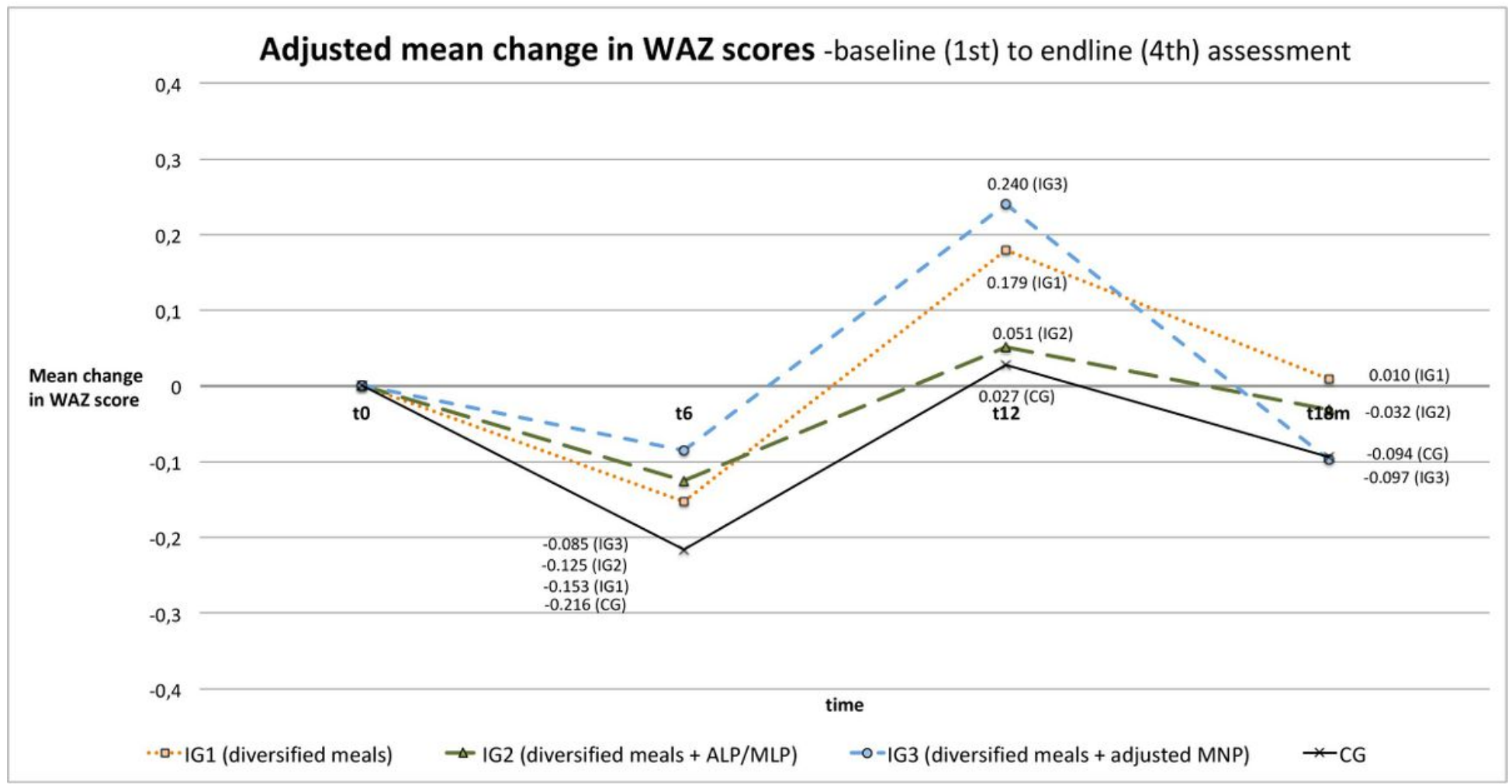

Figure 8 
Adjusted mean changes in WAZ scores occurred over time, per study group (covariates age and WAZ scores at baseline, time between baseline and investigated assessment point, gender).

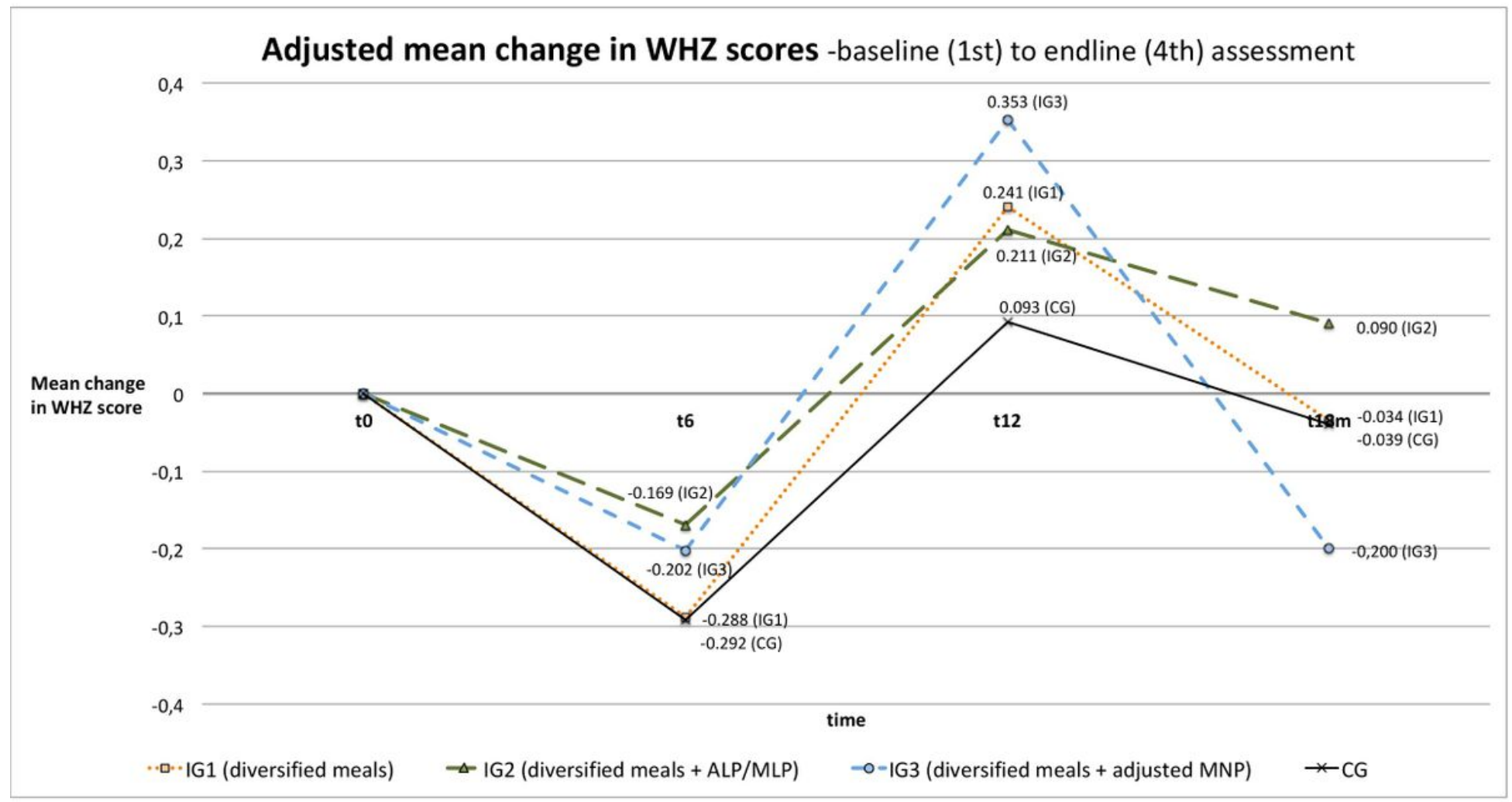

\section{Figure 9}

Adjusted mean changes in WHZ scores occurred over time, per study group (covariates age and WHZ scores at baseline, time between baseline and investigated assessment point, gender). 

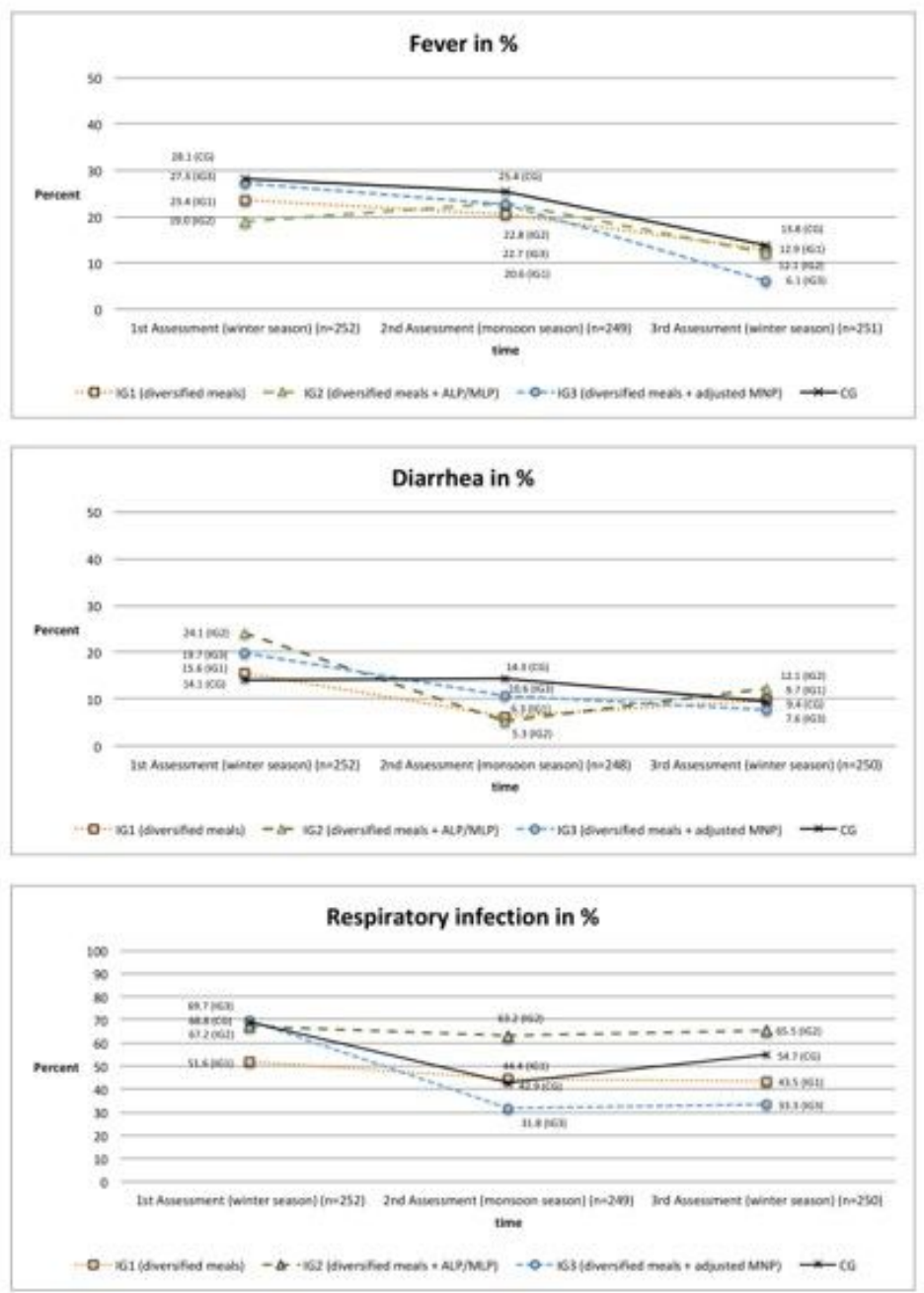

Figure 10

Prevalence of morbidity across different assessment points by study group

\section{Supplementary Files}

This is a list of supplementary files associated with this preprint. Click to download.

- SupFile.docx 